\title{
Conceptual Design and Optimization of a 1-1/2 Generation PFBC Plant Task 14
}

\section{Topical Report}

Lynn N. Rubow

Dennis A. Horazak

Jay $S$. White

Peter M. Witman

Lorabeth Harbaugh

December 1994

Work Performed Under Contract No.: DE-AC21-89MC25177

For

U.S. Department of Energy

Office of Fossil Energy

Morgantown Energy Technology Center

Morgantown, West Virginia

By

Gilbert/Commonwealth, Inc.

Reading, Pennsylvania 


\section{DISCLAIMER}

This report was prepared as an account of work sponsored by an agency of the United States Government. Neither the United States Government nor any agency thereof, nor any of their employees, makes any warranty, express or implied, or assumes any legal liability or responsibility for the accuracy, completeness, or usefulness of any information, apparatus, product, or process disclosed, or represents that its use would not infringe privately owned rights. Reference herein to any specific commercial product, process, or service by trade name, trademark, manufacturer, or otherwise does not necessarily constitute or imply its endorsement, recommendation, or favoring by the United States Government or any agency thereof. The views and opinions of authors expressed herein do not necessarily state or reflect those of the United States Government or any agency thereof.

This report has been reproduced directly from the best available copy.

Available to DOE and DOE contractors from the Office of Scientific and Technical Information, 175 Oak Ridge Turnpike, Oak Ridge, TN 37831; prices available at (615) 576-8401.

Available to the public from the National Technical Information Service, U.S. Department of Commerce, 5285 Port Royal Road, Springfield, VA 22161; phone orders accepted at (703) 487-4650. 


\title{
Conceptual Design and Optimization of a 1-1/2 Generation PFBC Plant Task 14
}

\section{Topical Report}

\author{
Lynn N. Rubow \\ Dennis A. Horazak \\ Jay S. White \\ Peter M. Witman \\ Lorabeth Harbaugh
}

Work Performed Under Contract No.: DE-AC21-89MC25177

\author{
For \\ U.S. Department of Energy \\ Office of Fossil Energy \\ Morgantown Energy Technology Center \\ P.O. Box 880 \\ Morgantown, West Virginia 26507-0880
}

\author{
By \\ Gilbert/Commonwealth, Inc. \\ 2675 Morgantown Road \\ Reading, Pennsylvania 19607
}

December 1994 


\section{TABLE OF CONTENTS}

SUMMARY

1.0 INTRODUCTION

TECHNICAL APPROACH

Plant Site Conditions............................................................... 34

Coal Properties ........................................................................... 35

Sorbent Properties....................................................................... 35

Large 1.5-Generation PFBC Plant................................................ 36

Intermediate 1.5-Generation Plant ................................................ 39

Small 1.5-Generation Plant ............................................................ 42

Design Sensitivity to Excess Air ...................................................... 45

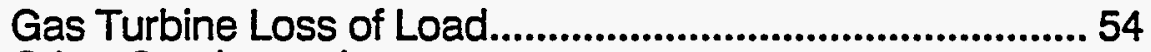

Other Contingencies................................................................ 57 
Bare Erected Cost .........................................................71

6.2 .2

Total Plant Cost

Economic Sensitivities ............................................................. 77

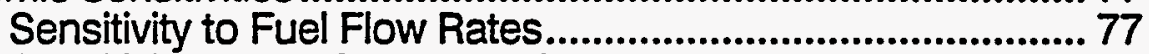

6.4 .1

6.4 .2

6.4 .3

Sensitivity to PFBC Excess Air

Sensitivity to Fuel Prices 


\section{LIST OF FIGURES}

2-1 1st-Generation PFBC Cycle ........................................................................ 13

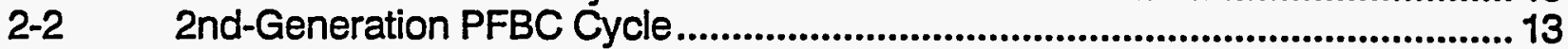

2-3 1.5-Generation PFBC Cycle ...................................................................... 14

3-1 1.5-Generation PFBC Simplified Flow Diagram ..................................................2 21

4-1 Power Production and Use Comparison............................................................31

4-2 Gas Turbine Power and Efficiency Comparison ..............................................33

4.2-1 Large 1.5-Generation PFBC Plant ..................................................................3 37

4.3-1 Intermediate 1.5-Generation PFBC Plant ..........................................................40 40

4.4-1 Small 1.5-Generation PFBC Plant................................................................ 43

4.5-1 Low Excess Air Case Flowsheet ...................................................................4 46

4.5-2 High Excess Air Case Flowsheet .................................................................4 47

4.5-3 Effect of Excess Air on Performance.............................................................48

5.3-1 Schematic Arrangement of CPFBC Bypass System ......................................55

5.4-1 Effect of Topping Combustor Temperature on Power and Efficiency................60

5.5-1 Effect of Fuel Flow on Gas Turbine and Steam Turbine Power...........................6.63

5.5-2 Effect of Fuel Flow on Power and Efficiency..........................................................6. 64

6-1 Economies of Scale .......................................................................................67

6.4-1 Effect of Load Reduction on COE ...................................................................79

6.4-2 Effect of Topping Combustor Temperature on COE ........................................ 80

6.4-3 Effect of Excess Air on Capital Cost.................................................................8. 82

6.4-4 Effect of Excess Air on COE...........................................................................8 83

6.4-5 COE Sensitivity to Coal Prices ..................................................................................8 85

6.4-6 COE Sensitivity to Natural Gas Prices ..........................................................8 86

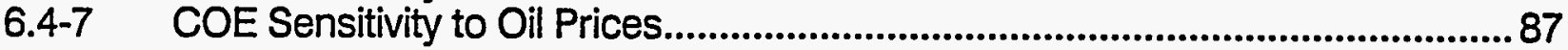




\section{LIST OF TABLES}

Thermal Performance Comparison .....................................................................3

Combined Cycle Efficiency Comparison.................................................................. 4

Economic Performance - Plant Type Comparison ..................................................5

Economic Performance - Plant Type Comparison ..................................................5

Plant Design Conditions...................................................................................... 7

Cost of Electricity Comparison.................................................................................7

2-1 Candidate Combustion Turbines ......................................................................... 18

2-2 Combustion Turbine Evaluations ................................................................ 19

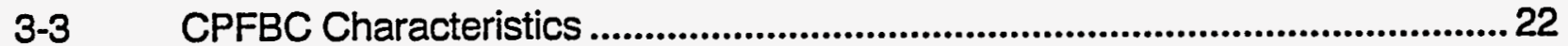

3-4 Fluid Bed Heat Exchanger Characteristics......................................................23

3-5 Compressor Discharge Pressures and Temperatures ....................................... 24

3-6 Gas Turbine Performance Parameters............................................................2 24

3-7 Heat Recovery Steam Generator Characteristics.................................................2 26

3-8 Steam Cycle Design Characteristics .....................................................................22

3-9 Waste Production Summary ......................................................................... 28

4-1 Thermal Performance Comparison .............................................................29

4-2 Gross Efficiency Comparison............................................................................30

4-3 Combined Cycle Power and Efficiency Comparison .......................................... 32

4.1-1 Pittsburgh No. 8 Coal Analysis............................................................................35

4.1-2 Sorbent Composition ............................................................................................... 35

4.2-1 Large PFBC Plant Performance Summary .......................................................36

4.2-2 Large PFBC Plant Auxiliary Power Requirements...................................................36

4.2-3 Large PFBC Plant Heat and Material Balance ....................................................... 38

4.3-1 Intermediate PFBC Plant Periormance Summary............................................. 39

4.3-2 Intermediate PFBC Plant Auxiliary Power Requirements ...................................39

4.3-3 Intermediate PFBC Plant Heat and Material Balance...........................................41

4.4-1 Small PFBC Plant Performance Summary............................................................ 42

4.4-2 Small PFBC Plant Auxiliary Power Requirements ............................................... 42

4.4-3 Small PFBC Plant Heat and Material Balance........................................................ 44

4.5-1 Sensitivity to PFBC Excess Air ............................................................................. 45

5.2-1 Plant Start-Up Sequence..............................................................................52

5.4-1 Sensitivity to Topping Combustor Temperature .................................................5 59

5.5-1 Sensitivity to Reduced Coal Feed Rate .................................................................6 62

6-1 Economic Performance ................................................................................65

6-2 Economic Comparison to PFBC-II and PC/FGD ............................................66 66

6.1-1 Plant Design Conditions................................................................................................6 69

6.4-1 COE Sensitivity to Topping Combustor Temperature ......................................... 78

6.4-2 COE Sensitivity to PFBC Excess Air .............................................................. 81

6.4-3 COE Sensitivity to Fuel Prices .............................................................................. 84 


\section{SUMMARY}

The economics and performance of advanced pressurized fluidized bed (PFBC) cycles developed for utility applications during the last 10 years (especially the 2nd-Generation PFBC cycle) are projected to be favorable compared to conventional pulverized coal power plants. However, the improved economics of 2nd-Generation PFBC cycles are accompanied by the perception of increased technological risk related to the pressurized carbonizer and its associated gas cleanup systems. A PFBC cycle that removed the uncertainties of the carbonizer while retaining the high efficiency and low cost of a 2nd-Generation PFBC cycle could improve the prospects for early commercialization and pave the way for the introduction of the complete 2nd-Generation PFBC cycle at some later date.

One such arrangement is a PFBC cycle with natural gas topping combustion, referred to as the 1.5-Generation PFBC cycle. This cycle combines the advantages of the 2ndGeneration PFBC plant.with the reduced risk associated with a gas turbine burning natural gas, and can potentially be part of a phased approach leading to the commercialization of utility 2nd-Generation PFBC cycles. The 1.5-Generation PFBC may also introduce other advantages over the more complicated 2nd-Generation PFBC system.

This report describes the technical and economic evaluation of 1.5-Generation PFBC cycles for utility or industrial power generation.

\section{Technical Approach}

The objective of this project is to develop a reference plant design and cost estimate for a pressurized fluidized bed combustor (PFBC) system that uses oil or natural gas to fire the topping combustor. The project was divided into three main activities: development of plant design; development of cost estimates; and sensitivity studies. The emphasis in this study was on thermal performance, which involved extensive computer modeling, while budgetary costs were estimated using various scaling techniques.

\section{Selected Plant Sizes}

Because the 1.5-Generation PFBC concept has the potential to satisfy a wide range of applications, therefore the study cases were selected to cover a wide range of capacities. Three plant sizes were chosen.

- The large plant was assumed to be an alternative to conventional gas-fired combined cycles and integrated gasification combined cycles, which are nominally sized around $250 \mathrm{MW}$.

- The medium plant is about half the size of the large plant, in the range of 100 to $150 \mathrm{MW}$.

- The small plant was configured around the energy needs of remote rural areas not connected to central power stations. A size of $4 \mathrm{MW}$ was chosen to represent a typical electrical demand of such a community. Although the thermodynamic 
configuration and performance of this small plant is similar to that of the medium and large plants, the physical design would probably be different, reflecting specific siting, transportation, and construction constraints of a remote community.

In this type of power cycle, about 40 percent of the power is generated by the gas turbine, so the nominal gas turbine sizes for the large, medium, and small plants are about $100 \mathrm{MW}, 50 \mathrm{MW}$, and $2 \mathrm{MW}$, respectively. This selection was the result of a fourstep process:

1. Define the approximate sizes of the large, intermediate, and small plants.

2. Define the criteria for evaluating the candidate combustion turbines.

3. Identify candidate combustion turbines for each size plant.

4. Use the criteria in Step 2 to select a combustion turbine.

The combustion turbine that is best suited to the large 1.5-Generation PFBC system is the 501D5 by Westinghouse. The Westinghouse $251 \mathrm{~B} 12$ was selected as the gas turbine for the nominal 100-MW plant because it is the only domestic turbine that can generate about 50 MW of power without steam injection. The Nuovo Pignone PGT-2 was selected as the gas turbine for the nominal 4-MW plant because it has no domestic counterparts in that size range.

\section{Major Equipment}

The heart of the 1.5-Generation PFBC power plant is a coal-burning PFBC that generates heat to make steam and hot gas for the gas turbine. The PFBC uses compressed air from the gas turbine compressor to fluidize and provide combustion air to the bed. Vitiated air from the PFBC exhaust is used as the oxidant in a natural-gasfired gas turbine-generator. Energy in the gas turbine exhaust is used to heat feedwater in an exhaust heat recovery steam generator (HRSG), and heat from the PFBC is used to evaporate, superheat, and reheat the steam in a fluid bed heat exchanger (FBHE). Finally, a steam turbine-generator in a Rankine cycle generates power using the PFBC and HRSG as its heat sources.

The major subsystems of the 1.5-Generation PFBC power plant are:

- Coal and Limestone Preparation Systems

- Circulating PFB Combustors (CPFBC)

- Fluid Bed Heat Exchangers (FBHE)

- Compressed Air Systems

- Combustion Turbine-Generator Systems (Westinghouse W501D5, the Westinghouse 251B12, and the Nuovo Pignone PGT-2)

- Heat Recovery Steam Generators (HRSG)

- Steam Turbine-Generator Systems (1800 psig/ $1000^{\circ} \mathrm{F} / 1000^{\circ} \mathrm{F} ; 1450 \mathrm{psig} /$ $1000 \mathrm{~F} / 1000^{\circ} \mathrm{F}$; and $600 \mathrm{psig} / 750^{\circ} \mathrm{F}$ ) 
- Feedwater Systems

- Ash Disposal Systems

\section{Conceptual Designs}

The conceptual design and performance of large, intermediate, and small 1.5-Generation PFBC combined cycle power plants are compared in Table 1.

Table 1

Thermal Performance Comparison

\begin{tabular}{lccr} 
& $\begin{array}{c}\text { Large } \\
\text { Plant }\end{array}$ & $\begin{array}{c}\text { Intermediate } \\
\text { Plant }\end{array}$ & $\begin{array}{c}\text { Small } \\
\text { Plant }\end{array}$ \\
\hline ENERGY INPUT & & & \\
Coal Feed, Ib/h & 128,861 & 61,581 & 3,031 \\
Coal HHV, Btu/lb & 12,452 & 12,452 & 12,452 \\
& & & 492 \\
Nat. Gas Feed, Ib/h & 19,257 & 7,781 & 492 \\
Nat HHV, Btu/lb & 21,799 & 21,799 & 21,799 \\
Coal Energy, MW & & & \\
Coal Drying Energy, MW & 470.268 & 227.734 & 11.061 \\
Nat. Gas Energy, MW & 1.887 & 0.902 & 0.044 \\
Plant Energy Input & 123.026 & 49.710 & 3.142 \\
& 595.181 & 275.345 & 14.247 \\
ENERGY OUTPUT & & & \\
Gas Turbine, MW & & & 1.512 \\
Steam Turbine, MW & 87.501 & 38.107 & 2.648 \\
Auxiliaries, MW & 169.369 & 77.408 & $(0.201)$ \\
Plant Net Power, MW & $(10.590)$ & $(4.774)$ & 3.960 \\
Thermal Efficiency, \% & 246.272 & 110.741 & $27.8 \%$
\end{tabular}

The reduced efficiency of the small plant is caused by the reduced efficiency of its nonreheat steam cycle and smaller gas turbine, and increased losses of smaller components.

The thermal efficiency of the 1.5-Generation PFBC plant ranks between the 1st- and 2nd-Generation PFBC plants, higher than IGCC but lower than gas-fired combined cycles, as shown in Table 2. 
Table 2

\section{Combined Cycle Efficiency Comparison}

\begin{tabular}{rrc}
\multicolumn{2}{c}{ Combined Cycle Plant Type } & HHV Efficiency \\
\hline GTCC & Gas Turbine Combined Cycle & $49 \%$ \\
PFBC-2 & 2nd-Generation PFBC Plant & $45 \%$ \\
PFBC-1.5 & $1.5-$ Generation PFBC Plant & $41 \%$ \\
PFBC-1 & 1st-Generation PFBC Plant & $40 \%$ \\
IGCC & Dry-fed oxygen-blown IGCC & $39 \%$
\end{tabular}

A design sensitivity study was performed to determine the effects of PFBC excess air on the design, capital cost, and COE of the intermediate (111-MW) 1.5-Generation PFBC plant. PFBC excess air has only a minor effect on overall efficiency, but a profound effect on plant generating capacity. Using the same gas turbine, plants with lower PFBC excess air have smaller vessels and generate more power.

\section{Plant Operation}

The operational concept for the 1.5-Generation PFBC plant is a base-loaded plant with the capability for significant turndown. About 24 percent of the generated power is fueled by natural gas, to which the plant responds quickly, and the other 76 percent fueled by coal, to which the plant responds more slowly. This combination of fuels allows rapid adjustments between 76 and 100 percent of load by adjusting the natural gas flow to the gas turbine.

Plant load following assumes that the PFBC/FBHE system is capable of a 50-percent turndown, an assumption that seems to be supported by recent operating experience. (See Section 2.1) With a 50-percent turndown, plant load levels between 38 and 76 percent can be attained by adjusting the coal feed rate. As a result, the effective turndown ratio of a single-train 1.5-Generation PFBC plant is almost 3:1, compared with the 2:1 turndown of a 1st- or 2nd-Generation PFBC plant.

Plant capacity is expected to range from full-load (design flows of natural gas and coal) down to 38-percent load (zero natural gas and 50-percent coal flow). The operation of a 1.5-Generation PFBC plant under various steady-state, start-up, and emergency conditions is feasible.

An operational sensitivity study was performed to determine the effects of load change on the intermediate (111-MW) 1.5-Generation PFBC plant. The plant can be reduced to 76-percent load by reducing natural gas flow without disturbing the coal feed to the rest of the plant. Thermal efficiency over this range is constant to within three percentage points. By reducing coal instead of natural gas, the plant can be reduced to 38-percent load, at which point the PFBC becomes adiabatic bed.

\section{Economic Performance}

The estimated capital cost (TPC, 12/92 dollars) and cost of electricity (COE) for the 1.5Generation PFBC plants compare favorably with conventional pulverized-coal steam power plant with flue gas desulfurization, as shown in Table 3. The 1.5-Generation PFBC plant is more efficient than the PC plant ( $41.9 \%$ vs. $35.2 \%)$, but much of this efficiency advantage is offset when calculating COE by its smaller size (246 MW vs. $560 \mathrm{MW}$ ) and the assumed higher price of natural gas compared to coal fuel $(\$ 2.50 / \mathrm{MBtu}$ vs. $\$ 1.80 / \mathrm{MBtu})$. 
Table 3

Economic Performance - Plant Type Comparison

Net Power, MW

Conventional

$P C / F G D$

HHV Efficiency

Total Plant Cost, $\$ / \mathrm{kW}$

$\mathrm{COE}, \$ / \mathrm{MWh}$

Plant

559

$35.2 \%$

1291.5

90.3

Large
PFBC-1.5
Plant
246.3
$41.4 \%$
1119.7
83.4

The smaller plants suffer more from the electrical economy of scale. Table 4 and Figure 1 show this cost effect of scale.

Table 4

Economic Performance - Plant Size Comparison

$\begin{array}{lrrr} & \begin{array}{r}\text { Large } \\ \text { PFBC-1.5 }\end{array} & \begin{array}{r}\text { Medium } \\ \text { PFBC-1.5 }\end{array} & \begin{array}{r}\text { Small } \\ \text { PFBC-1.5 }\end{array} \\ \text { Net Power, MW } & \frac{\text { Plant }}{\text { Plant }} & \frac{110.3}{110.7} & \frac{1 \text { Plant }}{4.0} \\ \text { HHV Efficiency } & 41.4 \% & 40.2 \% & 27.8 \% \\ \text { Total Plant Cost, \$/kW } & 1119.7 & 1553.1 & 5136.4 \\ \text { COE, } \$ / \text { MWh } & 83.4 & 108.4 & 349.0\end{array}$

\section{Economic Evaluation Methods}

The economics of the 1.5-Generation PFBC plant cost estimates were developed by consistently evaluating the capital and operating costs for each plant and subsequently performing an economic analysis based on the cost of electricity (COE) as the figure of merit. The conceptual cost estimates for each plant were determined on the basis of previous evaluations of utility-sized PC and 2nd-Generation PFBC power plants [G/C, 6/92] and smaller industrial sized-power plants [FWDC, 7/92].

Estimated costs for the major components were established by a variety of methods. In-house cost data and support data from previous PFBC reports were supplemented by vendor budgetary pricing for major items as required.

As a general approximation, the capital costs and COEs of these plants have economies of scale, as shown in Figure 1. 


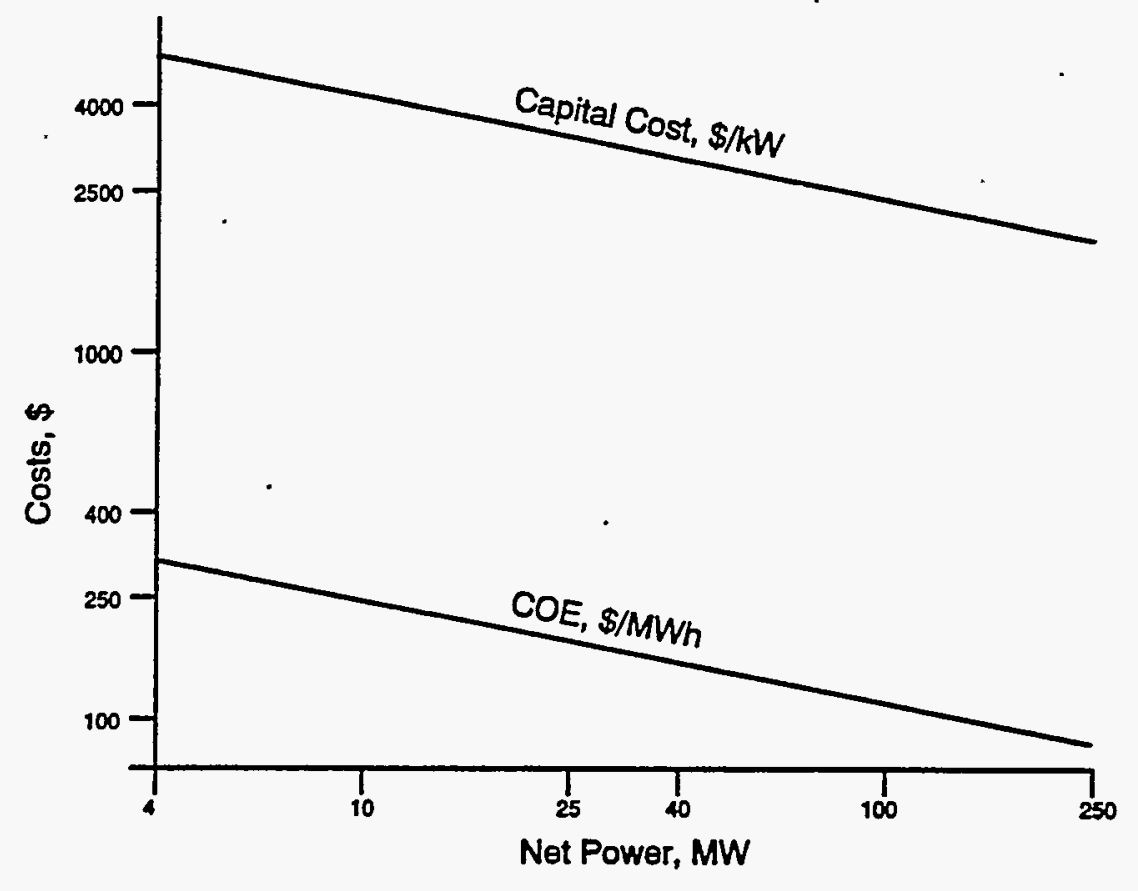

Figure 1 - Economies of Scale

Operation and maintenance (O\&M) cost values were determined on a first-year basis and subsequently levelized over the 30 year plant life. Consumables were evaluated on the basis of the quantity required and individual commodity unit prices. Operation cost was determined on the basis of the number of operators, and maintenance was evaluated on the basis of maintenance costs required for each major plant section. These operating costs were then converted to unit values of $\$ / \mathrm{MWh}$ or mills $/ \mathrm{kWh}$. Operating, maintenance, and consumable costs were based on the plant design conditions listed in Table 5. 
Table 5

Plant Design Conditions

$\begin{array}{lrrr} & \begin{array}{c}\text { Large } \\ \text { Plant }\end{array} & \begin{array}{c}\text { Medium } \\ \text { Plant }\end{array} & \begin{array}{r}\text { Small } \\ \text { Plant }\end{array} \\ \text { Net Plant Output, MW } & 246.3 & 110.7 & 4.0 \\ \text { Plant Heat Rate, Btu/kWh } & 8,246 & 8,484 & 12,277 \\ \text { Coal Type } & \text { Pgh. } 8 & \text { Pgh. } 8 & \begin{array}{r}\text { Pgh. } 8 \\ \text { Coal HHV Btu per lb }\end{array} \\ \text { Coal Cost \$/MBtu } & 12,450 & 12,450 & 12,450 \\ \text { Natural Gas Cost \$/MBtu } & \$ 1.80 & \$ 1.80 & \$ 1.80 \\ \text { Coal (as rec'd), Ib/h } & 128,861 & 61,581 & 3,031 \\ \text { Natural Gas, Ib/h } & 19,257 & 7,781 & 492 \\ \text { scfm } & 7,014 & 2,834 & 179 \\ \text { Dolomite, Ib/h } & 51,117 & 24,428 & 1,202 \\ \text { Construction Time, yrs } & 3.50 & 2.5 & 1.5\end{array}$

In addition, the following economic assumptions were made:

- Plant book life is 30 years,

- Capacity factor is 65 percent, and

- Plant in-service date is January 1993.

The capital and operating costs of the plant are combined with plant performance in the comprehensive evaluation of cost of electricity (COE). Table 6 presents the 30-year levelized costs of electricity for the three 1.5-Generation PFBC cases.

\section{Table 6 \\ Cost of Electricity Comparison}

$\begin{array}{lccr} & \begin{array}{c}\text { Large } \\ (246-\mathrm{MW}) \\ \text { Plant }\end{array} & \begin{array}{c}\text { Medium } \\ (111-\mathrm{MW}) \\ \text { Plant }\end{array} & \begin{array}{c}\text { Small } \\ \text { (4-MW) } \\ \text { Plant }\end{array} \\ \text { Capital Charges, mills/kWh } & 36.5 & 49.8 & 157.6 \\ \text { Fixed Oper \& Maint, mills/kWh } & 9.4 & 16.4 & 92.0 \\ \text { Variable Oper \& Maint, mills/kWh } & 5.1 & 8.8 & 49.5 \\ \text { Consumables, mills/kWh } & 5.2 & 5.5 & 8.0 \\ \text { Fuel, mills/kWh } & \underline{27.3} & \underline{27.8} & \underline{41.9} \\ \text { Levelized COE, mills/kWh (\$/MWh) } & 83.4 & 108.4 & 349.0\end{array}$

As a comparison, the COE for the 246-MW 1.5-Generation plant is lower than the $\$ 90 / \mathrm{MWh}$ for a 560-MW conventional PC/FGD plant, but higher than the $\$ 75 / \mathrm{MWh}$ for a 536-MW 2nd-Generation PFBC plant [G/C, 1993]. 


\section{Economic Sensitivities}

Sensitivity studies were performed to determine the effects of design, operating, and market conditions on capital cost and COE.

- Fuel Flow: Because of reduced efficiencies, the performance penalty for operating at below-design conditions makes it uneconomical to run at reduced load.

- PFBC Excess Air: Plants designed with lower PFBC excess air use more coal, which increases equipment capital costs (in dollars), but the increased generating capacity results in lower costs per kilowatt. Plants designed with higher PFBC excess air have higher levelized costs of electricity because of their reduced power generating capacity.

- Fuel Prices: The largest fuel-price influence on COE was coal price (0.201-percent increase in COE for each 1-percent increase in coal price), followed by oil price ( 0.106 percent per percent increase) and natural gas price ( 0.063 percent per percent increase).

\section{Conclusions and Recommendations}

The conceptual design and analysis of the 1.5-Generation PFBC plant leads to the following conclusions.

1. The 1.5-Generation PFBC plant provides a reasonable bridge to the commercialization of 2nd-Generation PFBC technology, and it is the. logical alternative to 2 nd-Generation PFBC.

2. By eliminating the carbonizer and its associated hot-gas cleanup system, the 1.5-Generation PFBC plant has less technological risk than a 2nd-Generation PFBC plant.

3. The 1.5-Generation PFBC plant has excellent load-following potential, and is probably more responsive than a 2nd-Generation PFBC plant. Power output can be reduced by 24 percent by adjusting the natural gas, with stable operation down to 38-percent load by reducing the coal feed rate. Plant operation is well within commercial equipment and controls design capability.

4. The projected turndown in a 1.5-Generation PFBC plant is about 3:1, since $1 / 3$ of the power supplied by natural gas, and the rest is supplied by coal in a PFBC that can be turned down by 50 percent.

5. The gas turbine operating conditions in a 1.5-Generation PFBC cycle are relatively close to "standard" gas turbine design conditions, allowing fairly "standard" turbines to be considered as candidates.

6. The 1.5-Generation gas turbine/steam turbine power split is about $34 / 66 \%$, which places it between the 1st-Generation plant $(23 \% / 77 \%)$ and the 2nd-Generation plant $(45 \% / 55 \%)$.

7. The HHV efficiency of a large 1.5-Generation PFBC plant is about $41 \%$, which also places it between the 1st-Generation plant (40\%) and the 2nd-Generation plant $(45 \%)$. 
8. The 1.5-Generation PFBC plant follows classical economy of scale over the range of sizes studied --4 to 250 MW.

9. The greatest fuel-related $\mathrm{COE}$ sensitivity is the sensitivity to coal price (0.201-percent increase in COE for each 1-percent increase in coal price), followed by the sensitivity to oil price ( 0.106 percent per percent increase) and to natural gas price ( 0.063 percent per percent increase).

10. Plants designed with less PFBC excess air have lower capital costs (per kW) and lower COEs than plants designed with more PFBC excess air.

11. The design of the small plant should be reviewed to include consideration of less complex configurations, such as the steam-injected Cheng cycle. 


\subsection{INTRODUCTION}

The PFBC cycles developed for utility applications during the last 10 years have been shown to have favorable economics and performance, compared to conventional pulverized coal power plants. However, the pressurized carbonizer and its associated gas cleanup systems are perceived to have the most technological risk in the 2ndGeneration PFBC cycle. A PFBC cycle that removed the uncertainties of the carbonizer while retaining the high efficiency and low cost of a 2nd-Generation PFBC cycle would improve the prospects for early commercialization and pave the way for the introduction of the complete 2nd-Generation PFBC cycle at some later date.

One such cycle is a PFBC cycle with natural gas topping combustion, referred to as the 1.5-Generation PFBC cycle. This cycle combines the advantages of the 2nd-Generation PFBC plant with the reduced risk associated with a gas turbine fueled by natural gas, and can potentially provide a shorter path toward the commercialization of utility 2ndGeneration PFBC cycles with carbonizers. 


\subsection{TECHNICAL APPROACH}

The objective of this project is to develop a reference plant design and cost estimate for a pressurized fluidized bed combustor (PFBC) system that uses oil or natural gas to fire the topping combustor. This system is called a 1.5-Generation PFBC.

The project was divided into three main activities: development of plant design; development of cost estimates; and sensitivity studies.

The emphasis in this study was on thermal performance, which involved extensive computer modeling, while budgetary costs were estimated using various scaling techniques. The tasks are described as follows.

1 Development of Plant Design

Develop a reference plant design for a 1.5-Generation PFBC power plant.

1.1 As part of the conceptual design process, use approximated data in a cursory screening study to select a gas turbine, considering load-following capability, and the gas turbine need of at least 10 percent excess $\mathrm{O}_{2}$.

1.2 Develop heat and material balances for the a 1.5-Generation PFBC power plants.

1.3 Develop equipment lists for the 1.5-Generation PFBC power plants.

2 Development of Cost Estimates

2.1 Estimate the capital cost, for a 1.5-Generation PFBC power plant, in 1992 dollars.

2.2 Estimate the operating and maintenance (O\&M) costs for a 1.5-Generation PFBC power plant, in 1992 dollars.

2.3 Estimate the cost of electricity (COE) for a 1.5-Generation PFBC power plant, in 1992 dollars.

3 Sensitivity Studies

Develop a reference plant design, estimate of capital cost, O\&M cost, and COE in 1992 dollars for two smaller plants:

3.1 an intermediate-sized ( $-80-100 \mathrm{MW})$ plant with an intermediate gas turbine

3.2 a small (less than $10 \mathrm{MW}$ ) plant, using a small gas turbine with a turbine inlet temperature around $1900^{\circ} \mathrm{F}$ and a requirement for at least 4 percent excess $\mathrm{O}_{2}$.

4 Evaluate the effects of gas turbine topping combustor temperature on power output and COE for a medium-sized 1.5-Generation PFBC plant. 
The study includes the full range of natural gas feed rates from 100 percent of design to zero.

5 Evaluate the effects of PFBC excess air (excess $\mathrm{O}_{2}$ ) on the design, performance, capital cost, and COE of a medium-sized 1.5-Generation PFBC plant.

6 Determine the effects of changes in oil, natural gas, and coal prices on the operating costs and COE of a medium-sized 1.5-Generation PFBC plant.

\subsection{DERIVATION OF THE 1.5-GENERATION PFBC}

The PFBC cycles developed for utility applications during the last 10 years have been shown to have favorable economics and performance, compared to conventional pulverized coal power plants.

Sized for utility applications, 2nd-Generation PFBC (PFBC-II) plants utilizing conventional steam cycles are projected to have HHV efficiencies of 45 percent, with capital costs and costs of electricity lower than the costs associated with a pulverized coal steam power plant [FWDC, 1989]. The efficiency of 2nd-Generation PFBC cycles utilizing advanced steam cycles may approach 50 percent $[G / C, 1992]$.

Figures 2-1 and 2-2 compare the 1st- and 2nd-Generation PFBC cycles. In the 1stGeneration PFBC cycle (Figure 2-1), the PFB combustor burns coal to produce steam and heat air for a gas turbine. The gas turbine generates electricity, and its waste heat is used by a gas turbine heat recovery steam generator (HRSG) to produce more steam. The steam is used in a condensing steam turbine cycle to generate additional power.

In the 2nd-Generation PFBC cycle (Figure 2-2), the pressurized carbonizer converts part of the coal into fuel gas and the rest into char. The PFB combustor burns the carbonizer char to produce steam and heat air for the gas turbine. The carbonizer gas is burned in the topping combustor of the gas turbine to produce power. The gas turbine heat recovery steam generator (HRSG) produces more steam, and a condensing steam turbine cycle uses the steam to produce additional power.

Currently, the pressurized carbonizer and its associated gas cleanup systems are perceived to have the most technological risk in the 2nd-Generation PFBC cycle. A PFBC cycle that removed the uncertainties of the carbonizer while retaining the high efficiency and low cost of a 2nd-Generation PFBC cycle would improve the prospects for early commercialization and pave the way for the introduction of the fully carbonized 2nd-Generation PFBC cycle at some later date. One such cycle is referred to as the 1.5-Generation PFBC (PFBC-1.5) cycle because it combines the advantages of the 2 ndGeneration PFBC plant with the reduced risk associated with a gas turbine fueled by natural gas. 


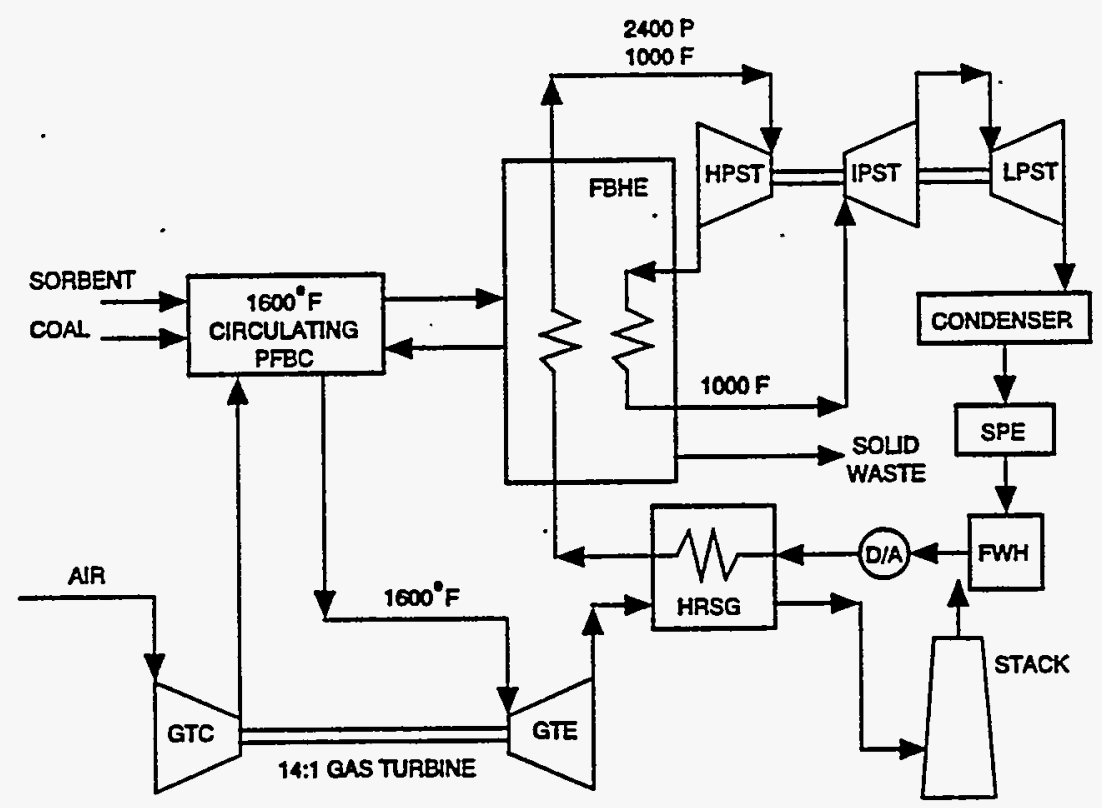

Figure 2-1 - 1st-Generation PFBC Cycle

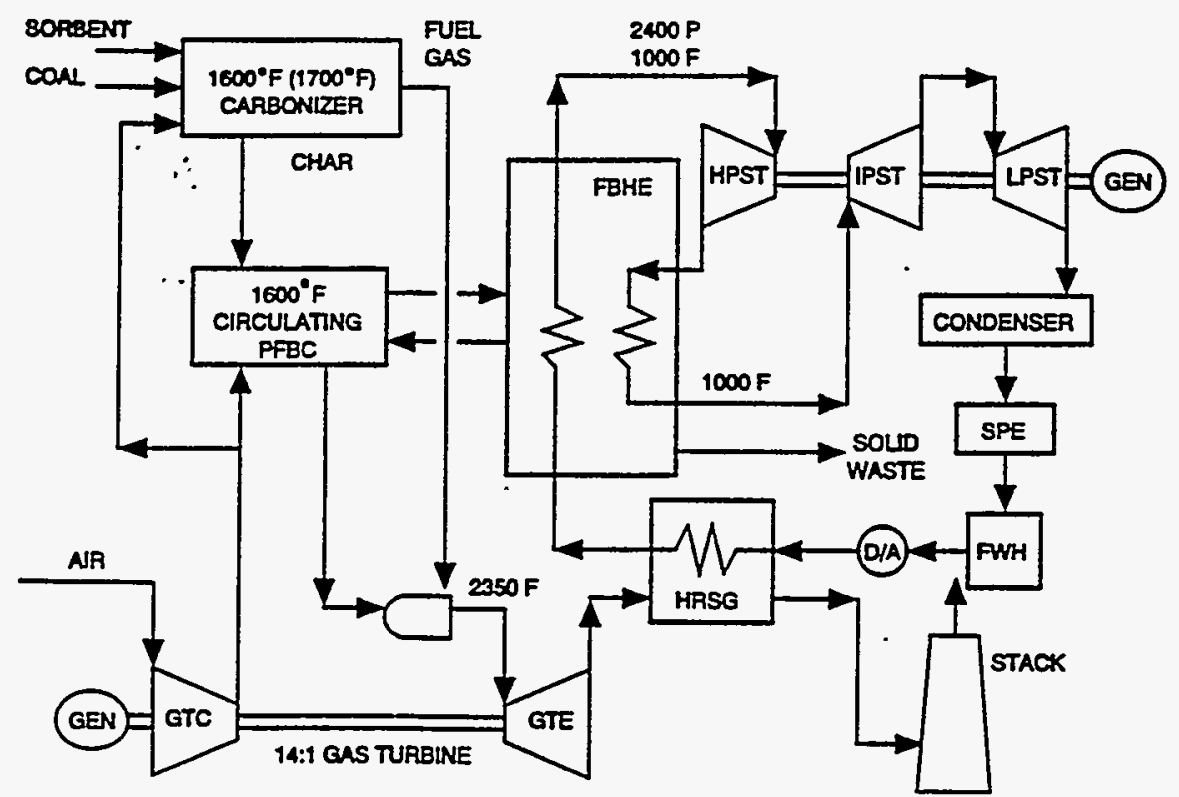

Figure 2-2 - 2nd-Generation PFBC Cycle 
The 1.5-Generation PFBC cycle is shown in Figure 2-3. This cycle is similar to the 2ndGeneration PFBC cycle, except that the topping combustor is fueled by natural gas instead of by carbonizer fuel gas, eliminating the need for a carbonizer. This cycle was identified and briefly investigated as part of an evaluation of industrial cogeneration applications of 2nd-Generation PFBC systems [FWDC, 7/92]. In its cogeneration application, the 1.5-Generation PFBC cycle had a lower cost of steam and higher thermal utilization than comparably sized 2nd-Generation PFBC units.

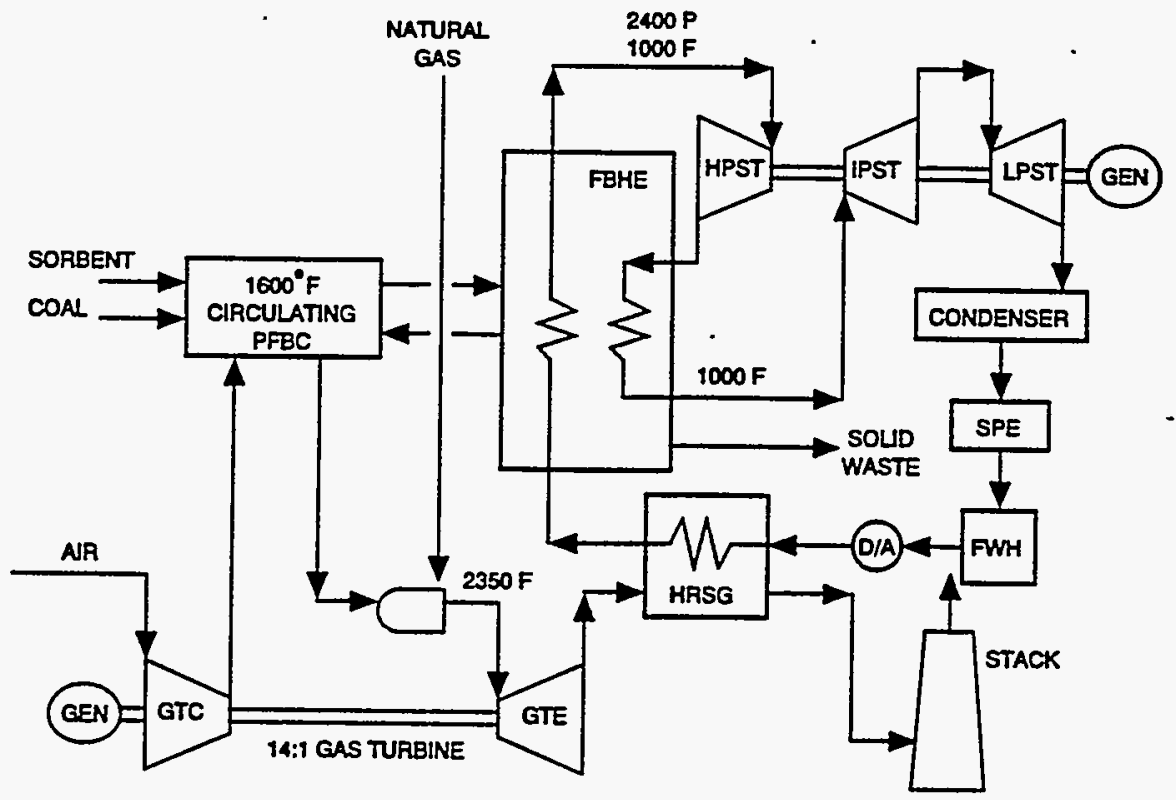

Figure 2-3 - 1.5-Generation PFBC Cycle

The 1.5-Generation PFBC plant also has potential operational benefits compared to single-fuel plants. About 24 percent of the generated power is fueled by natural gas, so rapid adjustments can be made between 76 and 100 percent of load by adjusting the natural gas flow to the gas turbine.

Plant load following assumes that the PFBC/FBHE system is capable of a 50-percent turndown, an assumption that seems to be supported by recent operating experience. Tests by von Wedel and others (1993) reported test results on a 15-MWt PFBC from $100 \%$ load to $50 \%$ load; A 350-MWe design by Anderson and Nilsson (1993) includes part-load performance values down to 50\% load; and Anders (1993) includes test results from $100 \%$ down to $25 \%$ load for the 135 -MWe PFBC plant in Vartan, Stockholm. With a 50-percent turndown, plant load levels between 38 and 76 percent can be attained by adjusting the coal feed rate. As a result, the effective turndown ratio of a single-train 1.5-Generation PFBC plant is almost 3:1, compared with the 2:1 turndown of a 1st- or 2nd-Generation PFBC plant.

Because the 1.5-Generation PFBC cycle has the potential for high efficiency and low cost, and with its enhanced load-following capabilities, this cycle can potentially provide 
a shorter path toward the commercialization of utility 2nd-Generation PFBC cycles with carbonizers. 


\subsection{SELECTED PLANT SIZES}

The 1.5-Generation PFBC is a new concept that has the potential to satisfy a wide range of applications, so the study cases were selected to cover a wide range of capacities. The three approximate plant sizes reflect this span of potential applications.

- The large plant was studied as an alternative to conventional gas-fired combined cycles and integrated gasification combined cycles, which are nominally sized around $250 \mathrm{MW}$.

- The medium plant was evaluated as a possible repowering application and also evaluated for the ability to follow load technically and economically.

- The small plant was conceived to address the energy needs of remote rural areas not connected to central power stations. A size of $4 \mathrm{MW}$ was chosen to represent a typical electrical demand of such a community. Although the thermodynamic configuration and performance of this small plant is similar to that of the medium and large plants, the physical design would probably be different, reflecting specific siting, transportation, and construction constraints at the remote community.

About 40 percent of the power is generated by the gas turbine in a 1.5-Generation PFBC power cycle, so the nominal gas turbine sizes for the large 250-MW, medium 150-MW, and small 4-MW plants are about $100 \mathrm{MW}, 50 \mathrm{MW}$, and $2 \mathrm{MW}$, respectively.

\subsection{SELECTED GAS TURBINES}

The selection of the gas turbine for the large (nominal 250-MW) plant is explained below. The Westinghouse 251B12 was selected as the gas turbine for the nominal 100-MW plant because it is the only domestic turbine that can generate about $50 \mathrm{MW}$ of power without steam injection. The Nuovo Pignone PGT-2 was selected as the gas turbine for the nominal 4-MW plant because it has no domestic counterparts in that size range.

The combustion turbine that is best suited to the large 1.5-Generation PFBC (PFBC-1.5) system is the 501D5 by Westinghouse, although similar turbines, such as the ABB 11N or the GE 7EA, were evaluated and would be compatible with the system. The rationale behind the gas turbine selection is described below in four steps:

1. Define a range of gas turbine sizes for the Large Plant.

2. Define the criteria for evaluating the candidate combustion turbines.

3. Identify candidate combustion turbines for the selected range of plant sizes.

4. Use the criteria in Step 2 to select a combustion turbine.

1. Define a range of gas turbine sizes for the Large Plant.

In a conventional gas-fired combined cycle plant, about $1 / 3$ of the power is generated by the steam turbine and about $2 / 3$ of the power is generated by the 
combustion turbine. The allocation of power is different in a 1.5-Generation PFBC plant; because of the coal energy that the PFBC adds to the steam cycle, about 60-70 percent of the power is generated by the steam turbine and about 3040 percent of the power is generated by the combustion turbine.

Using the assumption that the gas turbine generates about $30-40$ percent of the power, a 1.5-Generation PFBC plant with a nominal capacity of $250 \mathrm{MW}$, would use a combustion turbine that generates approximately 75 to $100 \mathrm{MW}$.

2. Define the criteria for evaluating the candidate combustion turbines.

The gas turbine for the 1.5-Generation PFBC plant is chosen based on its ability to meet the special requirements of the plant, such as load-following, turndown capability (including running without natural gas), and performance at low ambient temperatures. Combustion turbine selection criteria have been divided into primary (must) and secondary (want) categories.

\section{Primary Criteria}

1. Low ratio of natural gas to coal mass flow rates running at the design capacity of the 1.5-Generation PFBC system.

2. Good performance of the gas turbine under partial load conditions, including lower mass flow and lower temperatures, down to the design temperature of the PFBC.

\section{Secondary Criteria}

3. Ability of the turbine to control $\mathrm{NO}_{x}$ emissions.

4. Ability of the turbine to adapt to the addition of a carbonizer that makes the system into a 2nd-Generation PFBC system.

5. Ability of the turbine to use steam as a power augmentation method.

3. Identify candidate combustion turbines for the selected range of plant sizes.

The operating conditions (particularly the turbine inlet temperature) of the gas turbine in a 1.5-Generation PFBC cycle are relatively close to its design conditions, allowing fairly "standard" turbines to be considered as candidates. By contrast, the gas turbine inlet temperature in a 1st-Generation cycle is $250^{\circ}$ to $700^{\circ} \mathrm{F}$ lower than its design temperature, limiting the number of applicable turbines. This compatibility of operating conditions with turbine design conditions is a potential advantage of the 1.5-Generation cycle over the 1st-Generation PFBC cycle, with its special low-temperature turbine inlet conditions.

For the range of plant size defined in step 1 above, five combustion turbines were identified, as listed in Table 2-1. 
Table 2-1

Candidate Combustion Turbines

(ISO Ratings)

\begin{tabular}{|c|c|c|c|c|c|}
\hline $\begin{array}{l}\text { Company } \\
\text { Frame }\end{array}$ & $\begin{array}{l}\text { ABB } \\
\text { Power } \\
\text { Generation } \\
11 N\end{array}$ & $\begin{array}{l}\text { General } \\
\text { Electric } \\
7 E A\end{array}$ & $\begin{array}{l}\text { Siemens } \\
\text { V84.2 }\end{array}$ & $\begin{array}{l}\text { Westing- } \\
\text { house } \\
\text { 501D5 }\end{array}$ & $\begin{array}{l}\text { ABB } \\
\text { Power } \\
\text { Generation } \\
11 N 2\end{array}$ \\
\hline $\begin{array}{l}\frac{\text { Timple Cycle }}{\text { Simple }} \\
\text { Output, kW } \\
\text { Simple Cycle } \\
\text { Efficiency (LHV) }\end{array}$ & $\begin{array}{l}82,660 \\
32.5 \%\end{array}$ & $\begin{array}{l}82,370 \\
32.2 \%\end{array}$ & $\begin{array}{l}101,640 \\
32.9 \%\end{array}$ & $\begin{array}{l}105,090 \\
32.8 \%\end{array}$ & $\begin{array}{l}107,700 \\
33.7 \%\end{array}$ \\
\hline $\begin{array}{l}\text { Pressure Ratio } \\
\text { Air Flow, lb/s } \\
\text { Rotor Inlet Temp, of } \\
\text { Exhaust Temp, of } \\
\text { Comb. Turbine } \\
\text { Sp. Power, kW-s/lb }\end{array}$ & $\begin{array}{l}13.3 \\
699 \\
1975 \\
941 \\
118\end{array}$ & $\begin{array}{l}12.4 \\
644 \\
2020 \\
986 \\
128\end{array}$ & $\begin{array}{l}10.7 \\
770 \\
1924 \\
1004 \\
132\end{array}$ & $\begin{array}{l}14.2 \\
803 \\
2045 \\
987 \\
131\end{array}$ & $\begin{array}{l}14.6 \\
827 \\
2100 \\
977 \\
130\end{array}$ \\
\hline
\end{tabular}

4. Use the criteria in Step 2 to select a combustion turbine.

The primary criterion is the ratio of natural gas-to-coal mass flow rates running at the design capacity of the 1.5-Generation PFBC system. Since this criterion must be evaluated before any cycle calculations are performed, the gas-to-coal ratio was estimated using a simplified procedure to approximate plant performance.

The simplified procedure is based on turbine performance specifications published by Gas Turbine World. The inlet air flow for each candidate turbine (reduced by an assumed fraction for cooling flow) is used to determine the coal feed rate, based on Pittsburgh 8 coal burned in the PFBC with 100-percent excess air. After an assumed 1.3-percent thermal loss in the PFBC (as in 2ndGeneration PF.BC plants), about 40 percent of the remaining coal energy was used to generate $1600^{\circ} \mathrm{F}$ PFBC exhaust gas for the topping combustor. The remaining coal energy was used by the steam turbine cycle. Combustion turbine performance parameters were adjusted for mixed fuel properties and pressure loss through the PFBC system.

The thermal input from the PFBC to the topping combustor is less than the specified combustion turbine thermal input (rated power multiplied by heat rate). Natural gas flow is estimated as the amount required to satisfy the energy shortfall.

Characteristics of candidate turbines relating to the criteria previously defined are compared in Table 2-2. 
Table 2-2

Combustion Turbine Evaluations

\begin{tabular}{|c|c|c|c|c|c|}
\hline Company & $\begin{array}{l}\text { ABB Power } \\
\text { Generation }\end{array}$ & $\begin{array}{l}\text { General } \\
\text { Electric }\end{array}$ & Siemens & $\begin{array}{l}\text { Westin } \\
\mathrm{g}^{-}\end{array}$ & $\begin{array}{l}\text { ABB Power } \\
\text { Generation }\end{array}$ \\
\hline$\frac{\text { Frame }}{\text { CT Output, kW(ISO) }}$ & $\frac{11 N}{82,660}$ & $\frac{7 E A}{82,370}$ & $\frac{V 84.2}{101,640}$ & $\frac{501 \mathrm{D} 5}{105,090}$ & $\frac{11 \mathrm{~N} 2}{107,700}$ \\
\hline $\mathrm{lb} / \mathrm{lb}$ & 0.169 & 0.205 & 0.209 & 0.207 & \\
\hline $\begin{array}{l}\text { Btu/Btu } \\
\text { Load following ability }\end{array}$ & $\begin{array}{l}0.295 \\
\text { Good }\end{array}$ & $\begin{array}{l}0.359 \\
\text { Very Best }\end{array}$ & $\begin{array}{l}0.367 \\
\text { Best }\end{array}$ & $\begin{array}{l}0.362 \\
\text { Better }\end{array}$ & $\begin{array}{l}0.376 \\
\text { Better }\end{array}$ \\
\hline Performance at low & Good & Good & Good & Good & Good \\
\hline $\begin{array}{l}\text { Adequate turndown } \\
\text { capability including no }\end{array}$ & Better & Good & Worse & Best & Good \\
\hline $\begin{array}{l}\text { Proven low NOx } \\
\text { emission control } \\
\text { capability }\end{array}$ & $\begin{array}{l}\text { Good } \\
\text { [Note 1] }\end{array}$ & $\begin{array}{l}\text { Better } \\
\text { [Note 2] }\end{array}$ & $\begin{array}{l}\text { Best } \\
\text { [Note 3] }\end{array}$ & $\begin{array}{l}\text { Good } \\
\text { [Note }\end{array}$ & $\begin{array}{l}\text { Better } \\
\text { [Note 5] }\end{array}$ \\
\hline $\begin{array}{l}\text { Adaptable to PFBC-II } \\
\text { systems }\end{array}$ & Yes & Yes & Yes & Yes & Yes \\
\hline $\begin{array}{l}\text { Steam injection for } \\
\text { power augmentation }\end{array}$ & Yes & Yes & Yes & No & Yes \\
\hline
\end{tabular}

Notes:

[1] ABB 11N uses dry low-NOx "EV" combustor meeting 25 ppm(v) as 11N2.

[2] GE 7EA uses dry low-NOx combustor meeting $25 \mathrm{ppm}(\mathrm{v})$ as 7FA.

[3] Siemens V84.2 equipped with hybrid burner may provide emission as low as $9 \mathrm{ppm}(\mathrm{v})$ without steam or water injection.

[4] Westinghouse 501D5 presently uses steam injection for NOx control. Dry low NOx combustor of the 501F type will be available later. A considerable amount of research and development has been directed at the Westinghouse combustor to ensure low NOx operation when applied to 2nd and 1.5-Generation PFBC applications. Efforts also include designs for air takeoff and reinjection requirements.

[5] ABB 11N2 has external silo combustor, uses dry low-NOx "EV" combustor meeting $25 \mathrm{ppm}(\mathrm{v})$. A 9-ppm(v) version will be available in 1994.

Although the ABB $11 \mathrm{~N}$ has the lowest gas-to-coal ratio, the Westinghouse 501D5 was selected because of better load-following ability and best turndown capability down to the level where no natural gas is being added to the topping combustor. The other candidates in Table 2-2, however, could also be used in 1.5-Generation PFBC. applications. 


\subsection{DESCRIPTIONS OF MAJOR EQUIPMENT}

As shown in the simplified flow diagram of Figure 3-1, the 1.5-Generation PFBC power plant centers around a coal-burning PFBC that generates heat to make steam. The PFBC uses compressed air from the gas turbine compressor to fluidize and oxidize the bed. Vitiated air from the PFBC exhaust is used as the oxidant in a natural-gas-fired gas turbine-generator. Energy in the gas turbine exhaust is used to heat feedwater in an exhaust heat recovery steam generator (HRSG), and heat from the PFBC is used to evaporate, superheat, and reheat the steam in a fluid bed heat exchanger (FBHE). Finally, a steam turbine-generator in a Rankine cycle generates power using the PFBC and HRSG as its heat sources.

The performance parameters of major subsystems are described in this section; the performance parameters of the complete plants are presented in Section 4. The large plant was used as the basis for designing the intermediate and small plants, but other design approaches should be considered for the other plants, especially the small plant as was done in the Foster Wheeler (1992) study.

The major subsystems described in this section are:

Sect Subsystem

3.1 Coal and Limestone Preparation Systems

3.2 Circulating PFB Combustors (CPFBC)

3.3 Fluid Bed Heat Exchangers (FBHE)

3.4 Compressed Air Systems

3.5 Combustion Turbine-Generator Systems

3.6 Heat Rẹcovery Steam Generators (HRSG)

3.7 Steam Turbine-Generator Systems

3.8 Feedwater Systems

3.9 Waste Disposal Systems 


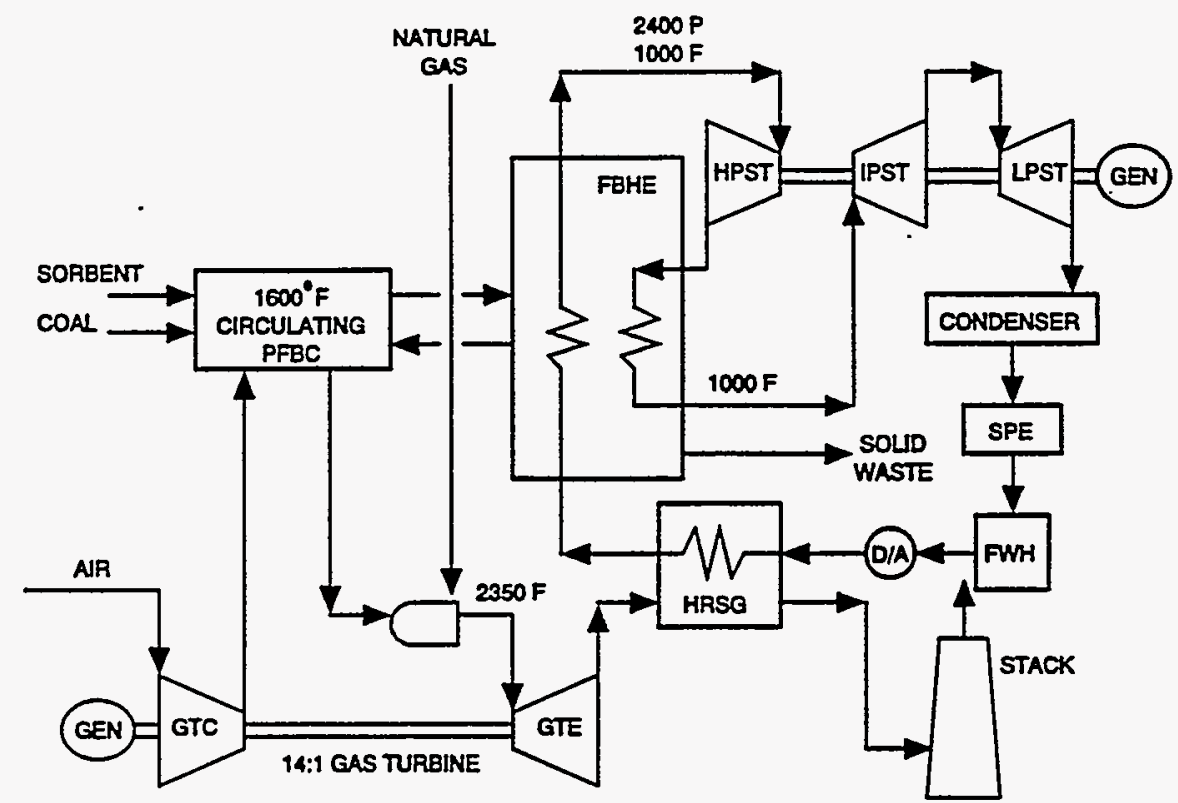

Figure 3-1 - 1.5-Generation PFBC Simplified Flow Diagram

\subsection{COAL AND LIMESTONE PREPARATION SYSTEMS}

For the purposes of this study, feedstock preparation refers to coal handling and dolomite handling. Natural gas is assumed to be delivered by pipeline, without need for further equipment. .

The coal-handling system unloads coal from barges and conveys it to the coal storage pile area; piles, reclaims, crushes, and samples it; conveys it to the in-plant storage silo (bunker); and from there, conveys it to the Petrocarb injection system that feeds the CPFBC unit. Portions of the coal-handling system equipment are also used for dolomite handling. Primarily, these include the barge unloader, bucket-wheel stacker/reclaimer, and associated conveyors.

The main functions of the dolomite-handling system are to unload dolomite from barges; convey it to the dolomite storage pile area; pile, reclaim, crush, and sample it; and convey it via the in-plant dolomite storage silo (bunker) to the Petrocarb injection system that feeds the CPFBC units. 


\subsection{CIRCULATING PFB COMBUSTORS (CPFBC)}

The Circulating Pressurized Fluid Bed Combustor (CPFBC) uses coal as fuel. The air from the gas turbine compressor is partially vitiated (heated to $1600^{\circ} \mathrm{F}$ while some of the oxygen is used for combustion) in the CPFBC. A 93.3-percent sulfur capture is assumed in the PFBC and is equal to the sulfur capture in the PFBC of 2 nd-Generation plants. All three plant cycles use the same general type of CPFBC design, although the sizes and duties vary. General parameters of the CPFB combustors are listed in Table 3-3.

Table 3-3

CPFBC Characteristics

\begin{tabular}{lccc} 
& $\begin{array}{c}\text { Large } \\
\text { Plant }\end{array}$ & $\begin{array}{c}\text { Intermediate } \\
\text { Plant }\end{array}$ & $\begin{array}{c}\text { Small } \\
\text { Plant }\end{array}$ \\
\hline Operating Pressure, atm 14 & & \\
Operating Temp, of & 1600 & 15 & 12 \\
Excess Air, \% & $100 \%$ & $100 \%$ & 1600 \\
Ca/S, molar ratio & 2.4 & 2.4 & $100 \%$ \\
Sulfur Capture & $93.3 \%$ & $93.3 \%$ & 93.4 \\
\end{tabular}

Particulate carryover of combustion products from the CPFBC are removed first by cyclones and then by ceramic barrier filters. Solids captured by the cyclones are recirculated to the fluid bed heat exchangers (FBHEs), while solids from the barrier filters are combined with the ash and spent sorbent in solid waste stream for disposal.

\subsection{FLUID BED HEAT EXCHANGERS (FBHE)}

Energy from coal combustion is used in the Fluid Bed Heat Exchanger (FBHE) to generate a large portion of the steam, and to superheat the high-pressure steam for the steam turbine. The FBHE transfers sensible heat from the particulates and solids captured by the CPFBC recycle system to the water/steam circuitry that generates steam to power the steam turbine.

Feedwater preheating and a portion of the steam generating and primary superheating are accomplished in the gas turbine heat-recovery steam generator (HRSG). The balance of the plant steam generating and superheating, along with all reheating, is performed in the FBHE.

Superheater and reheater steam temperatures are controlled primarily by regulating the solids flow rates through their respective passes; motionless " $\mathrm{J}$ " valves or loop seals control the solids circulation rates. Additional steam temperature control and faster response are obtained by injecting atomized water directly into the steam in spray attemperators. These attemperators are located between primary and finishing superheaters, between primary and finishing LP reheaters, and between secondary and finishing HP reheaters: 
The performance characteristics of the fluid bed heat exchangers are tabulated in Table 3-4.

Table 3-4

Fluid Bed Heat Exchanger Characteristics

\begin{tabular}{|c|c|c|}
\hline & $\begin{array}{l}\text { Large } \\
\text { Plant }\end{array}$ & $\begin{array}{c}\text { Intermediate } \\
\text { Plant }\end{array}$ \\
\hline $\begin{array}{l}\text { Solids Inlet Temp, oF } \\
\text { Solids Exit Temp, of }\end{array}$ & $\begin{array}{l}1600 \\
1050\end{array}$ & $\begin{array}{l}1600 \\
1050\end{array}$ \\
\hline $\begin{array}{l}\text { Throttle Steam: } \\
\text { Pressure, psia } \\
\text { Exit Temp, of }\end{array}$ & $\begin{array}{l}1815 \\
1000\end{array}$ & $\begin{array}{l}1465 \\
1000\end{array}$ \\
\hline $\begin{array}{l}\text { Reheat Steam: } \\
\text { Pressure, psia } \\
\text { Exit Temp, of }\end{array}$ & $\begin{array}{c}421 \\
1000\end{array}$ & $\begin{array}{c}341 \\
1000\end{array}$ \\
\hline $\begin{array}{l}\text { Steam Inlet: } \\
\text { Pressure, psia } \\
\text { Inlet Temp, of }\end{array}$ & $\begin{array}{l}1995 \\
656\end{array}$ & $\begin{array}{l}1611 \\
626\end{array}$ \\
\hline $\begin{array}{l}\text { Water Inlet: } \\
\text { Pressure, psia } \\
\text { Inlet Temp, of }\end{array}$ & $\begin{array}{l}2016 \\
637\end{array}$ & $\begin{array}{l}1627 \\
607\end{array}$ \\
\hline
\end{tabular}

\subsection{COMPRESSED AIR SYSTEMS}

Except for turbine cooling flows required by the gas turbine, all of the air produced by the gas turbine compressor is collected from the compressor discharge and ducted to the coal feed and CPFBC area. This pressurized air supplies three subsystems:

- CPFBC primary combustion air.

- Boost compressors, which provide pressurization and atomizing air above the CPFBC entry pressure. The air is cooled and dried before being compressed by the boost compressors.

- Fluidized Bed Heat Exchanger fluidizing air.

Table 3-5 shows the exit conditions of the compressed air systems used in the study. 
Table 3-5

Compressor Discharge Pressures and Temperatures

\begin{tabular}{lccr} 
& $\begin{array}{c}\text { Large } \\
\text { Plant }\end{array}$ & $\begin{array}{c}\text { Intermediate } \\
\text { Plant }\end{array}$ & $\begin{array}{r}\text { Small } \\
\text { Plant }\end{array}$ \\
\hline $\begin{array}{l}\text { Main Compressor } \\
\text { Discharge Press, psia }\end{array}$ & & & \\
Discharge Temp, of & 202 & 218 & 171 \\
& 712 & 737 & $\ldots 657$ \\
Boost Compressor & & & \\
$\quad$ Discharge Press, psia & 250 & 266 & 219 \\
Discharge Temp, of & 151 & 150 & 149
\end{tabular}

\subsection{COMBUSTION TURBINE-GENERATOR SYSTEMS}

Combustion turbine systems include the gas turbine-generator, compressed air piping from the compressor to the CPFBC and FBHE (see "Compressed Air Systems"), and hot gas piping from the PFBC to the gas turbine. The turbine is connected to a generator that supplies power through an isolated-phase bus duct and dedicated step-up transformer to an overhead connection to a high-voltage transmission line. The combustion turbine-generator unit is supplied as a package.

Three gas turbines were selected for analysis: the Westinghouse W501D5, the Westinghouse 251B12, and the Nuovo Pignone PGT-2. The nominal exit temperatures of the topping combustors in the three PFBC cycles are listed in Table 3-6 along with other design parameters. The "T-G" efficiencies are based on commercial heat rates for simple-cycle turbine-generator units using natural gas with an LHV/HHV ratio of 0.91.

Table 3-6

\section{Gas Turbine Performance Parameters}

\begin{tabular}{lccc} 
& $\begin{array}{c}\text { Large } \\
\text { Plant }\end{array}$ & $\begin{array}{c}\text { Intermediate } \\
\text { Plant }\end{array}$ & $\begin{array}{c}\text { Small } \\
\text { Plant }\end{array}$ \\
\hline Vendor & & & \\
& Westing- & Westing- & Nuovo \\
house & house & Pignone \\
Performance Basis & W501D5 & $251 \mathrm{~B} 12$ & PGT-2 \\
Inlet Air Flow, lb/s & 807 & 374 & 22 \\
Firing Temp, oF & 2038 & 1965 & 2054 \\
Turbine Exit Temp, of & 987 & 950 & 1011 \\
T-G Efficiency (HHV),\% & 30.3 & 29.7 & 22.7
\end{tabular}

In 1.5-Generation applications, the combustion characteristics of natural gas are similar to the design characteristics of the turbine, but air off-take and re-injection requirements are different. In a 1.5-Generation application, some of the compressed air is ducted away from the turbine compressor to the CPFBC and FBHE (see "Compressed Air 
Systems"), while hot, vitiated air from the CPFBC is ducted back into the topping combustor. These air off-take and re-injection requirements require modifications to the transition piece between the compressor and the combustor.

Ceramic-lined piping is used to transport compressed air and vitiated air to and from the PFBC. Compressed air from the compressor is conveyed to the PFBC and FBHE by ceramic-insulated hot gas piping. Hot, vitiated air produced by the CPFBC is conveyed to the gas turbine by ceramic-insulated hot gas piping with metallic liners on the inner diameter to protect the turbine from eroded ceramic material. Carbon steel outer liners provide structural strength to these pipes.

\subsection{HEAT RECOVERY STEAM GENERATORS (HRSG)}

Exhaust gas leaving the gas turbine flows through a heat recovery steam generator (HRSG), where it is cooled while producing steam and heated feedwater. Gas leaving the HRSG is ducted to the stack. Together, the FBHE and HRSG provide about 99 percent of the required steam energy. The remaining one percent of steam cycle thermal input is provided by the ash screw coolers in the form of condensate heating.

The large and intermediate plants use the same general heat exchanger arrangement, in which the HRSG is the only component between the gas turbine and the stack. In the small plant, however, exhaust gas leaving the HRSG provides heat for a low-temperature economizer before entering the stack. The main characteristics of the heat exchangers are tabulated in Table 3-7. 
Table 3-7

Heat Recovery Steam Generator Characteristics

\begin{tabular}{|c|c|c|c|}
\hline & $\begin{array}{l}\text { Large } \\
\text { Plant }\end{array}$ & $\begin{array}{c}\text { Intermediate } \\
\text { Plant }\end{array}$ & $\begin{array}{l}\text { Small } \\
\text { Plant }\end{array}$ \\
\hline $\begin{array}{l}\text { Exhaust Gas: } \\
\text { HRSG: }\end{array}$ & & & \\
\hline $\begin{array}{l}\text { Inlet Temp, of } \\
\text { Exit Temp, of }\end{array}$ & $\begin{array}{l}987 \\
280\end{array}$ & $\begin{array}{l}950 \\
280\end{array}$ & $\begin{array}{r}1011 \\
385\end{array}$ \\
\hline Low-Temp Econ: & & & \\
\hline $\begin{array}{l}\text { Inlet Temp, of } \\
\text { Exit Temp, of }\end{array}$ & - & - & $\begin{array}{l}385 \\
280\end{array}$ \\
\hline $\begin{array}{l}\text { Water to HRSG: } \\
\text { Pressure, psia } \\
\text { Inlet Temp, oF }\end{array}$ & $\begin{array}{r}2316 \\
245\end{array}$ & $\begin{array}{r}1927 \\
244\end{array}$ & $\begin{array}{l}983 \\
242\end{array}$ \\
\hline $\begin{array}{l}\text { Water to FBHE: } \\
\text { Pressure, psia } \\
\text { Inlet Temp, oF }\end{array}$ & $\begin{array}{r}2016 \\
637\end{array}$ & $\begin{array}{r}1627 \\
607\end{array}$ & $\begin{array}{l}683 \\
500\end{array}$ \\
\hline $\begin{array}{l}\text { Steam to FBHE: } \\
\text { Pressure, psia } \\
\text { Inlet Temp, oF }\end{array}$ & $\begin{array}{r}1996 \\
656\end{array}$ & $\begin{array}{r}1610 \\
626\end{array}$ & $\begin{array}{l}614 \\
750\end{array}$ \\
\hline
\end{tabular}

\subsection{STEAM TURBINE-GENERATOR SYSTEMS}

The basic steam turbine-generator cycle configuration is identical for the large and intermediate plants. The turbine is a $3600-\mathrm{rpm}$, tandem-compound reheat unit with a double-flow low-pressure section. The small plant turbine-generator is a single-flow, non-reheat unit. Determination of the preferred speed $(\mathrm{rpm})$ of the small plant turbine will require consultation with designers and manufacturers. In all cases, the low-pressure turbine stage exhausts to a single pressure, water-cooled condenser.

The steam turbine throttle pressures in this study are representative of commercial steam turbine-generators in corresponding size ranges: 1800 psig for 100 to $200 \mathrm{MW}$; $1450 \mathrm{psig}$ for 50 to $100 \mathrm{MW}$; and 600 psig below $50 \mathrm{MW}$. While these pressures are lower than the conventional 2400 psig of larger steam turbines, they are more conducive to part load operation. The steam expansion lines from these turbines tend to remain in the slightly "wet" region at the LP turbine exhaust even at low loads, while the part-load expansion lines from 2400-psi turbines often exhaust slightly superheated.

The turbine is connected to a generator that supplies power through an isolated-phase bus duct and dedicated step-up transformer to an overhead connection to a highvoltage transmission line. 
All steam turbine cycles in this study are condensing Rankine cycles that convert energy from the FBHE, HRSG, and ash cooler into electric power. All steam cycles use commercially available equipment. The principal design characteristics of the cycles are tabulated in Table 3-8.

Table 3-8

Steam Cycle Design Characteristics

\begin{tabular}{lrrr} 
& $\begin{array}{c}\text { Large } \\
\text { Plant }\end{array}$ & $\begin{array}{r}\text { Intermediate } \\
\text { Plant }\end{array}$ & $\begin{array}{r}\text { Small } \\
\text { Plant }\end{array}$ \\
\hline Throttle press, psig & 1800 & 1450 & 600 \\
Throttle temp, of & 1000 & 1000 & 750 \\
First Reheat, of & 1000 & 1000 & - \\
Deaerator press, psia & 25 & 25 & 25 \\
Condenser press, "Hg & 2.5 & 2.5 & 2.5 \\
Feedwater Heaters & 1 & 1 & -
\end{tabular}

\subsection{FEEDWATER SYSTEMS}

Condensate leaving the condenser is heated in a series of shell-and-tube heat exchangers before being converted to steam for the steam turbines.

Because of the feedwater heating capability of the HRSG, PFBC plants have fewer feedwater heaters than do PC plants. Heating and deaeration of low pressure condensate is provided primarily by extraction steam. The deaerator operates at $240^{\circ} \mathrm{F}$ and a pressure of 25 psia. A fraction of the condensate is diverted around the feedwater heater to cool the ash screw coolers. The hot water leaving the screw coolers is discharged directly into the deaerator.

Water from the deaerator is pressurized by electrically-driven booster pumps and feedwater pumps, then heated by the HRSG economizer sections to a temperature 10 degrees lower than the saturation temperature.

Feedwater leaving the HRSG economizers is split into two streams: one to the HRSG evaporator, and the other to the FBHE evaporator. The water in the HRSG steam drum is evaporated and slightly superheated, then piped to the FBHE to be mixed with steam produced there. The feedwater piped to the FBHE evaporator is also heated to steam. The combined steam flows are superheated to the steam turbine throttle temperature.

\subsection{ASH DISPOSAL SYSTEMS}

Excess solids from the FBHE are extracted from the heat exchanger at $1050^{\circ} \mathrm{F}$ and de-pressurized through a Restricted Pipe Discharge (RPD) vessel, then cooled to $300 \circ \mathrm{F}$ in a screw cooler. RPD vessels utilize the waste solids as a pressure let-down device, in 
place of an extra valve. Solids collected by the cross-flow filters are also de-pressurized in the RPD vessels, and then cooled in screw coolers.

The type and amount of waste produced by the study plants are tabulated in Table 3-9. The solid waste includes small amounts of unburned carbon, giving the waste stream a small heating value. The energy in the waste stream represents less than $0.6 \%$ of the thermal input to each plant.

Table 3-9

Waste Production Summary

\begin{tabular}{lrrr} 
& $\begin{array}{r}\text { Large } \\
\text { Plant }\end{array}$ & $\begin{array}{r}\text { Intermediate } \\
\text { Plant }\end{array}$ & $\begin{array}{r}\text { Small } \\
\text { Plant }\end{array}$ \\
\hline Coal Ash, Ib/h & 12,808 & 6,121 & 301 \\
Spent Sorbent, lb/h & 43,820 & 20,941 & 1,031 \\
Solid Waste, lb/h & 56,628 & 27,062 & 1,332 \\
Plant Net Power, MW & 246 & 111 & 4 \\
Total Solids, lb/MWh & 230 & 244 & 333 \\
& & & \\
Waste HHV, Btu/lb & 156 & 156 & 156 \\
Waste Energy, MW & 3.4 & 1.6 & 0.08 \\
Plant Input, MW & 595.18 & 275.35 & 14.25 \\
Waste/Input, MW/MW & $0.57 \%$ & $0.58 \%$ & $0.56 \%$
\end{tabular}




\subsection{CONCEPTUAL DESIGNS}

This section compares the conceptual design and performance of large, intermediate, and small 1.5-Generation PFBC combined cycle power plants. The thermal performance of the plants are compared in Table 4-1 below. Plant flowsheets and detailed performance parameters for each plant are given in their individual sections.

Table 4-1

Thermal Performance Comparison

\begin{tabular}{lrrr} 
& $\begin{array}{c}\text { Large } \\
\text { Plant }\end{array}$ & $\begin{array}{r}\text { Intermediate } \\
\text { Plant }\end{array}$ & $\begin{array}{r}\text { Small } \\
\text { Plant }\end{array}$ \\
\hline ENERGY INPUT & & & \\
Coal Feed, Ib/h & 128,861 & 61,581 & 3,031 \\
Coal HHV, Btu/lb & 12,452 & 12,452 & 12,452 \\
Nat. Gas Feed, Ib/h & 19,257 & 7,781 & 492 \\
Nat HHV, Btu/lb & 21,799 & 21,799 & 21,799 \\
Coal Energy, MW & & & \\
Coal Drying Energy, MW & 470.268 & 227.734 & 11.061 \\
Nat. Gas Energy, MW & 1.887 & 0.902 & 0.044 \\
Plant Energy Input & 123.026 & 49.710 & 3.142 \\
& 595.181 & 275.345 & 14.247 \\
ENERGY OUTPUT & & & \\
Gas Turbine, MW & 87.501 & 38.107 & 1.512 \\
Steam Turbine, MW & 169.362 & 77.408 & 2.648 \\
Auxiliaries, MW & 10.590 & 4.774 & 0.201 \\
Plant Net Power, MW & 246.272 & 110.741 & 3.960 \\
Thermal Efficiency, \% & $41.4 \%$ & $40.2 \%$ & $27.8 \%$
\end{tabular}

The large and intermediate plants have similar efficiency levels, while efficiency of the small plant is significantly lower. The reduced efficiency of the small plant is caused by the reduced efficiency of its smaller gas turbine and non-reheat steam cycle, as shown in Table 4-2.

The relative power contributions of the gas turbine and steam turbine place the 1.5Generation plant between the 1st- and 2nd-Generation plants, as shown in Table 4-3 and Figure 4-1. Gas turbine power plus steam turbine power equal 100 percent of gross power, from which auxiliary power is subtracted to get net power. The net power ranges from 87 to 99 percent of gross power for the six types of combined cycles shown. 


\section{Table 4-2 \\ Gross Efficiency Comparison}

\begin{tabular}{ccc} 
Large & Intermediate & Small \\
Plant & Plant & Plant \\
\hline
\end{tabular}

Topping Cycle Efficiency

Plant Energy Input, MW

FBHE to Steam Cycle, MW

Net Energy Input, MW

Gas Turbine, MW

Topping Cycle Efficiency, \%

\begin{tabular}{rrr}
595.181 & 275.345 & 14.247 \\
253.296 & 122.814 & $\underline{5.573}$ \\
\hline 341.885 & 152.531 & 8.674 \\
87.501 & 38.107 & 1.512 \\
$25.6 \%$ & $25.0 \%$ & $17.4 \%$
\end{tabular}

Bottoming Cycle Efficiency

FBHE Input, MW

HRSG Input, MW

Ash Cooler Input, MW

Bottoming Cycle Input, MW

Steam Turbine, MW

Bottoming Cycle Efficiency, \%

$\begin{array}{rrr}253.296 & 122.814 & 5.573 \\ 164.139 & 71.835 & 4.557 \\ 3.393 & 1.621 & \underline{0.079} \\ 420.828 & 196.271 & 10.210 \\ 169.369 & 77.408 & 2.648 \\ 40.2 \% & 39.4 \% & 25.9 \%\end{array}$

Plant Efficiency

Plant Energy Input, MW

Gas Turbine, MW

\begin{tabular}{rrr}
595.181 & 275.345 & 14.247 \\
87.501 & 38.107 & 1.512 \\
169.369 & 77.408 & 2.648 \\
10.590 & 4.774 & 0.201 \\
\hline 246.272 & 110.741 & 3.960 \\
$41.4 \%$ & $40.2 \%$ & $27.8 \%$
\end{tabular}

Steam Turbine, MW

Auxiliaries, MW

Plant Net Power, MW

Net Plant Efficiency, \%

$41.4 \%$

$40.2 \%$

$27.8 \%$ 


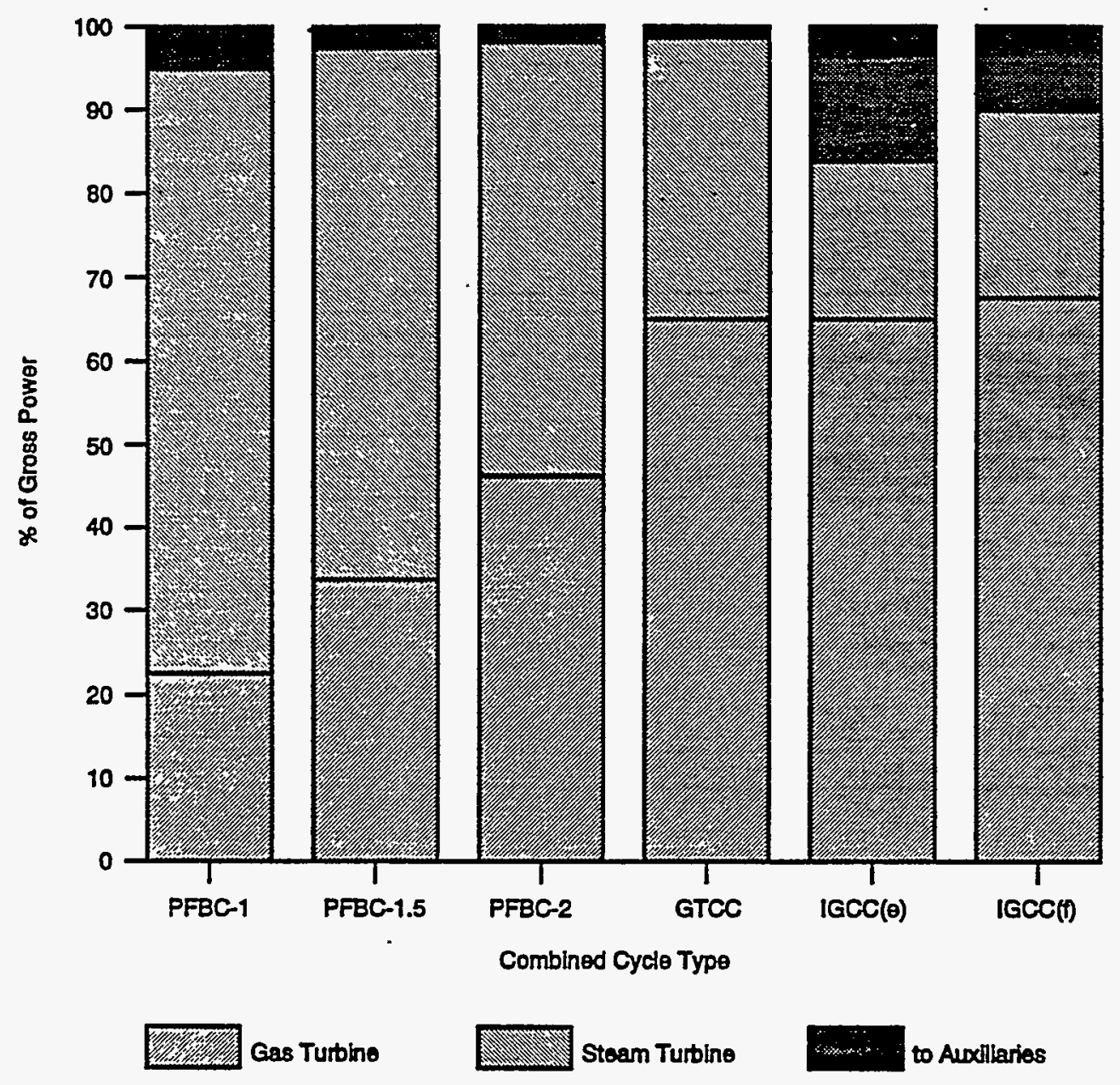

Figure 4-1 - Power Production and Use Comparison

There is a strong (but not absolute) correlation between gas turbine contribution and plant thermal efficiency for combined cycle plants. Figure 4-2 compares typical gas turbine contributions and HHV efficiencies for five types of combined cycle plants: 1st-, 1.5-, and 2nd-Generation PFBC; Gas-fueled gas turbine combined cycle; and oxygenblown, dry-fed integrated gasification combined cycles (IGCCs) with entrained (e) and fluidized (f) beds. The lower efficiencies of the IGCCs are due to their larger auxiliary power requirements. 
Table 4-3

Combined Cycle Power and Efficiency Comparison

(Power as percent of gross power)

(Efficiency as percent of plant heat input)

\begin{tabular}{lrrrrrr} 
Cycle Type & PFBC-1 & PFBC-1.5 & PFBC-2 & GTCC & IGCC(e) & IGCC(f) \\
\hline Gas Turb Power & $19 \%$ & $34 \%$ & $45 \%$ & $65 \%$ & $65 \%$ & $69 \%$ \\
Stm Turb Power $81 \%$ & $66 \%$ & $55 \%$ & $35 \%$ & $35 \%$ & $31 \%$ \\
Gross Power & $100 \%$ & $100 \%$ & $100 \%$ & $100 \%$ & $100 \%$ & $100 \%$ \\
Auxil Power & $-2 \%$ & $-4 \%$ & $-3 \%$ & $-1 \%$ & $-13 \%$ & $-9 \%$ \\
Net Power & $98 \%$ & $96 \%$ & $97 \%$ & $99 \%$ & $87 \%$ & $91 \%$ \\
HHV Efficiency & $40 \%$ & $41 \%$ & $45 \%$ & $49 \%$ & $39 \%$ & $39 \%$
\end{tabular}

PFBC-1 1st-Generation PFBC Plant: 230 MW [Aggregate of McKinsey, Booras, and McClung, 1991; Provol and Ambrose, 1993; Carpenter and others, 1991; Wheeldon and others, 1993; Sugiura and others, 1993; and EPRI, 1993]

PFBC-1.5 1.5-Generation PFBC Plant: $246 \mathrm{MW}$ [this report]

PFBC-2 2nd-Generation PFBC Plant: 496 MW [FWDC, 10/92]

GTCC Gas Turbine Combined Cycle: 340 MW [Farmer, 1992]

IGCC(e) Dry-fed oxygen-blown IGCC with entrained bed: 454 MW [Ahn, Chen, and White, 1992]

IGCC(f) Dry-fed oxygen-blown IGCC with fluidized bed: $440 \mathrm{MW}$ [Ahn, Chen, and White, 1992] 


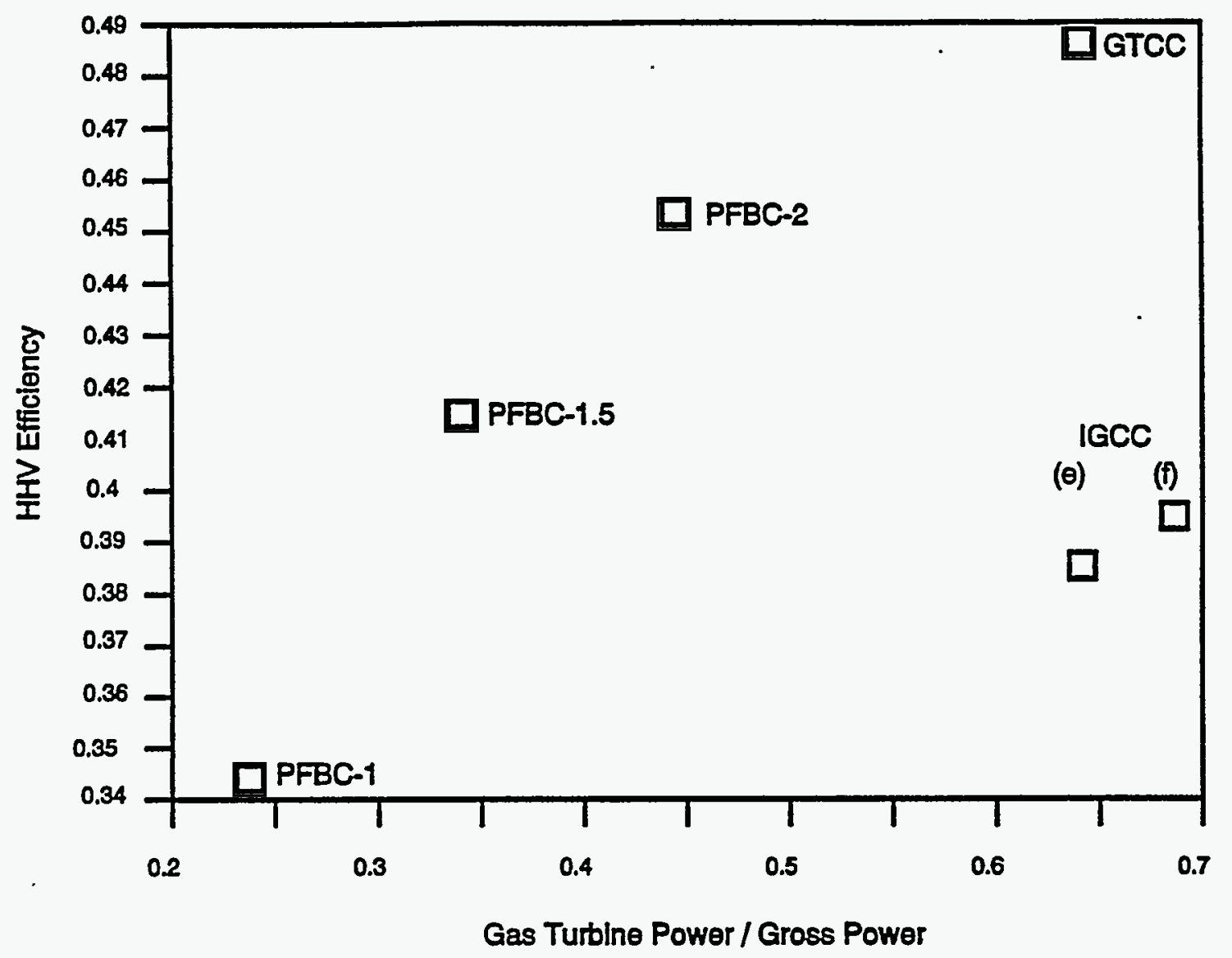

Figure 4-2 - Gas Turbine Power and Efficiency Comparison

The remainder of this section contains the assumptions used and the performance characteristics of each of the three study plants:

4.1 Assumptions

4.2 Large 1.5-Generation PFBC Power Plant

4.3 Intermediate 1.5-Generation PFBC Power Plant

4.4 Small 1.5-Generation PFBC Power Plant

4.5 Design Sensitivity to Excess Air 


\subsection{ASSUMPTIONS}

Thermal performance results in this study were based on consistent boundary conditions and calculation software. All cases had the same plant boundary conditions: ISO ambient conditions, Pittsburgh No. $8 \mathrm{coal}$, and Plum Run dolomite for the PFBC process. Thermal performance for all cases were calculated by the same integrated program -- ASPEN/SP -- to ensure consistent results.

ASPEN/SP is the modular computer program used to model the fluid bed combustor, gas turbine, HRSG, and steam turbine cycle in a single, integrated calculation stream. Performance coefficients for the gas turbines and steam turbines were based on data published by Westinghouse. The performance calculations for the remaining items of equipment were based on accepted practices and in-house calculation procedures.

The following sections present assumptions for the selected site conditions, coal and sorbent.

\subsubsection{Plant Site Conditions}

For purposes of consistency, all plant sites are considered to be identical with regard to the following parameters:

- The location is the Ohio River Valley of southwestern Pennsylvania/eastern Ohio.

- The site encompasses 300 acres within 15 miles of a medium-sized metropolitan area.

- The surrounding area is a mixture of agriculture and light industry.

- The site is served by a navigable river.

- A railroad line is located within 2-1/2 miles of the site.

- There is a well-developed road network in the vicinity of the site.

- The site contains relatively flat land with a 30 -ft elevation differential within its boundaries.

- The site is classified as Seismic Zone 1.

- Average ambient air conditions are:

- Pressure

- Dry bulb temperature

- Wet bulb temperature 


\subsubsection{Coal Properties}

Pittsburgh No. 8 coal is used as the feed coal for all cases in this study. The ultimate and proximate analyses for this coal are tabulated in Table 4.1-1.

Table 4.1-1

Pittsburgh No. 8 Coal Analysis

(weight percent, as received)

$\begin{array}{rrr}\text { Constituent } & \text { Ultimate Analysis } & \text { Proximate Analysis } \\ \text { Carbon } & 69.36 & \\ \text { Hydrogen } & 4.51 & \\ \text { Nitrogen } & 1.22 & \\ \text { Sulfur } & 2.89 & \\ \text { Ash } & 9.94 & 9.94 \\ \text { Oxygen } & 6.08 & 6.00 \\ \text { Moisture } & 6.00 & 35.91 \\ \text { Volatile Matter } & & 48.15 \\ \text { Fixed Carbon } & 100.00 & 100.00 \\ \text { Total } & 12,452 & 12,452 \\ \text { HHV, Btu/lb } & & \end{array}$

\subsubsection{Sorbent Properties}

Plum Run Dolomite is used as the in-bed sulfur sorbent for all of the 2nd-Generation PFBC cycles evaluated in this study. Dolomite is utilized in 2nd-Generation PFBC applications due to its superior performance at higher pressures.

The composition of Plum Run Dolomite is tabulated in Table 4.1-2.

Table 4.1-2

Sorbent Composition

(weight percents)

Calcium Carbonate, $\mathrm{CaCO} 3$

Magnesium Carbonate, $\mathrm{MgCO} 3$

Moisture, $\mathrm{H} 2 \mathrm{O}$

Inert Material
$54.4 \%$

$43.3 \%$

$0.5 \%$

$1.7 \%$ 


\subsection{LARGE 1.5-GENERATION PFBC PLANT}

The large ( 250-MW) 1.5-Generation PFBC system uses a Westinghouse $501 \mathrm{D} 5$ gas turbine, with a 1800/1000/1000 steam turbine bottoming cycle. The plant flowsheet is shown in Figure 4.2-1, and the major systems of the plant are described in more detail in Section 3.

The plant performance is summarized in Table 4.2-1.

Table 4.2-1

Large PFBC Plant Performance Summary

\begin{tabular}{|c|c|c|c|}
\hline $\begin{array}{l}\text { Gas Turbine Power } \\
\text { Steam Turbine Power } \\
\text { Plant Gross Power } \\
\text { Plant Auxiliary Power } \\
\text { Plant Net Power }\end{array}$ & $\begin{array}{r}87.501 \\
169.369 \\
256.862 \\
10.590 \\
246.272\end{array}$ & $\begin{array}{l}\text { MW } \\
\text { MW }\end{array}$ & $\begin{array}{l}\text { Westinghouse 501D5 } \\
1800 / 1000 / 1000 / 2.5^{\prime \prime} \mathrm{Hg}\end{array}$ \\
\hline $\begin{array}{l}\text { Coal HHV } \\
\text { Coal Drying Energy } \\
\text { Natural Gas HHV } \\
\text { Plant Thermal Input }\end{array}$ & $\begin{array}{r}470.268 \\
1.887 \\
123.026 \\
595.181\end{array}$ & $\begin{array}{l}\text { MW } \\
\text { MW }\end{array}$ & $\begin{array}{l}\text { 128,861 lb/h @ 12,452 Btu/lb } \\
19,257 \text { lb/h @ 21,799 Btu/lb }\end{array}$ \\
\hline $\begin{array}{l}\text { Net Electric Efficiency } \\
\text { Net Heat Rate (HHV) }\end{array}$ & $\begin{array}{r}41.38 \% \\
8,246\end{array}$ & & \\
\hline
\end{tabular}

The auxiliary power requirements are listed in Table 4.2-2, and the plant heat and material balance is shown in Table 4.2-3.

Table 4.2-2

\section{Large PFBC Plant Auxiliary Power Requirements}

$\begin{array}{lrl}\text { Transport Compressor } & 0.261 & \text { MW } \\ \text { Feedwater Pumps } & 2.745 & \\ \text { Condensate Pumps } & 0.148 & \\ \text { Cooling Tower Fans } & 0.572 & \\ \text { Circ Water Pumps } & 1.494 \\ \text { Ash Cooling \& Handling } & 0.323 \\ \text { Coal Feeding } & 0.244 \\ \text { Coal Handling } & 0.027 \\ \text { Sorbent Handling } & 0.422 \\ \text { Rail Unloading, etc. } & 0.059 \\ \text { Service Water System } & 0.045 \\ \text { Sorbent Feeding } & 0.097 \\ \text { Transformer Losses } & 3.853 & \\ \text { Miscellaneous } & 0.300 & \\ \text { Total Auxiliaries } & 10.590 & \text { MW }\end{array}$




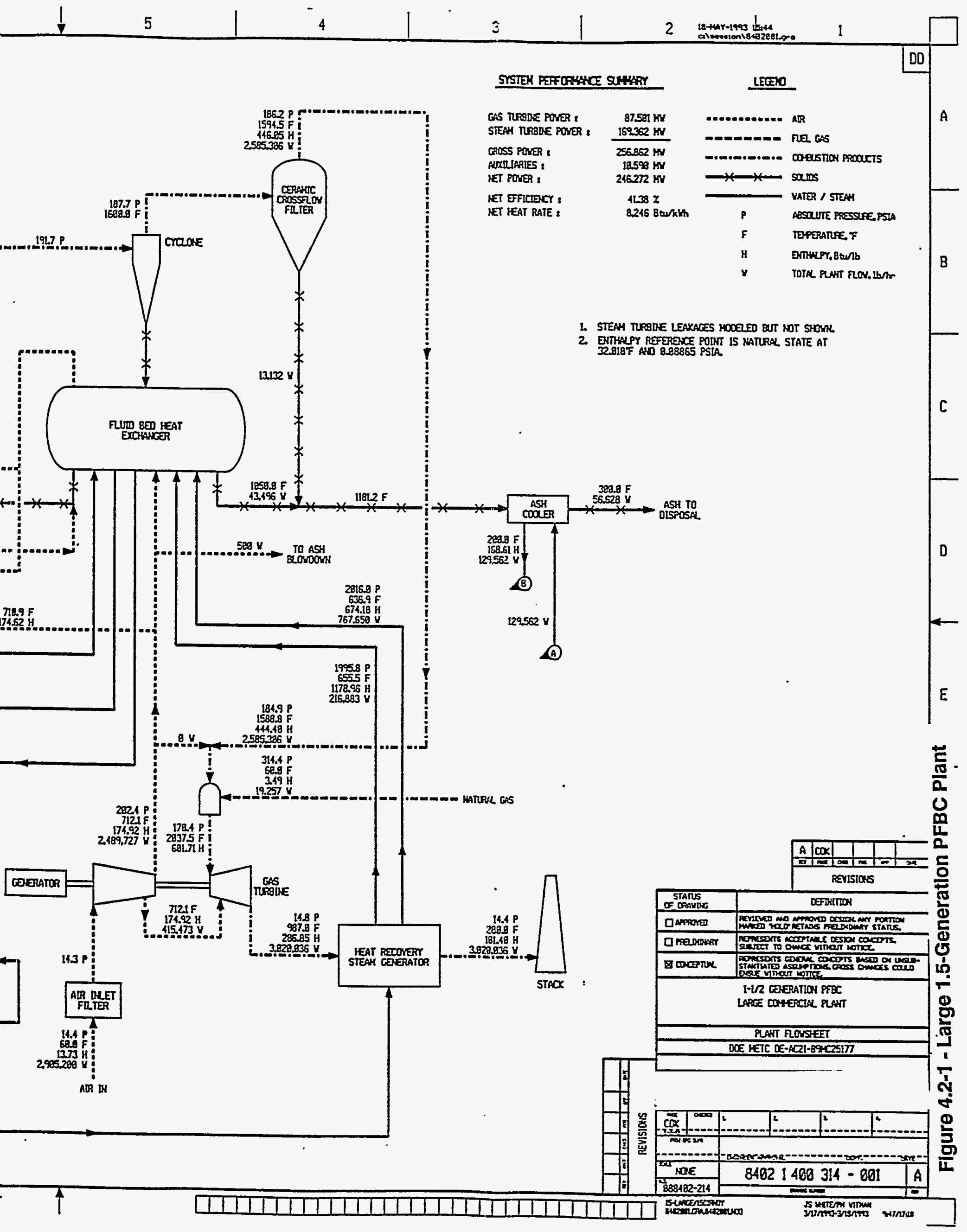


Table 4.2-3

Large PFBC Plant Heat and Material Balance

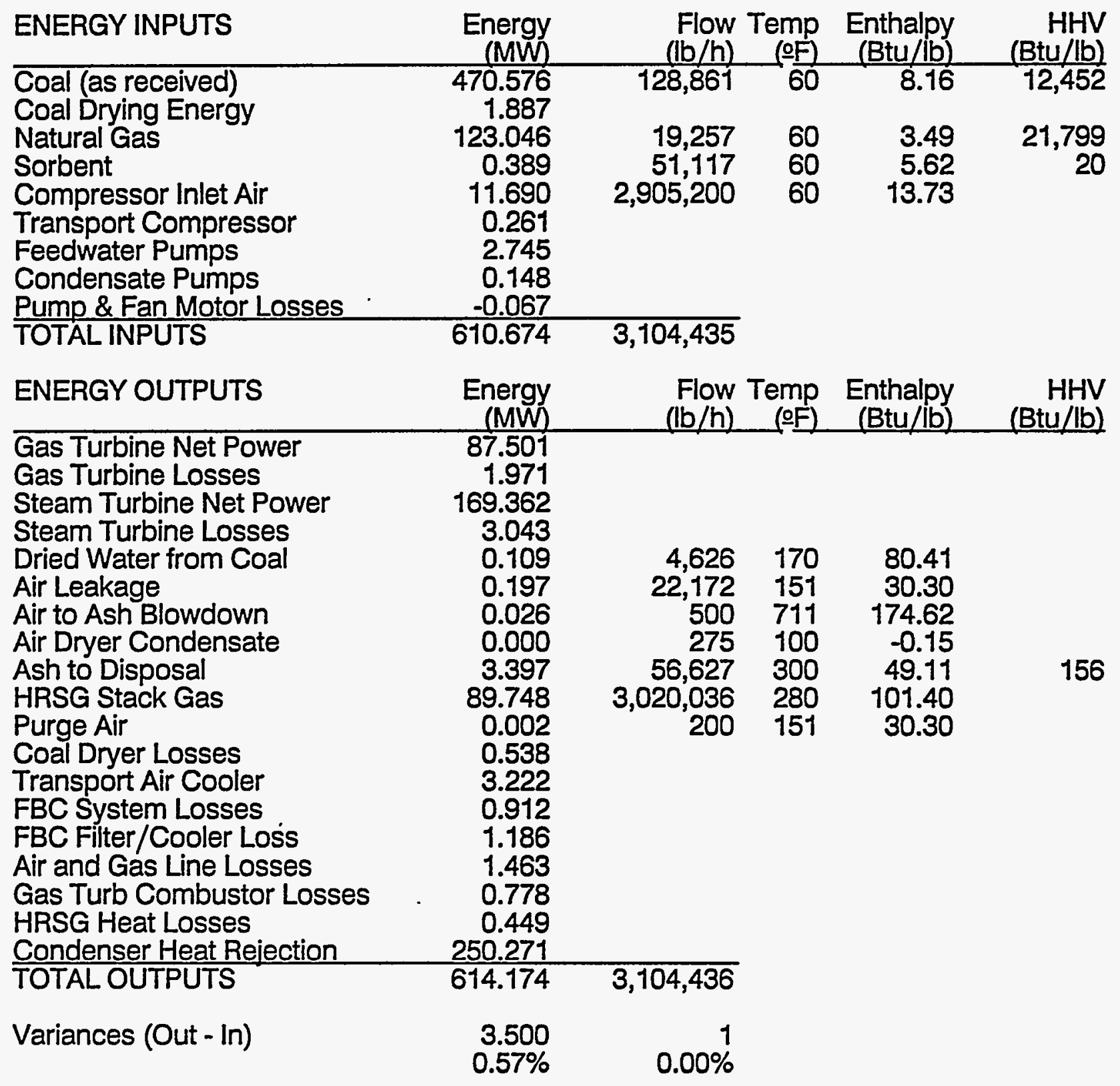




\subsection{INTERMEDIATE 1.5-GENERATION PLANT}

The intermediate ( 110-MW) 1.5-Generation PFBC system uses a Westinghouse W251B12 gas turbine with a 1450/1000/1000 steam turbine bottoming cycle. The plant flowsheet is shown in Figure 4.3-1, and the major systems of the plant are described in more detail in Section 3.

The plant performance is summarized in Table 4.3-1.

Table 4.3-1

Intermediate PFBC Plant Performance Summary

\begin{tabular}{|c|c|c|}
\hline $\begin{array}{l}\text { Gas Turbine Power } \\
\text { Steam Turbine Power } \\
\text { Plant Gross Power } \\
\text { Plant Auxiliary Power } \\
\text { Plant Net Power }\end{array}$ & $\begin{array}{r}38.107 \mathrm{MW} \\
77.408 \\
115.515 \\
4.774 \\
110.741 \mathrm{MW}\end{array}$ & $\begin{array}{l}\text { Westinghouse 251B12 } \\
1450 / 1000 / 1000 / 2.5^{2} \mathrm{Hg}\end{array}$ \\
\hline $\begin{array}{l}\text { Coal HHV } \\
\text { Coal Drying Energy } \\
\text { Natural Gas HHV } \\
\text { Plant Thermal Input }\end{array}$ & $\begin{array}{r}224.734 \mathrm{MW} \\
0.902 \\
49.710 \\
275.345 \mathrm{MW}\end{array}$ & $\begin{array}{l}\text { 61,581 lb/h @ 12,452 Btu/lb } \\
7,781 \text { lb/h @ 21,799 Btu/lb }\end{array}$ \\
\hline $\begin{array}{l}\text { Net Electric Efficiency } \\
\text { Net Heat Rate (HHV) }\end{array}$ & $\begin{array}{r}40.22 \% \\
8,484 \text { B }\end{array}$ & \\
\hline
\end{tabular}

The auxiliary power requirements are listed in Table 4.3-2, and the plant heat and material balance is shown in Table 4.3-3.

Table 4.3-2

Intermediate PFBC Plant Auxiliary Power Requirements

$\begin{array}{lll}\text { Transport Compressor } & 0.121 & \text { MW } \\ \text { Feedwater Pumps } & 1.139 & \\ \text { Condensate Pumps } & 0.074 & \\ \text { Cooling Tower Fans } & 0.270 & \\ \text { Circ Water Pumps } & 0.712 & \\ \text { Ash Cooling \& Handling } & 0.154 & \\ \text { Coal Feeding } & 0.117 & \\ \text { Coal Handling } & 0.013 & \\ \text { Sorbent Handling } & 0.202 & . \\ \text { Rail Unloading, etc. } & 0.028 & \\ \text { Service Water System } & 0.021 \\ \text { Sorbent Feeding } & 0.046 & \\ \text { Transformer Losses } & 1.733 & \\ \text { Miscellaneous } & 0.143 & \\ \text { Total Auxiliaries } & 4.774 & \text { MW }\end{array}$


Table 4.3-3

Intermediate PFBC Plant Heat and Material Balance

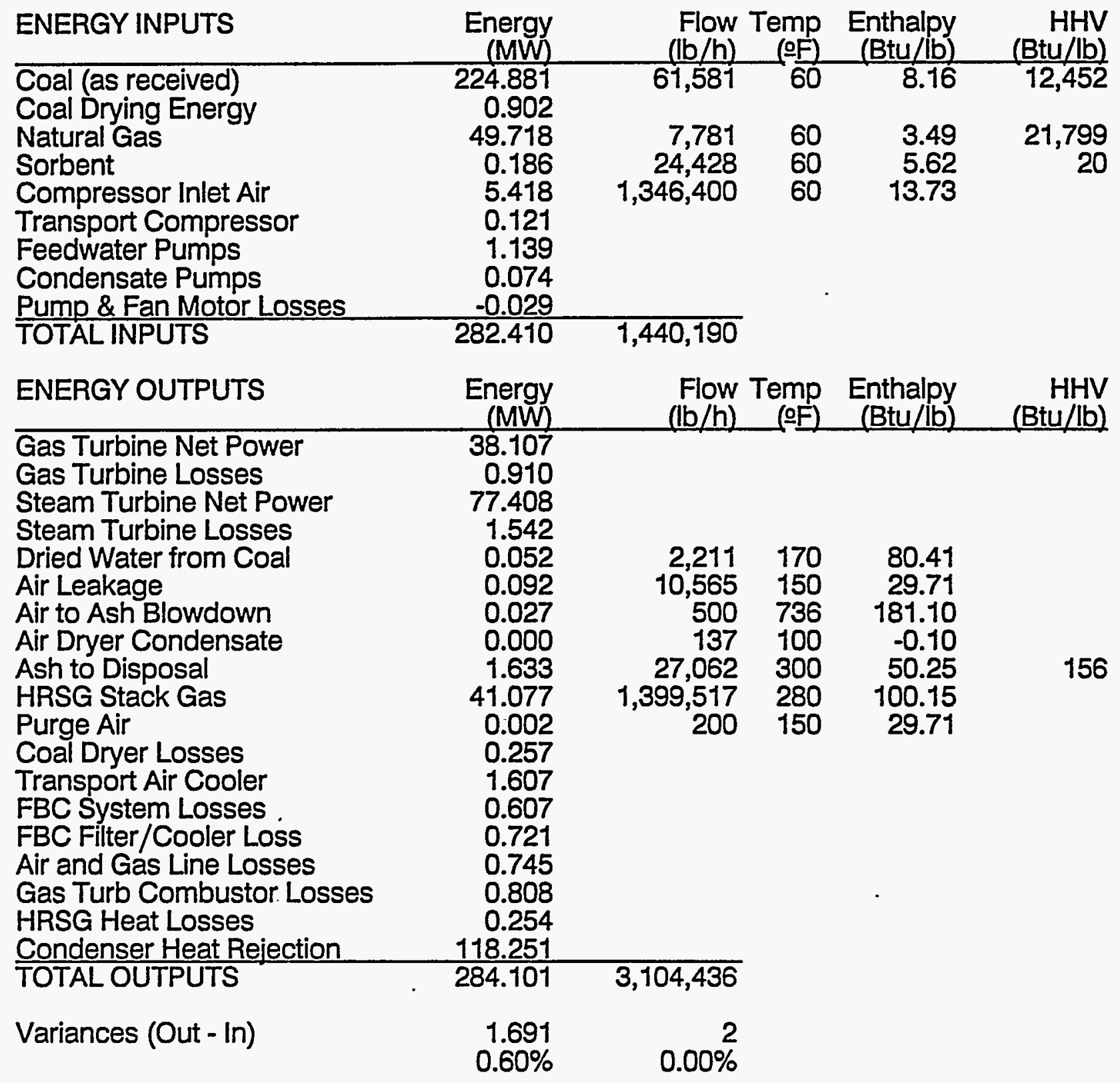




\subsection{SMALL 1.5-GENERATION PLANT}

The small ( $\sim 4 \mathrm{MW})$ 1.5-Generation PFBC system uses a Nuovo Pignone PGT-2 gas turbine and a 600/750 non-reheat steam turbine bottoming cycle. The 27.8-percent efficiency is low compared to the 40-and 41-percent efficiencies of the larger plants due to the reduced efficiency of its smaller gas turbine and non-reheat steam cycle (see Table 4-2).

The fuel flexibility and load-following capability of the small plant show promise for remote locations, but its design should be reviewed to include consideration of less complex configurations, such as the steam-injected Cheng cycle.

The plant flowsheet is shown in Figure 4.4-1, and the major systems of the plant are described in more detail in Section 3. Plant performance is summarized in Table 4.4-1.

Table 4.4-1

Small PFBC Plant Performance Summary

\begin{tabular}{|c|c|c|c|}
\hline $\begin{array}{l}\text { Gas Turbine Power } \\
\text { Steam Turbine Power } \\
\text { Plant Gross Power } \\
\text { Plant Auxiliary Power } \\
\text { Plant Net Power }\end{array}$ & $\begin{array}{l}1.512 \\
2.648 \\
4.161 \\
0.201 \\
3.960\end{array}$ & $\begin{array}{l}\text { MW } \\
\text { MW }\end{array}$ & $\begin{array}{l}\text { Nuovo Pignone PGT-2 } \\
600 / 750 / 2.5^{\prime \prime} \mathrm{Hg}\end{array}$ \\
\hline $\begin{array}{l}\text { Coal HHV } \\
\text { Coal Drying Energy } \\
\text { Natural Gas HHV } \\
\text { Plant Thermal Input }\end{array}$ & $\begin{array}{r}11.061 \\
0.044 \\
3.142 \\
14.247\end{array}$ & $\begin{array}{l}\text { MW } \\
\text { MW }\end{array}$ & $\begin{array}{l}3,031 \text { lb/h @ 12,452 Btu/lb } \\
492 \text { lb/h @21,799 Btu/lb }\end{array}$ \\
\hline $\begin{array}{l}\text { Net Electric Efficiency } \\
\text { Net Heat Rate (HHV) }\end{array}$ & $\begin{array}{l}27.79 \% \\
12,277\end{array}$ & 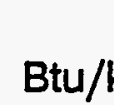 & \\
\hline
\end{tabular}

The auxiliary power requirements are listed in Table 4.4-2, and the plant heat and material balance is shown in Table 4.4-3.

Table 4.4-2

\section{Small PFBC Plant Auxiliary Power Requirements}

\begin{tabular}{lll} 
Transport Compressor & 0.007 & MW \\
Feedwater Pumps & 0.030 & \\
Condensate Pumps & 0.004 \\
Cooling Tower Fans & 0.017 \\
Circ Water Pumps & 0.045 \\
Ash Cooling \& Handling & 0.008 \\
Coal Feeding & 0.006 \\
Coal Handling & 0.001 \\
Sorbent Handling & 0.010 \\
Rail Unloading, etc. & 0.001 \\
Service Water System & 0.001 \\
Sorbent Feeding & 0.002 \\
Transformer Losses & 0.062 \\
Miscellaneous & 0.007 \\
\hline Total Auxiliaries & 0.201 & MW
\end{tabular}




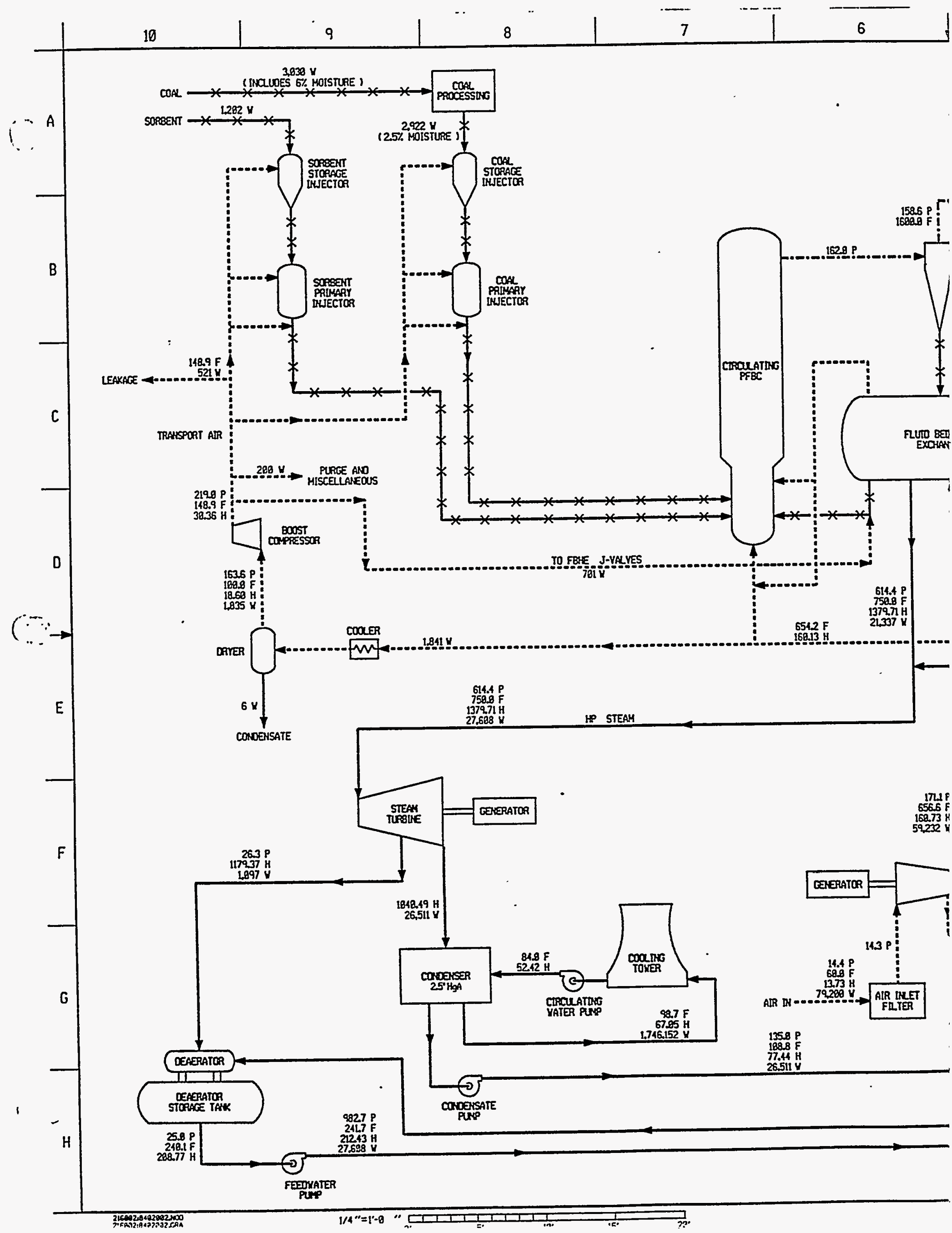


CAS TRRBDE POXER: STEAH TURBDE PONER : GROSS POUER: AXXLIARIES: FET POWER :

VET ERTCIECY: HET HEAT RATE :

\begin{tabular}{|c|}
\hline $\begin{array}{r}1512 \mathrm{MM} \\
25518 \mathrm{KN} \\
\end{array}$ \\
\hline $\begin{array}{l}416 \mathrm{MV} \\
0201 \mathrm{HY} \\
3968 \mathrm{MV}\end{array}$ \\
\hline $\begin{array}{l}27.79 \mathrm{~K} \\
12277 \mathrm{Btu} / \mathrm{k}\end{array}$ \\
\hline
\end{tabular}

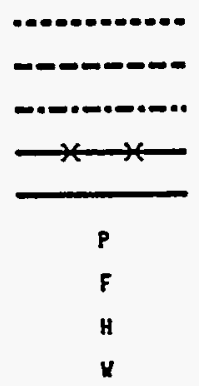

ALR

flet cas

coneustion ppococts

souss

VATER / STEAY

HESOUTE PRESSURE,PSLA

TEPERATRE, $F$

ENTHCPY, Btu/b

TOTH PLATT ROY,ILAT

2. STEAM TURBDE leakaGes hot hoOeled.

2. ENTHALPY REFERENCE POINT IS MATURAL STATE AT 32.018 F AND 8.98855 PSIA

craat 
Table 4.4-3

Small PFBC Plant Heat and Material Balance

\begin{tabular}{|c|c|c|c|c|c|}
\hline ENERGY INPUTS & $\begin{array}{l}\text { Energy } \\
(\mathrm{MW})\end{array}$ & $\begin{array}{r}\text { Flow } \\
(\mathrm{lb} / \mathrm{h})\end{array}$ & $\begin{array}{l}\text { remp } \\
(O F)\end{array}$ & $\begin{array}{r}\text { Enthalpy } \\
\text { (Btu/lb) }\end{array}$ & $\begin{array}{r}\text { HHV } \\
\text { (Btu/lb) }\end{array}$ \\
\hline $\begin{array}{l}\text { Coal (as received) } \\
\text { Coal Drving Eneray }\end{array}$ & $\begin{array}{r}11.068 \\
0.044\end{array}$ & 3,031 & 60 & 8.16 & $\frac{12,452}{12,42}$ \\
\hline $\begin{array}{l}\text { Natural Gas } \\
\text { Sorbent } \\
\text { Compressor Inlet Air } \\
\text { Transport Compressor } \\
\text { Feedwater Pumps } \\
\text { Condensate Pumps } \\
\text { Pump \& Fan Motor Losses } \\
\end{array}$ & $\begin{array}{r}0.143 \\
0.009 \\
0.319 \\
0.007 \\
0.030 \\
0.004 \\
-0.001 \\
\end{array}$ & $\begin{array}{r}492 \\
1,202 \\
79,200\end{array}$ & $\begin{array}{l}60 \\
60 \\
60\end{array}$ & $\begin{array}{r}3.49 \\
5.62 \\
13.73\end{array}$ & $\begin{array}{r}21,799 \\
20\end{array}$ \\
\hline TOTAL INPUTS & 14.622 & 83,925 & & & \\
\hline ENERGY OUTPUTS & $\begin{array}{r}\text { Energy } \\
\text { (MW) }\end{array}$ & $\begin{array}{l}\text { Flow } \\
(\mathrm{lb} / \mathrm{h})\end{array}$ & $\begin{array}{l}\text { remp } \\
\text { (OF) }\end{array}$ & $\begin{array}{l}\text { Enthalpy } \\
\text { (Btu/lb) }\end{array}$ & $\begin{array}{r}\mathrm{HHV} \\
(\mathrm{Btu} / \mathrm{lb})\end{array}$ \\
\hline $\begin{array}{l}\text { Gas Turbine Net Power } \\
\text { Gas Turbine Losses } \\
\text { Steam Turbine Net Power } \\
\text { Steam Turbine Losses }\end{array}$ & $\begin{array}{l}1.512 \\
0.057 \\
2.648 \\
0.052\end{array}$ & & & & \\
\hline $\begin{array}{l}\text { Dried Water from Coal } \\
\text { Air Leakage } \\
\text { Air to Ash Blowdown } \\
\text { Air Dryer Condensate } \\
\text { Ash to Disposal }\end{array}$ & $\begin{array}{l}0.003 \\
0.005 \\
0.023 \\
0.000 \\
0.080\end{array}$ & $\begin{array}{r}109 \\
521 \\
500 \\
6 \\
1,332\end{array}$ & $\begin{array}{l}170 \\
149 \\
654 \\
100 \\
300\end{array}$ & $\begin{array}{r}80.41 \\
30.36 \\
160.13 \\
-0.24 \\
49.11\end{array}$ & 156 \\
\hline $\begin{array}{l}\text { HRSG Stack Gas } \\
\text { Purge Air } \\
\text { Coal Dryer Losses }\end{array}$ & $\begin{array}{l}2.338 \\
0.002 \\
0.013\end{array}$ & $\begin{array}{r}81,256 \\
200\end{array}$ & $\begin{array}{l}280 \\
149\end{array}$ & $\begin{array}{l}98.17 \\
30.36\end{array}$ & \\
\hline $\begin{array}{l}\text { Transport Air Cooler } \\
\text { FBC System Losses }\end{array}$ & $\begin{array}{l}0.076 \\
0.152\end{array}$ & & & & \\
\hline $\begin{array}{l}\text { FBC Filter/Cooler Loss } \\
\text { Air and Gas Line Losses }\end{array}$ & $\begin{array}{l}0.114 \\
0.074\end{array}$ & & & & \\
\hline Gas Turb Combustor. Losses & 0.014 & & & & \\
\hline $\begin{array}{l}\text { HRSG Heat Losses } \\
\text { Condenser Heat Rejection }\end{array}$ & $\begin{array}{l}0.057 \\
7.487\end{array}$ & & & & \\
\hline TOTAL OUTPUTS & 14.705 & 83,924 & & & \\
\hline Variances (Out - In) & $\begin{array}{l}0.083 \\
0.57 \%\end{array}$ & $0.00 \%$ & & & \\
\hline
\end{tabular}




\subsection{DESIGN SENSITIVITY TO EXCESS AIR}

A design sensitivity study was performed to determine the effects of PFBC excess air on the design, capital cost, and COE of the 1.5-Generation PFBC plant. This sensitivity study considered three cases, based arbitrarily on the intermediate, 111-MW plant:

Low Excess Air

Base Excess Air

High Excess Air
The intermediate plant previously calculated, except that the coal flow is increased to reduce the PFBC excess air to about half its design value.

An intermediate plant with a nominal excess air value of 100 percent in the PFBC.

An intermediate plant in which the coal flow is reduced until the PFBC becomes adiabatic. No steam is generated or heated in the FBHE, so heat for the steam cycle is provided by the HRSG and the ash cooler.

Reducing the excess air increases the power output while slightly decreasing efficiency. Plant flowsheets for the low-excess-air case and the high-excess-air case are shown in Figures $4.5-1$ and $4.5-2$, respectively. Key performance results for all three cases are compared in Table 4.5-1.

Table 4.5-1

Sensitivity to PFBC Excess Air

\begin{tabular}{lrrr} 
Case & $\begin{array}{r}\text { Low } \\
\text { Excess Air }\end{array}$ & $\begin{array}{r}\text { Base } \\
\text { Excess Air }\end{array}$ & $\begin{array}{r}\text { High } \\
\text { Excess Air }\end{array}$ \\
\hline PFBC Excess Air & $63 \%$ & $107 \%$ & $414 \%$ \\
Plant Excess Air & $57 \%$ & $90 \%$ & $268 \%$ \\
Topping Combustor Temp & 1949 of & $1965 \circ$ & 2005 oF \\
Natural Gas Flow & $7,576 \mathrm{lb} / \mathrm{h}$ & $7,781 \mathrm{lb} / \mathrm{h}$ & $8,272 \mathrm{lb} / \mathrm{h}$ \\
Coal Feed & $77,060 \mathrm{lb} / \mathrm{h}$ & $61,581 \mathrm{lb} / \mathrm{h}$ & $24,725 \mathrm{lb} / \mathrm{h}$ \\
Gas Turbine Power & $38,144 \mathrm{~kW}$ & $38,107 \mathrm{~kW}$ & $38,110 \mathrm{~kW}$ \\
Stm Turbine Power & $97,990 \mathrm{~kW}$ & $77,408 \mathrm{~kW}$ & $18,832 \mathrm{~kW}$ \\
Plant Auxil Power & $5,847 \mathrm{~kW}$ & $4,774 \mathrm{~kW}$ & $1,760 \mathrm{~kW}$ \\
Plant Net Power & $130,287 \mathrm{~kW}$ & $110,741 \mathrm{~kW}$ & $55,182 \mathrm{~kW}$ \\
Plant HHV Efficiency & $39.39 \%$ & $40.22 \%$ & $38.47 \%$
\end{tabular}




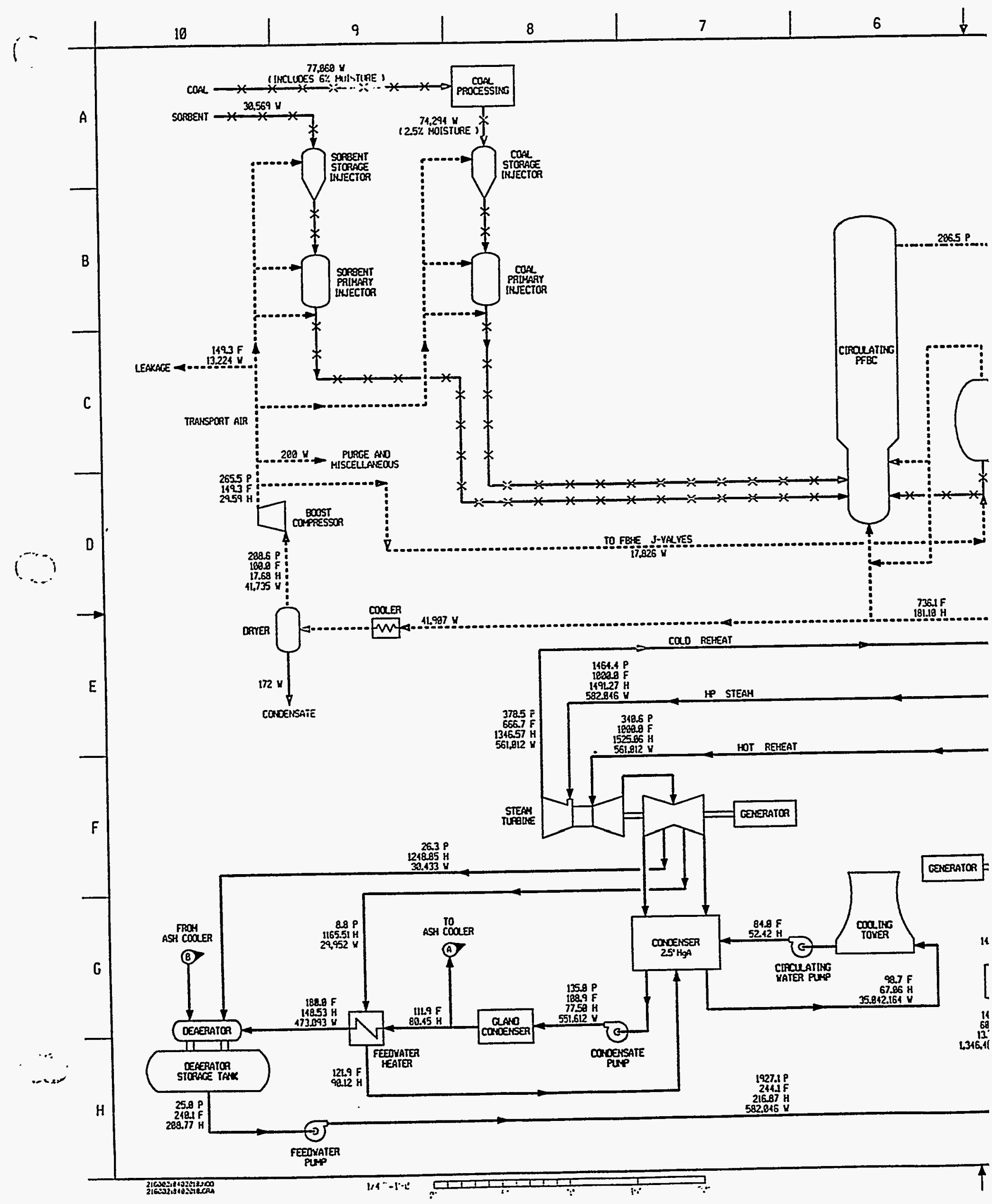




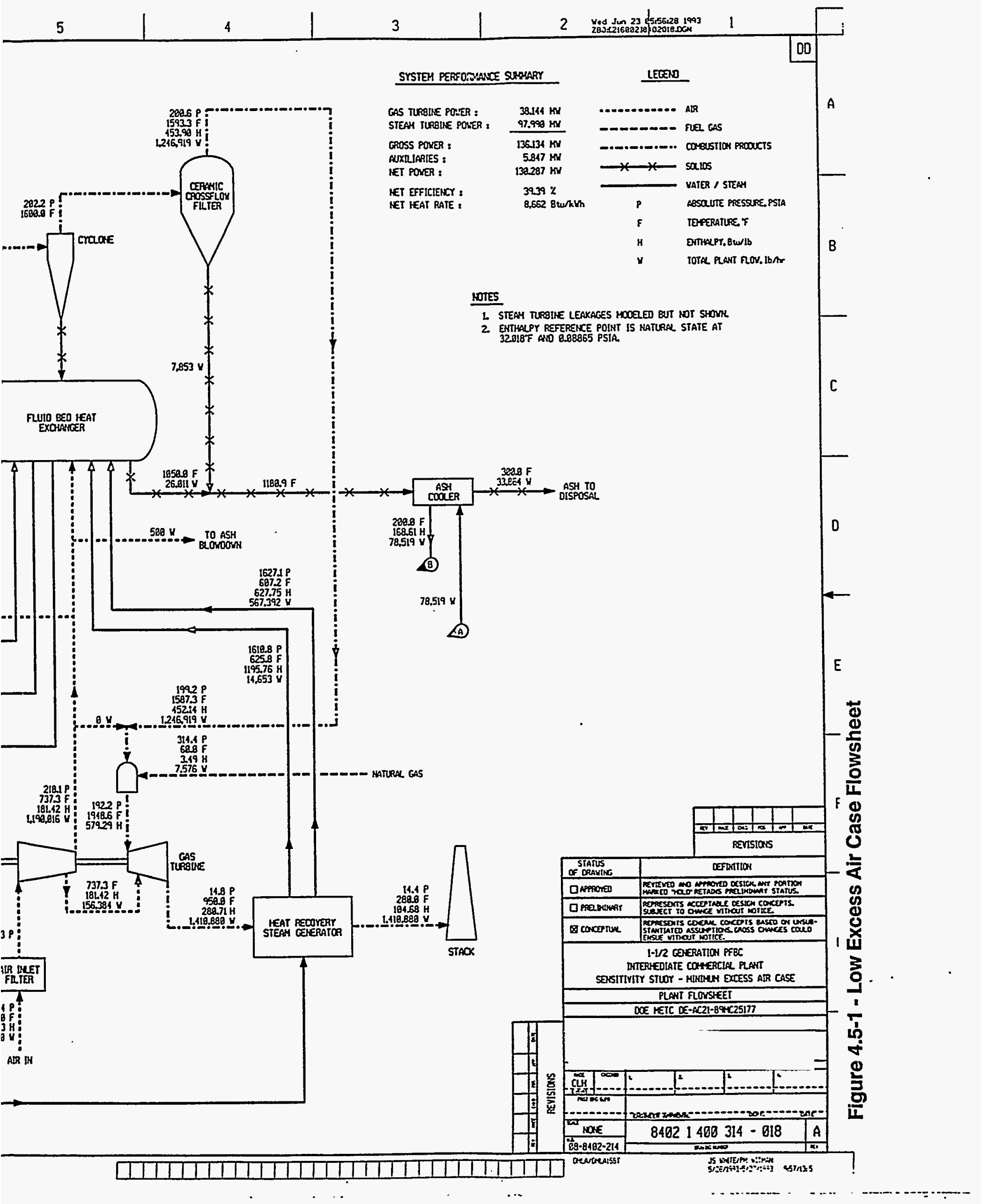




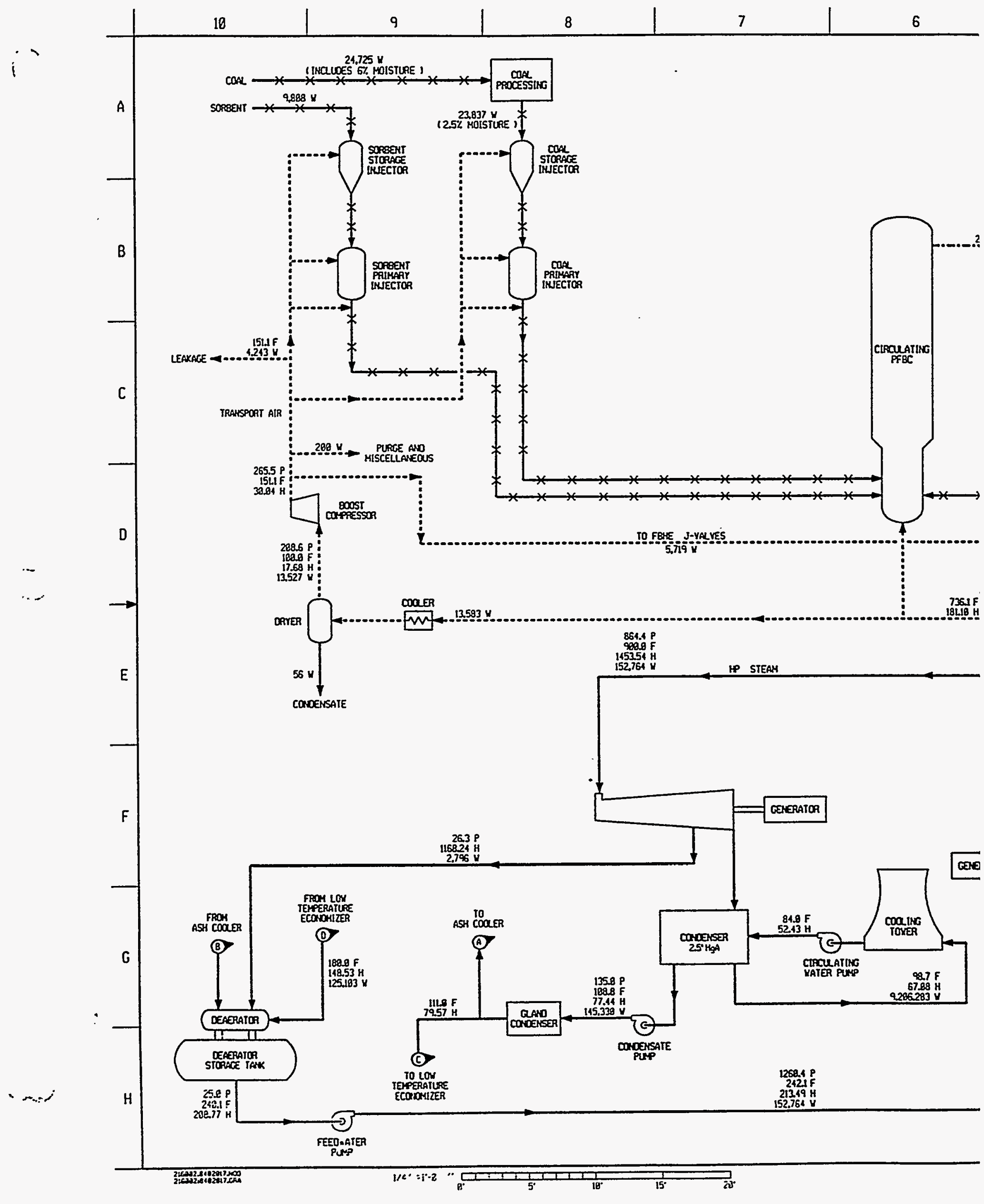




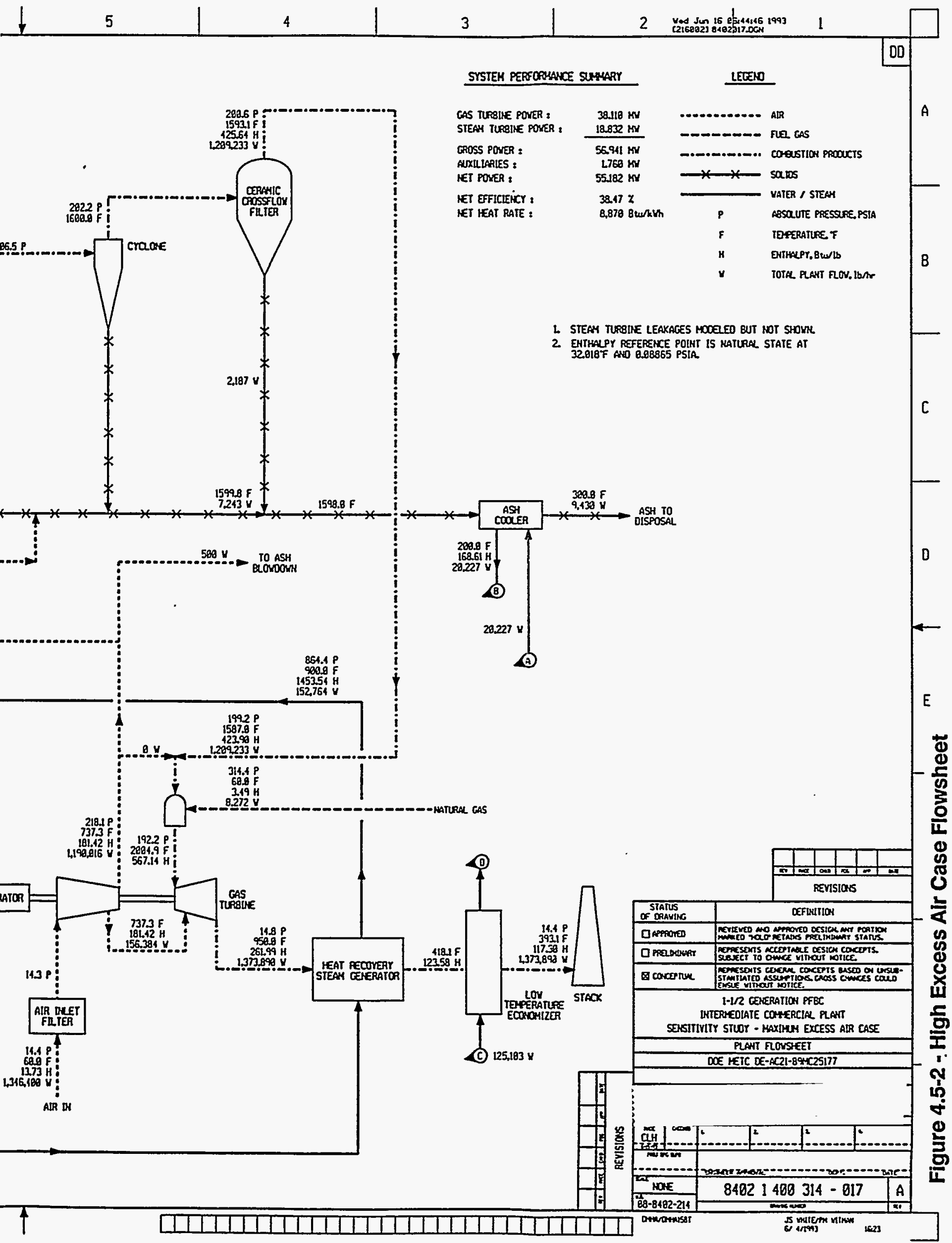


The effect of PFBC excess air on plant net power is shown in Figure 4.5-3. PFBC excess air has only a minor effect on overall efficiency, but a profound effect on plant generating capacity. Plants with lower PFBC excess air use smaller vessels to generate more power, and are therefore more cost-efficient. The economic effects of PFBC excess air on capital cost and COE are discussed in Section 6.4.2.

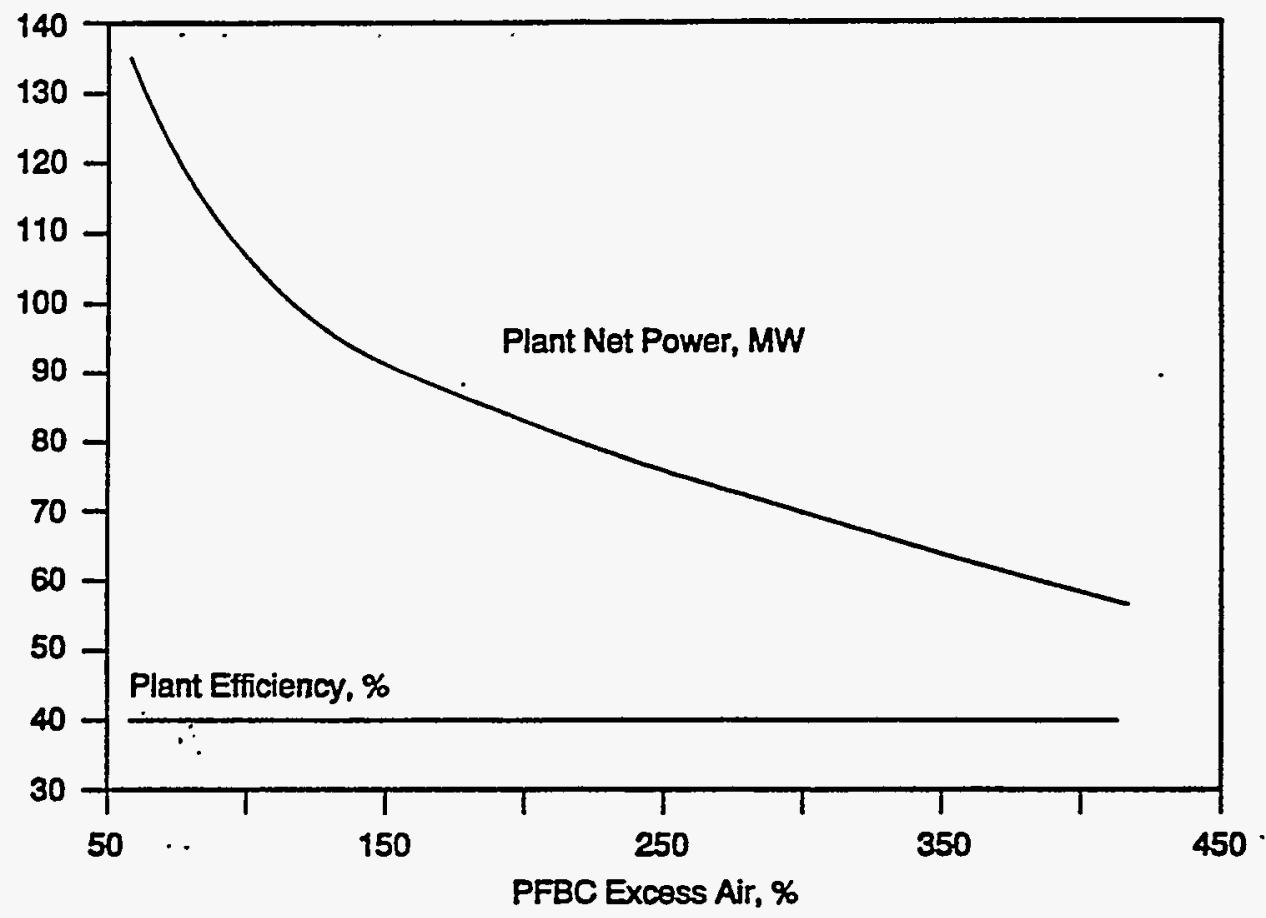

Figure 4.5-3 - Effect of Excess Air on Performance 


\subsection{PLANT OPERATION}

The operational concept for the 1.5-Generation PFBC plant is a base-loaded plant with the capability for significant turndown. The actual duty cycle of the plant will vary according to the installation. For the purposes of this conceptual design, plant capacity was assumed to range from full-load (design flows of natural gas and coal) down to 38-percent load (zero natural gas and 50-percent coal flow).

The purpose of this analysis was to explore the operational aspects of the 1.5Generation PFBC plant in a general way. Because the power from this plant can be controlled by adjusting either natural gas flow or coal feed rate, it is logical to assume that the 1.5-Generation PFBC plant should be more responsive to load changes than the 2nd-Generation PFBC plant.

The 1.5-Generation PFBC plant has excellent load-following potential. About 24 percent of the generated power is fueled by natural gas, to which the plant responds quickly, and the other 76 percent fueled by coal, to which the plant responds more slowly. This combination of fuels allows rapid adjustments between 76 and 100 percent of load by adjusting the natural gas flow to the gas turbine. The PFBC/FBHE system is expected to be capable of a 50-percent turndown, so plant load levels between 38 and 76 percent can be attained by adjusting the coal feed rate. As a result, the effective turndown ratio of a single-train 1.5-Generation PFBC plant is almost 3:1, compared with the 2:1 turndown of a first- or 2nd-Generation PFBC plant.

A complete analysis involving plant/component dynamic analysis and a rigorous controls design were not the intent of this study. However, sufficient information is available to conclude that operation of a 1.5-Generation PFBC plant is feasible, probably more responsive than a 2nd-Generation PFBC plant, and well within commercial equipment and controls design capability.

This section describes the general characteristics of four areas of plant operation:
5.1 Steady-State Control
5.2 Plant Start-up
5.3 Emergencies and Upsets
5.4 Sensitivity to Topping Combustor Temperature

\subsection{STEADY-STATE CONTROL}

Plant power generation is delivered by one combustion turbine-generator and one steam turbine-generator. Each generator supplies power through an isolated-phase bus duct and dedicated step-up transformer to an overhead connection to a high-voltage transmission line. From a control standpoint, the 1.5-Generation PFB combustion plant can be designed to operate in any of the following modes:

- Gas turbine leading--steam turbine following 
- Steam turbine leading--gas turbine following

- Coordinated/integrated gas turbine/steam turbine control.

To determine which of these control modes is optimum for a 1.5-Generation plant would require detailed transient and steady-state analyses and synchronizing strategies, all of which are beyond the scope of this study. Since the coordinated approach has proved the best means for controlling the Cool Water Integrated Coal Gasification Combined Cycle Plant, the 1.5-Generation plant is expected to use coordinated/integrated gas turbine/steam turbine control.

Control approaches for the turbines, PFB combustor, and HRSG/FBHE units are discussed in the following subsections.

Turbine Control Signals. The plant control system responds to a either an external megawatt demand signal from dispatch or an internal, manually entered load signal. Both the steam turbine and gas turbine megawatts develop the necessary steam turbine and steam generation system demand signals. These signals are modified by any steam turbine megawatt and steam pressure errors, and are then used to develop demand signals that are applied to the CPFBC module (a PFB combustor section and a steam generator section).

PFB Combustor Control. The plant master controller is networked with the CPFBC module and the steam turbine and gas turbine control subsystems, directing them to either increase or decrease load.

Assuming normal module operation near full load, three actions should apparently be taken simultaneously:

- Modulate the J-valve settings as a function of load (subject to appropriate rate of change limits)

- Modulate the coal flow rate as a function of load (subject to appropriate limits).

- Modulate the gas turbine fuel flow (subject to appropriate limits)..

Modulating the coal flow causes a corresponding change in the dolomite flow; at the same time, a change should be made in the gas turbine inlet guide vane setting to provide a predetermined overall plant air/coal ratio (which will vary somewhat with load). As a result of these two actions, the air flow to the CPFBC should settle down to a new value, with the load change absorbed by the combustor subsystem. If necessary, the controller can bias the air/coal ratio to improve the overall performance of the system.

HRSG/FBHE Control. The steam generator consists of the HRSG, which recovers heat from the gas turbine exhaust stream, and the FBHE, which recovers heat from solids circulated through the CPFBC. The steam generator requires a feedwater control system and a steam-temperature control.system.

In the feedwater control system, feedwater pump maintains the correct pressure in the feedwater supply header, and the feedwater control valves are controlled using a standard feedwater control scheme based on measurements of drum pressure, drum level, feedwater flow, and steam flow. 
Steam temperature from the superheater and reheater are controlled by a combination of $\mathrm{J}$ valves (which control solids residence time), spray attemperators, and a finishing superheater bypass. The bypass raises the final steam temperature to the required setpoint during start-up. The steam bypass contains a control valve, an isolation valve, and a desuperheating system for bypassing steam around the HP and IP/LP turbines. The bypass system provides a means to start up the CPFBC and raise the pressure and temperature of the steam it generates.

Steam temperature from the superheater and reheater is controlled by a combination of $J$ valves (which control solids flow rates) and spray attemperators. During start-up and shutdown, they are assisted by a finishing superheater bypass. The spray attemperators control short-term steam temperature variations, while the $\mathrm{J}$ valves provide long-term steam temperature control. The bypass is used to raise the final steam temperature to the required setpoint during start-up. The bypass contains a control valve, an isolation valve, and a desuperheating system for bypassing steam around the HP and IP/LP turbines. The bypass system provides a means to start the CPFBC, and raise the pressure of the steam generated by the CPFBC.

A variety of control schemes is possible, and final decisions can be made during subsequent design phases. For the purpose of this preliminary description, we have assumed that the HP steam valve remains closed until the steam temperatures and pressure are properly matched. Therefore, the system should be designed so that the LP bypass steam flow is equal to the HP bypass flow. The control valve in the cold reheat line should be modulated to match the HP steam flow.

The design requirements for the CPFBC, FBHE, and HRSG will dictate the time required for cold start-up to full load. In addition, the general requirements of refractory heat-up limits, condensation in hot filter elements, and plant safety dictate additional limitations in the start-up procedures. 


\subsection{PLANT START-UP}

This section describes three types of plant start-up:
5.2.1 Cold Start-up
5.2.2 Warm Start-up
5.2.3 Hot Start-up

\subsubsection{Cold Start-Up}

For a cold start-up, the CPFBC and steam turbine start-up are closely coordinated. The heating of large refractory-lined components is most likely the limiting factor in the initial portion of the start-up sequence.

The planned sequence is summarized in Table 5.2-1 and described following the table. The projected 12-hour cold start time is longer than the estimated 8-hours cold start time for a pulverized-coal-fired steam plant with FGD [EPRI, 1989, pages 2-13], but shorter than the 16 hours expected to be needed to start a 2nd-Generation PFBC plant [FWDC, 1989]

Table 5.2-1

\section{Plant Start-Up Sequence}

\begin{tabular}{llr} 
Step & Description & Hours \\
\hline 1 & Start gas turbine on natural gas or fuel oil & 0.2 \\
2 & Heat up CPFBC unit & 3.0 \\
3 & Establish Shallow bed in CPFBC & 2.0 \\
4 & Start up HRSG & \\
& Fire coal in CPFBC bed & 1.5 \\
& Synchronize gas turbine & 4.0 \\
5 & Start up and load steam turbine to 6 percent & 1.0 \\
6 & Bring CPFBC/FBHE module to full load & 11.7 \\
\hline & TOTAL &
\end{tabular}

1. In the first step, the gas turbine unit, driven by an electric motor, is started on liquid fuel fired directly into the dual-fuel topping combustor. Variable inlet guide vanes in the compressor are adjusted during the start-up sequence to provide efficient operation and control airflow. The exhaust gas from the gas turbine is vented to the stack until Step 4.

2. With airflow established to the CPFBC unit, auxiliary burners begin to heat the vessels and the interconnecting hot-gas ducting and hot-gas cleanup units. The rate of heating is limited by the refractory in the hot-gas path, probably on the order of 200 to $300^{\circ} \mathrm{F} / \mathrm{h}$.

3. In the third step, dolomite beds are established in the CPFBC unit. 
4. In the fourth step, warm-up of the HRSG begins. The isolation damper is modulated to heat the HRSG and to initiate steaming at a controlled rate. Steam pressure increases, and the drain valves are closed. A steam bypass valve opens when the specified pressure setpoint is reached, and the HRSG start-up is complete when the bypass damper is fully closed. At this point the HRSG is used in place of the auxiliary boiler.

When the CPFBC dolomite bed reaches 1100 to $1200^{\circ} \mathrm{F}$, coal is fed to each bed and combustion is begun; the CPFBC bed temperature increases to $1600^{\circ} \mathrm{F}$. The bed is built up to operating levels, and the CPFBC operates as a "bubbling bed," with recirculating solids flow held to a minimum. The CPFBC and FBHE beds operate in an oxidizing mode and at high excess air to control temperature. This condition is considered "idle."

CPFBC heat input is increased until a synchronous idle point is reached for the gas-turbine unit, and the plant begins to produce power.

5. Rolling, synchronizing, and initial loading of the steam turbine is initiated in the fifth step, when the main steam reaches approximately $1000 \mathrm{psia} / 700^{\circ} \mathrm{F}$. The steam turbine control system automatically brings the turbine up to speed by slowly opening the high-pressure steam valve and partially closing the bypass valves. The steam turbine load is then gradually increased to 50-percent plant load and the bypass valves are closed.

6. The unit is brought to full load while controlling steam turbine temperature differentials and gradually adjusting fuel feed and air flow split to the CPFBC.

\subsubsection{Warm Start-Up}

Start-up from a warm condition is generally required after a weekend or overnight shutdown. Heat is stored in refractory-lined components and in the bed inventory within the CPFBC subsystem, as well as in the metal parts of the plant. Warm start-up times depend on the temperature change limits imposed by each system. The CPFBC can probably be maintained above $1000^{\circ} \mathrm{F}$ for several days while the FBHE is cooled to avoid tube material problems. The warm start-up sequence is the same as the cold start-up sequence, except that the duration is correspondingly shorter.

\subsubsection{Hot Start-Up}

Start-up from a hot condition occurs following a generator trip or plant component failure that only causes momentary shutdown. Because all components are hot, the plant can be brought on line within 1 or 2 hours. 


\subsection{EMERGENCIES AND UPSETS}

For this conceptual study, three types of emergencies and upsets were considered:

- Steam Turbine Loss of Load

- Gas Turbine Loss of Load, and

- Other Contingencies

The general discussion of each of these conditions describes the feasibility of responding to each type of condition. However, more detailed analyses would be required at preliminary or later design stages.

\subsubsection{Steam Turbine Loss of Load}

The contingency action that follows a steam turbine loss of load depends, to a large extent, on the start-up philosophy adopted. The same steam bypass system used for start-up will be available for both controlled and emergency shutdown.

In an emergency situation, the steam bypass is open and the superheater and reheater safety valves lift. In a short time - the length of which depends on the response time of the steam generator - the superheater safety valves reseat, and the HP steam flow is reduced to match the capacity of the LP bypass. At this time the reheater safety valves close. Since a great deal of heat remains in the FBHE bed, feedwater flow is maintained, and steam continues to be generated to prevent the steam generator tubs from overheating.

\subsubsection{Gas Turbine Loss of Load}

In the event of a plant upset or sudden loss of load, the fuel gas valve system must quickly interrupt gas flow to the turbine. Because of the large inventory of hot, pressurized air in the CPFBC subsystem and piping, merely shutting off the fuel is not sufficient for overspeed protection. The considerable amount of pressurized air and thermal energy that exists in the CPFBC subsystem from the compressor discharge to the topping combustor inlet must be controlled to prevent excessive overspeed of the gas turbine-generator unit and subsequent catastrophic failure. An additional system of valves is required to ensure overspeed protection for the gas turbine.

Two scenarios relate to the use of the CPFBC bypass system for overspeed protection. The first relates to an externally caused event (e.g., the loss of load when a breaker opens because of some occurrence outside the plant), and the second relates to an internally caused event such as loss of lube oil to the turbine/generator bearings.

\section{Loss of Load - External Event}

The sudden loss of gas turbine load causes the rapid acceleration of the unit, and the topping combustor fuel system reacts quickly to halt the flow 
of fuel to the topping combustor. Another system of valves comes into play simultaneously. This system is shown schematically in Figure 5.3-1.

The proposed concept should protect the gas turbine from overspeed. Later design stages should include a full analysis and investigation of the design, configuration, operation, and dynamics of this valve system.

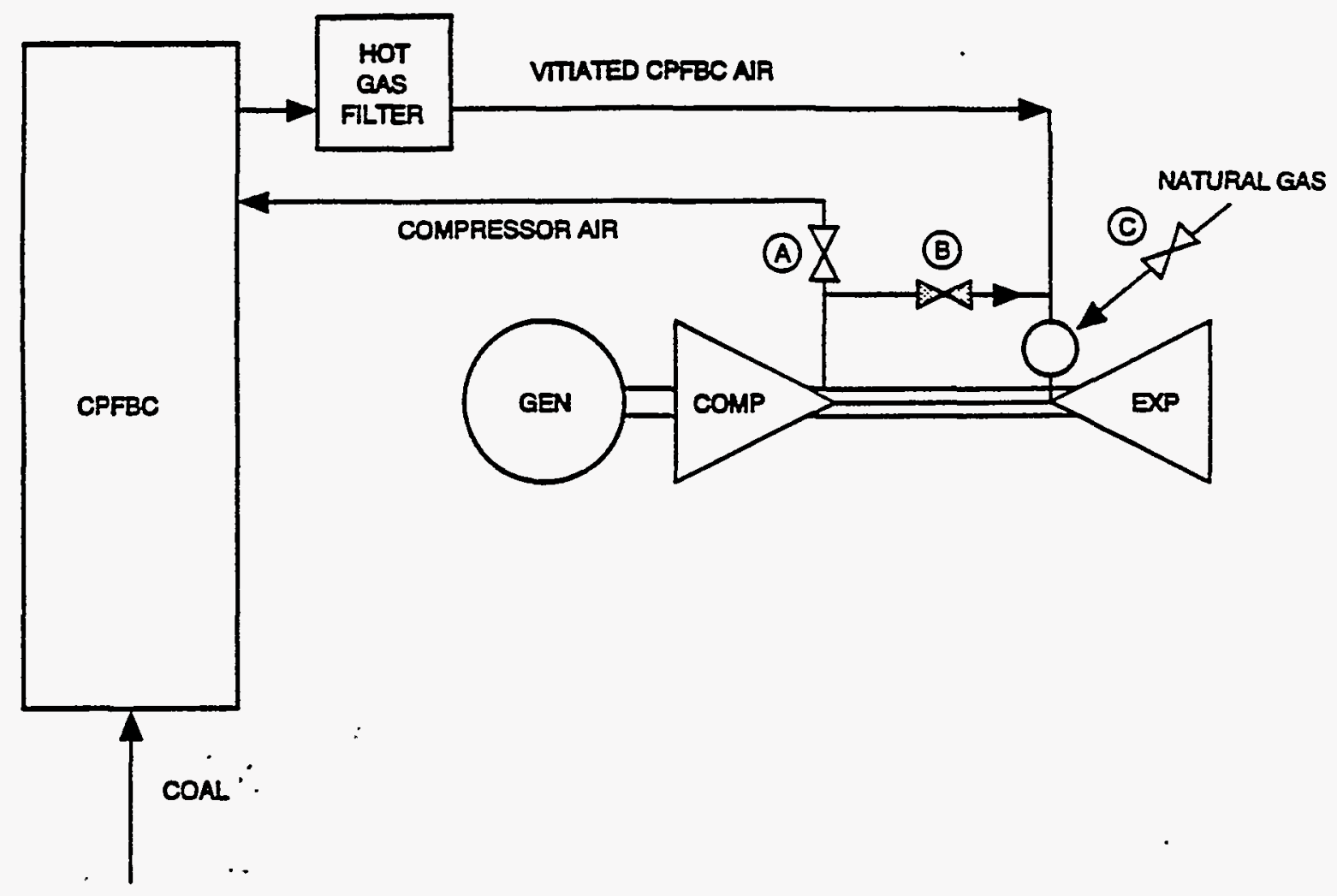

Figure 5.3-1 - Schematic Arrangement of CPFBC Bypass System

Compressed air is extracted and vitiated air is introduced to the hot section of the turbine during normal operation. At first indication of a loss of load and the resultant acceleration of the gas turbine unit, Valves $A, B$, and $C$ are actuated. Valve A (normally open, PFBC outlet valve) closes while Valve $B$ (normally closed, PFBC bypass valve) opens. With this new valve arrangement, the compressor air bypasses the CPFBC subsystem and is routed directly to the topping combustors. The fuel valve (Valve $\mathrm{C}$ ) also closes to stop the flow of natural gas to the gas turbine. Preliminary calculations indicate that the CPFBC bypass system, working with the fuel gas interrupt system, will protect the gas turbine from overspeed. In addition, there are a few variations of valve operation that can aid in 
handling this overspeed problem. Because the gas turbine compressor is equipped with inlet guide vanes, flow can be varied to some degree, depending on the vane position. If the inlet guide vanes are partially closed during normal operation, having them fully open during the overspeed event will increase airflow, increasing compressor work and, in turn, helping decelerate the turbine-generator. In addition, by judicious positioning of the CPFBC bypass valve (Valve B), the discharge pressure of the compressor can be kept high, increasing the compressor work and . gas turbine deceleration even further. Anything that can safely increase compressor work aids in controlling the overspeed problem.

There are several operating levels that the turbine-generator goes through during this rapid train of events. The following paragraphs present a brief look at some of these operating levels and their effects on overspeed.

At the first instant of load loss, steady-state operating parameters prevail. Immediately upon sensing overspeed, the fuel gas overspeed protection valve (Valve C) closes, stopping off the fuel flow. Thus the flow to the turbine hot section is reduced, and the turbo-expander inlet temperature approaches the vitiated air temperature.

At this same instant of load loss, the valves in the CPFBC bypass system are actuated. The CPFBC inlet valve (Valve A) closes as the CPFBC bypass valve (Valve B) opens. This set of events, in conjunction with fuel shutoff, rapidly rectifies the situation where damage resulting from overspeed could occur. The cooler compressor air mixes with the smaller amount of vitiated air leaking through the CPFBC outlet valve. By adjusting the bypass valve (Valve B), the compressor pressure ratio is elevated, increasing compressor work, which aids the deceleration process.

The amount of air leaking around Valve $A$ is of prime importance with regard to unit coast-down time. Under the conditions set forth in this instance (loss of load from an external event), the coast-down time is of lesser importance because none of the gas turbine equipment is at fault. Therefore, normal turbine auxiliaries and components are intact, and the unit can either be re-synchronized or shut down and put on turning gear eventually. The section that follows addresses valve leakage and its importance under other load-loss conditions.

Loss of Load -- Internal Event

Many of the possible emergency shutdown situations that occur within the plant boundary require the combustion turbine to coast down as rapidly as practical. For example, if high vibration suddenly occurs at one of the turbine or generator bearings, rapid shutdown might be of prime importance to preclude major damage or, possibly, catastrophic failure. Because the large shutoff valves at the compressor discharge and combustor inlet leak to some extent in the closed position, a quantity of hot, vitiated air is mixed with the compressor air that bypasses the CPFBC during the coast-down interval. The amount of leakage is a vital factor in determining the coast-down time. If the quantity leaked is too large, the coast-down is not rapid enough, and another valve has to be put in the CPFBC bypass system to minimize the leakage. 
Specific information about the valves, a detailed analysis of the dynamics of the power train, and an analysis of the transient behavior of the pressure vessels and piping are required to quantify the gas turbine coast-down characteristics under the referenced loss-of-load conditions. Nevertheless, we believe that the proposed bypasses and operating techniques can be made to protect the gas turbine during these conditions.

\subsubsection{Other Contingencies}

Normal shutdown procedures or emergency procedures used in typical power plant operations can be used for remaining contingencies.

Loss of solids recirculation through the PFBC or a steam leak in the FBHE would cause an emergency shutdown of the CPFBC subsystem. 


\subsection{SENSITIVITY TO NATURAL GAS FLOW RATE}

Two operational sensitivity studies were performed to determine the relationship between fuel flow rate, power output, and cost of electricity. This section describes the effect of reduced natural gas flow with constant coal flow, and Section 5.5 describes the effect of reduced coal flow with constant natural gas flow.

This sensitivity study determined the relationship between natural gas flow rate and the power output and cost of electricity of the intermediate (111-MW) 1.5-Generation PFBC plant. This sensitivity study is based on three cases:

No Natural Gas

Medium Natural Gas

Base Natural Gas
The 111-MW 1.5-Generation PFBC plant, operating with natural gas flow reduced to zero.

The same plant operating with its natural gas flow is reduced to half the base value.

The 111-MW 1.5-Generation PFBC plant at design conditions, with a base consumption of $7,781 \mathrm{lb} / \mathrm{h}$ of natural gas to the topping combustor.

In this steady-state off-design study, topping combustor temperature, cycle pressure ratio, net power and fuel consumption are all functions of gas fuel flow. Key performance results are tabulated in Table 5.4-1, and the effects of topping combustor exit temperature (natural gas flow rate) on plant net power and efficiency are shown in Figure 5.4-1.

The output from the 1.5-Generation PFBC plant can be reduced by 24 percent by reducing natural gas flow without disturbing the coal feed to the rest of the plant. Plant thermal efficiency over this range decreases by about three percentage points, which is similar to the efficiency reduction caused by a similar reduction in coal flow (see Section 5.5).

The economic consequences of part-load operation between 76 and 100 percent load are discussed in Section 6. 
Table 5.4-1

Sensitivity to Topping Combustor Temperature (Constant Coal Feed Rate)

Case

Topping Combustor

Temperature

Natural Gas Flow

Coal Feed

PFBC Excess Air

Plant Excess Air

Cycle Pressure Ratio

GT Expander Power

GT Compr Power

GT Gross Power

GT Net Power

Stm Turbine Power

Plant Auxiliary Power

Plant Net Power

$\%$ of Rated Load

Plant HHV Efficiency
No Natural Gas Medium Natural Gas 1586 oF

$0 \mathrm{lb} / \mathrm{h}$

$61,581 \mathrm{lb} / \mathrm{h}$

$104 \%$

$130 \%$

13.8

$85,275 \mathrm{~kW}$

$63,048 \mathrm{~kW}$

$22,227 \mathrm{~kW}$

$21,680 \mathrm{~kW}$

$66,557 \mathrm{~kW}$

$4,079 \mathrm{~kW}$

$84,158 \mathrm{~kW}$

$76 \%$

$37.30 \%$ 1779 o F

$3,890 \mathrm{lb} / \mathrm{h}$

$61,581 \mathrm{lb} / \mathrm{h}$

$104 \%$

$108 \%$

14.5

$95,269 \mathrm{~kW}$

$64,693 \mathrm{~kW}$

$30,576 \mathrm{~kW}$

$29,848 \mathrm{~kW}$

$72,024 \mathrm{~kW}$

$4,428 \mathrm{~kW}$

$97,444 \mathrm{~kW}$

$88 \%$

$38.90 \%$
Base Natural Gas 1965 oF

$7,781 \mathrm{lb} / \mathrm{h}$

$61,581 \mathrm{lb} / \mathrm{h}$

$107 \%$

$90 \%$

.15 .1

$105,186 \mathrm{~kW}$

$66,170 \mathrm{~kW}$

$39,107 \mathrm{~kW}$

$38,107 \mathrm{~kW}$

$77,408 \mathrm{~kW}$

$4,774 \mathrm{~kW}$

$110,741 \mathrm{~kW}$

$100 \%$

$40.22 \%$ 


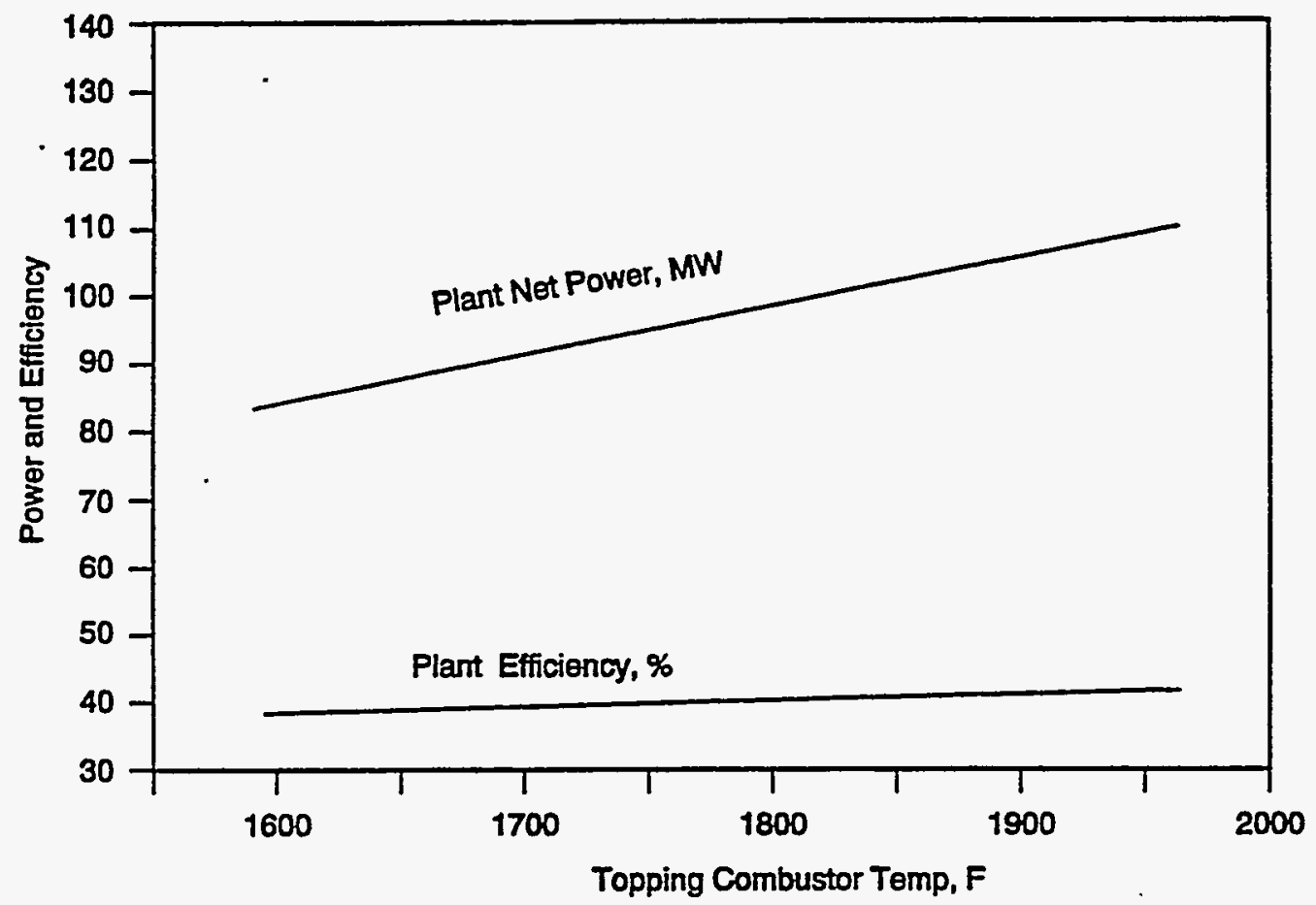

Figure 5.4-1 - Effect of Topping Combustor Temperature on Power and Efficiency 


\subsection{SENSITIVITY TO COAL FEED RATE}

An operational sensitivity study was performed to determine the effects of load change on power output for the intermediate (111-MW) 1.5-Generation PFBC plant. This sensitivity study holds natural gas flow to the gas turbine constant while varying the PFBC coal flow. The three cases investigated are summarized below.

$40 \%$ of Base Coal Feed

$70 \%$ of Base Coal Feed

- Base Coal Feed
The 111-MW 1.5 Generation PFBC plant operating with 40 percent of design coal flow to the PFBC. The FBHE operates adiabatically, providing no heat to the steam bottoming cycle.

The 111-MW 1.5 Generation PFBC plant operating with 70 percent of design coal flow to the PFBC. The FBHE supplies a reduced amount of heat to the steam bottoming cycle.

The 111-MW 1.5 Generation PFBC plant operating at 100 percent of design load. Steam turbine net power production at base load is $39,102 \mathrm{~kW}$.

This sensitivity study complements the natural gas flow sensitivity study described in Section 5.4. In the natural gas study, various natural gas flow rates were used with the coal flow held at the design value. In this study, coal flow to the PFBC is varied while the natural gas flow remains constant at its design flow. These two studies taken together define the edges of the operating envelope of the plant at various fuel flow rates. Actual plant turndown could also be accomplished by decreasing both coal and natural gas in tandem.

Key performance results are tabulated in Table 5.5-1. The effects of coal flow on plant net power and efficiency are shown in Figure 5.5-1. As can be seen in both the table and figure, decreased coal flow with constant natural gas flow results in reduced power and reduced cycle efficiency. Comparing net power values with those from Section 5.4 shows the greater turndown potential due to coal - 62 percent compared with 24 percent from natural gas.

Constant natural gas flow to the gas turbine results in almost constant gas turbine performance for all three cases. The only effect is a small decrease in outlet power due to a small decrease in the mass flow of the vitiated air stream. Since the change in gas turbine power is so small, it is assumed that the gas turbine performance remains constant over the range investigated.

Decreased coal flow to the PFBC results in significant changes to the steam bottoming cycle. Smaller coal feed flows combined with constant air flow through the gas turbine compressor result in increased excess air values. Larger excess air rates enable the vitiated air stream to carry a greater amount of heat out of the PFBC, resulting in decreased heat duty available to the steam cycle. At 40 percent of design coal flow, the FBHE operates adiabatically, providing zero heat duty to the steam cycle, so all steam must be generated in the HRSG.

The decrease in available heat for the bottoming cycle produces lower steam flow rates and decreased steam turbine efficiency. Lower steam flow rates and a fixed geometry cause the HRSG to be used less efficiently, so the flue gas temperature at the stack 
increases. The overall result is a decrease in plant efficiency, as can be seen in Table 5.5.1. The reduction in efficiency between 100 percent and 70 percent load is about four percentage points, similar to the 3-point decrease due to decreased natural gas (Section 5.4).

Table 5.5-1

Sensitivity to Reduced Coal Feed Rate (Constant Natural Gas Flow Rate)

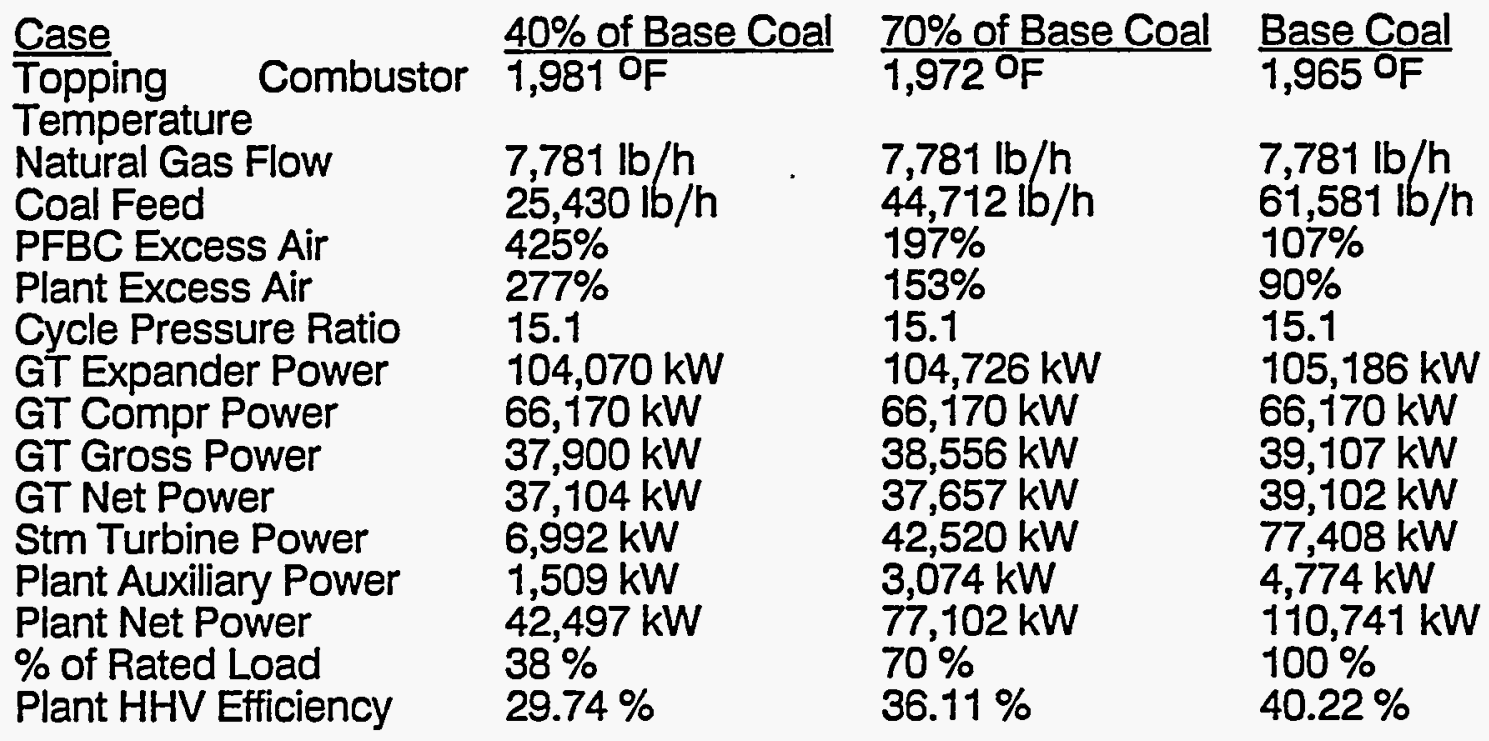

Figure 5.5-1 shows the effects of reduced coal and gas flow rate on gas turbine power and steam turbine power. The shorter, diagonal line represents reduced gas flow with design coal flow, and the longer, vertical line represents reduced coal flow with design gas flow. Since coal provides 4.5 times the thermal input of natural gas in the 1.5generation PFBC plant, each percent reduction in coal flow has 4 or 5 times the impact on plant power that a 1-percent reduction in natural gas would have.

Reducing the natural gas flow affects both gas turbine power and steam turbine power because the steam turbine generates about twice the power of the gas turbine, the HRSG provides almost half of the heat for the steam cycle, and the waste heat available to the HRSG is proportional to the power generated by the gas turbine. On the other hand, reducing the coal flow significantly affects steam turbine power while hardly affecting gas turbine power. A 40-percent reduction in coal flow virtually eliminates any heat contribution to the steam cycle from the PFBC, but continues to provide the same flow of 1600 oF vitiated air to the gas turbine.

The two lines in Figure 5.5-1 are two boundaries of the operating envelope for the 1.5generation PFBC cycle. The area between these two boundaries represents simultaneous reductions in both coal and gas feed rates.

Figure 5.5-2 shows the relationship between fuel flow rate, plant net power, and plant net efficiency. As shown in the figure, the curve is the same whether the modulated fuel is coal or natural gas.

The economic consequences of part-load operation are discussed in Section 6. 


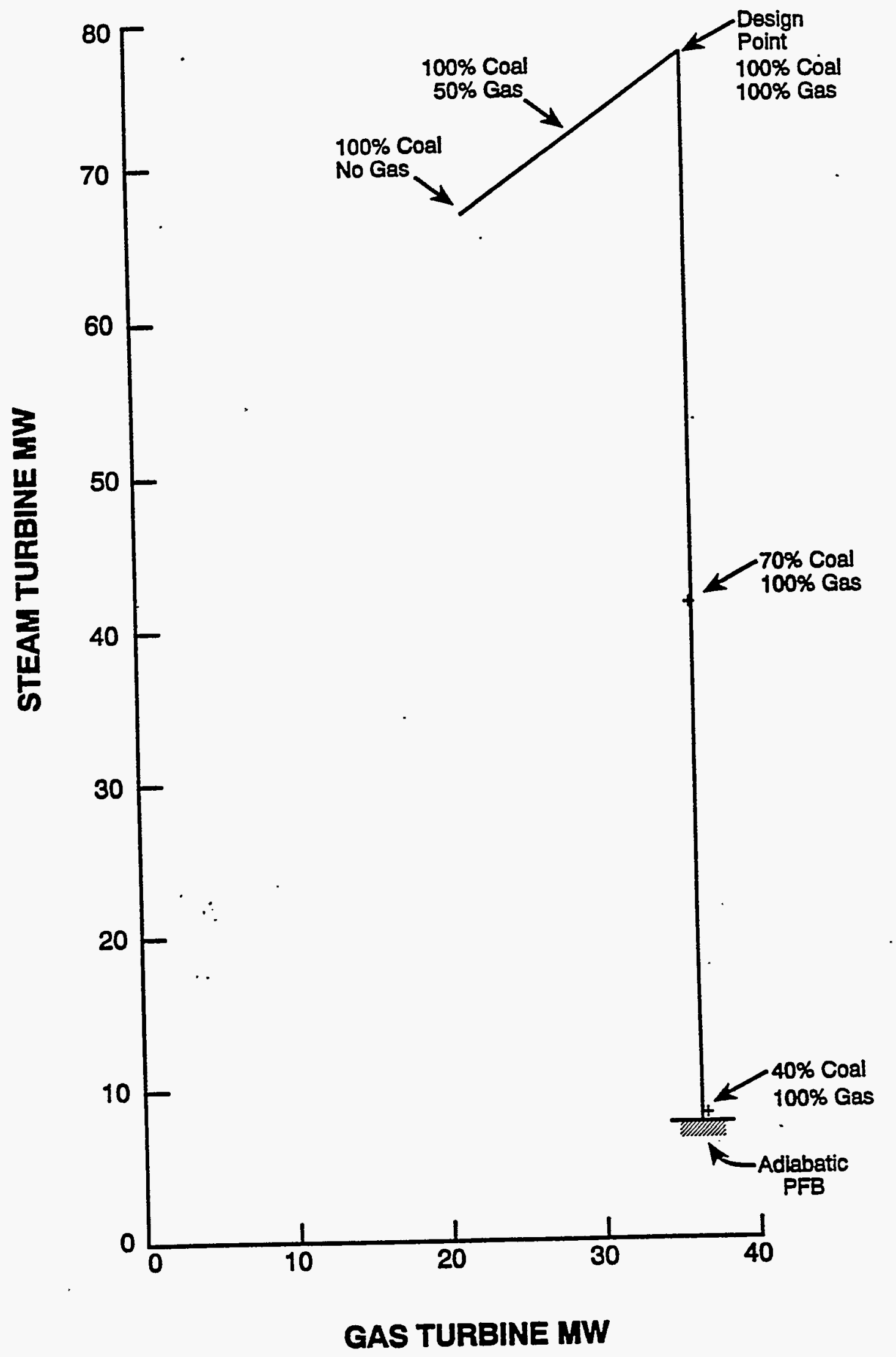

Figure 5.5-1 - Effect of Fuel Flow on Gas Turbine and Steam Turbine Power 


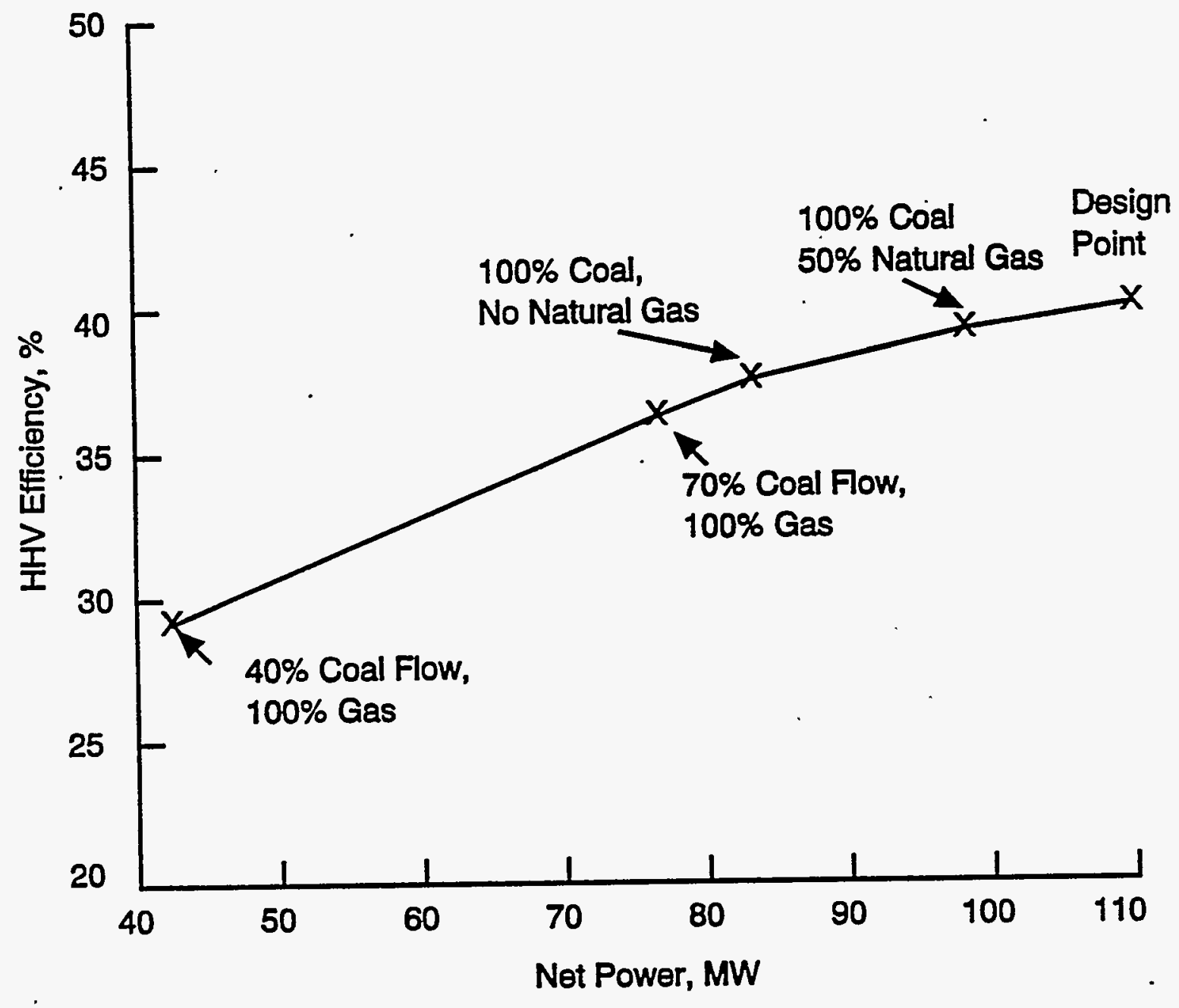

Figure 5.5-2 - Effect of Fuel Flow on Power and Efficiency 


\subsection{ECONOMIC PERFORMANCE}

Preliminary estimates of capital cost, operating cost, and cost of electricity (COE) for the 1.5-Generation PFBC plants have been developed. Itemized results are included Appendix A. The estimated capital cost (TPC, 12/92 dollars) for the large 1.5-Generation PFBC plant is about $\$ 1,120 / \mathrm{kW}$, compared to about $\$ 1,300 / \mathrm{kW}$ for a $560-\mathrm{MW}$ conventional pulverized-coal steam power plant with flue gas desulfurization. The 1.5Generation PFBC plant is more efficient than the PC plant (41.9\% vs. $35.2 \%)$, but much of this efficiency advantage is offset when calculating COE by its smaller size (246 MW vs. $560 \mathrm{MW}$ ) and the assumed higher price of natural gas compared to coal fuel ( $\$ 2.50 / \mathrm{MBtu}$ vs. $\$ 1.80 / \mathrm{MBtu})$.

Based on preliminary estimates, the unit capital cost and 30-year levelized COE of the 1.5-Generation PFBC plants are listed in Table 6-1 below. The corresponding COE for a $560-\mathrm{MW}$ conventional pulverized-coal steam power plant with flue gas desulfurization is about $\$ 90 / \mathrm{MWh}$.

Table 6-1

Economic Performance

(1992 dollars)

\begin{tabular}{|c|c|c|c|}
\hline & $\begin{array}{l}\text { Large } \\
\text { Plant }\end{array}$ & $\begin{array}{l}\text { Medium } \\
\text { Plant }\end{array}$ & $\begin{array}{l}\text { Small } \\
\text { Plant }\end{array}$ \\
\hline Net MW & 246 & 111 & 4 \\
\hline $\begin{array}{l}\text { Total Plant Cost } \\
\text { PFBC, } \$ M \\
\text { Turbines/Generators, } \$ M \\
\text { PFB Hot Gas Cleanup, } \$ M \\
\text { Balance of Plant, } \$ M \\
\text { Total Plant Cost, } \$ M\end{array}$ & $\begin{array}{r}\$ 38.8 \\
68.4 \\
16.8 \\
151.8 \\
\$ 275.8\end{array}$ & $\begin{array}{r}\$ 27.9 \\
38.7 \\
9.5 \\
95.9 \\
\$ 172.0\end{array}$ & $\begin{array}{r}\$ 2.8 \\
3.5 \\
3.3 \\
10.7 \\
\$ 20.3\end{array}$ \\
\hline $\operatorname{TPC}(\$ / \mathrm{kW})^{\cdots}$ & 1119.7 & 1553.1 & 5136.4 \\
\hline $\begin{array}{l}\text { Levelized Cost of Electricity } \\
\text { Capital Charges, mills/kWh } \\
\text { Fixed Oper \& Maint, mills/kWh } \\
\text { Variable Oper \& Maint, mills/kWh } \\
\text { Consumables, mills/kWh } \\
\text { Fuel, mills/kWh }\end{array}$ & $\begin{array}{r}36.5 \\
9.4 \\
5.1 \\
5.2 \\
27.3 \\
\end{array}$ & $\begin{array}{r}49.8 \\
16.4 \\
8.8 \\
5.5 \\
27.8 \\
\end{array}$ & $\begin{array}{r}157.6 \\
92.0 \\
49.5 \\
8.0 \\
41.9 \\
\end{array}$ \\
\hline Levelized COE, mills/kWh (\$/MWh) & 83.4 & 108.4 & 349.0 \\
\hline
\end{tabular}

The 246-MW "large" plant was the largest 1.5-Generation plant evaluated within the scope of this study. Two of these plants generate $492 \mathrm{MW}$, approximately the same as the 2nd-Generation PFBC (PFBC-II) plant and reference pulverized coal (PC-FGD) plant evaluated in another study [G/C, 1993]. Table 6-2 shows the upper and lower limits of the cost of a 492-MW 1.5-Generation PFBC plant, compared to the 2nd-Generation PFBC and PC-FGD plants. The first column is the upper limit cost, representing a simple 
doubling of the costs for the 246-MW plant with no economy of scale. The second column is the lower limit cost, assuming a single-train plant (currently designed 2 ndGeneration PFBC plants have multiple trains for the large vessels and gas turbines). The actual cost of a 492-MW 1.5-Generation PFBC plant would be between these extremes.

Table 6-2

\section{Economic Comparison to PFBC-II and PC/FGD \\ (1992 dollars)}

Net MW

Total Plant Cost, \$M

TPC $(\$ / \mathrm{kW})$

Levelized COE, mills/kWh
PFBC-1.5

Plant[1]

$2 \times 246$

551.6

1119.7

83.4
PFBC-1.5

Plant[2]

492

439.4

895.2

64.1
PFBC-II

Plant[3]

536

561.4

1048.2

75.4
PC-FGD

Plant[3]

559

772.1

1291.5

90.3

Assumed Number per Plant

Carbonizer, w/Filters

PFBC, boiler

PFBC Cyclone

PFBC Hot Gas Filter

Fluid Bed HX

Gas Turbine

Steam Piping

Steam Turbine

Balance of Plant

FGD

$\begin{array}{ll}- & \\ 2 & 1 \\ 8 & 4 \\ 4 & 2 \\ 2 & 1 \\ 2 & 1 \\ 2 & 1 \\ 2 & 1 \\ 2 & 1 \\ - & -\end{array}$

[1] Two 246-MW plants; simple doubling.

[2] Assumes single-train scale-up for all components except cyclones and hot gas filters.

[3] Conceptual design contains some multiple trains [G/C, 1993].

As a general approximation, the capital costs and COEs of these plants have economies of scale, as shown in Figure 6-1. Based on the slopes of the lines on this log-log plot, the capital cost (TPC) and COE for these plants can be represented as functions of generating capacity (MW):

$\operatorname{TPC}(\$ M)=\$ 172(M W / 111)^{0.63}$

$\operatorname{TPC}(\$ / \mathrm{kW})=\$ 1,553(\mathrm{MW} / 111)^{-0.37}$

$\operatorname{COE}(\$ / M W h)=\$ 108(M W / 111)^{-0.35}$ 


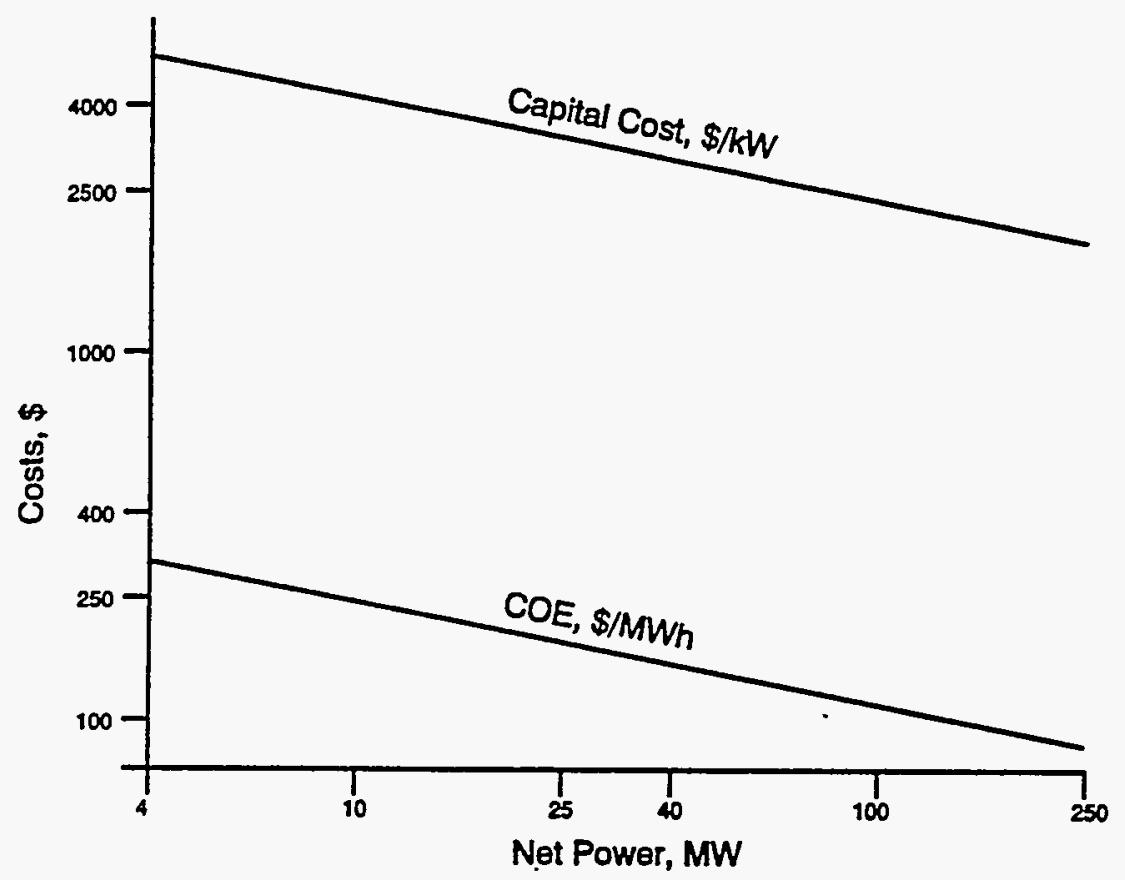

Figure 6-1 - Economies of Scale 


\subsection{ECONOMIC EVALUATION METHODS}

The economics of the 1.5-Generation PFBC plant cost estimates were developed by consistently evaluating the capital and operating costs for each plant and subsequently performing an economic analysis based on the cost of electricity (COE) as the figure of merit. The conceptual cost estimates for each plant were determined on the basis of previous evaluations of $P C$ and PFBC-ll power plants. [G/C, 6/92] The detail values from this reference cost data were adjusted for capacity, design condition changes and cost base.

Several portions of the 4-MW plant will most likely be designed differently from the larger units when its location, site conditions, and transportation constraints are defined for an actual plant. At that time, a re-estimate of the 4-MW plant would yield more accurate cost results. Since specific data was not available, however, extrapolation of existing data for larger plants to the 4-MW size was used as a first approximation of costs, even though the extent of the extrapolation could introduce large inaccuracies.

Estimated costs for the major components were established by a variety of methods. In-house cost data and support data from previous PFBC reports were supplemented by vendor budgetary pricing for major items as required. The capital costs for each plant at the Total Plant Cost (TPC) level includes equipment, materials, labor, indirect construction costs, engineering and contingencies (Table 6-1).

Operation and maintenance (O\&M) cost values were determined on a first-year basis and subsequently levelized over the 30 year plant life. Consumables were evaluated on the basis of the quantity required and individual commodity unit prices. Operation cost was determined on the basis of the number of operators, and maintenance was evaluated on the basis of maintenance costs required for each major plant section. These operating costs were then converted to unit values of $\$ / \mathrm{MWh}$ or mills $/ \mathrm{kWh}$. Operating, maintenance, and consumable costs were based on the plant design conditions listed in Table 6.1-1. 
Table 6.1-1

Plant Design Conditions

\begin{tabular}{|c|c|c|c|}
\hline & $\begin{array}{l}\text { Large } \\
\text { Plant }\end{array}$ & $\begin{array}{l}\text { Medium } \\
\text { Plant }\end{array}$ & $\begin{array}{l}\text { Small } \\
\text { Plant }\end{array}$ \\
\hline $\begin{array}{l}\text { Net Plant Output, MW } \\
\text { Plant Heat Rate, Btu/kWh }\end{array}$ & $\begin{array}{l}246.3 \\
8,246\end{array}$ & $\begin{array}{l}110.7 \\
8,484\end{array}$ & $\begin{array}{r}4.0 \\
12,277\end{array}$ \\
\hline $\begin{array}{l}\text { Coal Type } \\
\text { Coal HHV Btu per lb }\end{array}$ & $\begin{array}{l}\text { Pgh. } 8 \\
12,450\end{array}$ & $\begin{array}{l}\text { Pgh. } 8 \\
12,450\end{array}$ & $\begin{array}{l}\text { Pgh. } 8 \\
12,450\end{array}$ \\
\hline $\begin{array}{l}\text { Coal Cost } \$ / \text { MBtu } \\
\text { Natural Gas Cost } \$ / M B t u\end{array}$ & $\begin{array}{l}\$ 1.80 \\
\$ 2.50\end{array}$ & $\begin{array}{l}\$ 1.80 \\
\$ 2.50\end{array}$ & $\begin{array}{l}\$ 1.80 \\
\$ 2.50\end{array}$ \\
\hline $\begin{array}{l}\text { Coal (as rec'd), lb/h } \\
\text { Natural Gas, lb/h } \\
\text { scfm }\end{array}$ & $\begin{array}{r}128,861 \\
19,257 \\
7,014\end{array}$ & $\begin{array}{r}61,581 \\
7,781 \\
2,834\end{array}$ & $\begin{array}{r}3,031 \\
492 \\
179\end{array}$ \\
\hline Dolomite, lb/h & 51,117 & 24,428 & 1,202 \\
\hline Construction Time, yrs & 3.5 & 2.5 & 1.5 \\
\hline
\end{tabular}

In addition, the following economic assumptions were made:

- Plant book life is 30 years,

- Capacity factor is 65 percent, and

- Plant in-service date is January 1993.

The capital and operating costs of the plant are combined with plant performance in the comprehensive evaluation of cost of electricity (COE). 


\subsection{CAPITAL COSTS}

This section describes the approach, basis, and methods that were used to perform capital cost evaluations of the PFBC power plants. Included in this section are descriptions of:

- Bare Erected Cost (Section 6.2.1)

- Total Plant Cost (Section 6.2.2)

- Capital Cost Estimate Exclusions (Section 6.2.3)

The capital costs, as well as the operating costs, and expenses were established consistent with EPRI Technical Assessment Guide (TAG) [TAG, 1989] methods and the plant scope identified in Section 3. The cost of each component was quantitatively developed on the basis of its fundamental parameter determining cost. This approach was utilized to enhance credibility and establish a basis for subsequent comparisons and modification as the technology is further developed. The following assumptions were used:

- Total plant cost values are expressed in December 1992 dollars.

- The estimates represent mature technology plant, or "nth plant" (i.e., it does not include costs associated with a first-of-a-kind plant).

- The estimate represents a complete power plant facility with the exception of the exclusions listed in Section 6.2.3.

- The estimate boundary limit is defined as the total plant facility within the "fence line," including coal receiving and water supply system but terminating at the high side of the main power transformers.

- Site is considered to be located within the Ohio River Valley, southwestern Pennsylvania/eastern Ohio, but not specifically sited within the region except that it is considered to be located on a major navigable water way.

- Terminology used in connection with the estimate are consistent with the EPRI TAG [TAG, 1989].

- Costs are grouped according to a process/system-oriented code of accounts; all reasonably allocable components of a system or process are included in the specific system account in contrast to a facility, area, or commodity account structure.

- The basis for equipment, materials, and labor costing is described in Section 6.2.1.

- Design engineering services, including construction management and contingencies basis, are examined in Section 6.2.2.

The capital cost, specifically referred to as Total Plant Cost (TPC) for the mature power plant, was estimated using the EPRI structure. The major components of TPC consist of bare erected cost, engineering and home office overheads and fee plus contingencies. 
The capital cost for each case was determined through the process of estimating the cost of every significant piece of equipment, component, and major commodity for each case on the basis of the references previously noted. A Code of Accounts was developed to provide the required structure for the estimate. The Code facilitates recognition of estimated battery limits and the scope included in each account. This Code is presented in Appendix A along with a listing of scope included in each account.

\subsubsection{Bare Erected Cost}

The bare erected cost level of the estimate, also referred to as the sum of process capital and general facilities capital, consists of the cost of: factory equipment, field materials and supplies, direct labor, indirect field labor, and indirect construction costs.

- The large commercial 1.5-Generation PFBC Plant Cost Estimate is based on a similar estimate for the 2nd-Generation subcritical cycle PFBC, recently completed by $\mathrm{G} / \mathrm{C}[\mathrm{G} / \mathrm{C}, 1992]$. The 2nd-Generation PFBC estimate was modified to reflect the 1.5-Generation equipment configuration and adjusted for system operating parameters. The two main differences in 1.5-Generation equipment are the absence of a carbonizer, and single instead of multiple trains. All costs associated with the carbonizer and its auxiliary systems were deleted, including the cyclones, start up heater, flare system, and piping. The 2nd-Generation PFBC estimate was also modified to reflect the single train configuration of the 1.5-Generation PFBC cycle. The cost of each component in the estimate that represented a multiple train system was divided by the number of trains and the result, then increased by a factor to account for shared components. The cost estimate now represents a system configuration with the correct type and quantity of components.

The 2nd-Generation PFBC cost estimate requires adjustment to the capacities of the individual components to reflect the requirements of the 1.5-Generation PFBC. In most cases, the cost adjustments were achieved by using scaling factors to proportion the cost components. Some of the costs are based on vendor quotes or In-house Estimating Programs. The result of this process was the reference 1.5-Generation PFBC plant estimate.

- The intermediate commercial 1.5-Generation PFBC plant is based on the large (reference) commercial 1.5-Generation PFBC plant. The configuration for the two plants is the same, only the capacity of the components differ. The same method is used to adjust the capacities of the components from the large commercial plant to the intermediate commercial plant as was used to adjust the capacities of the 2nd-Generation PFBC plant to the large commercial plant.

- The small commercial PFBC 1.5-Generation plant is too small to be scaled from the 2nd-Generation PFBC plant. The basis of the small commercial plant is the 2nd-Generation pressurized fluidized bed combustion - small gas turbine Industrial Plant Study. The same method was used to modify this study to the small commercial PFBC 1.5-Generation plant parameters as was used to modify the 2nd-Generation PFBC to the large commercial 1.5-Generation plant.

Construction labor costing in the estimate is equivalent to a multiple contract labor basis with the labor cost including direct and indirect labor costs plus fringe benefits and 
allocations for contractor expenses and markup. The indirect labor cost was estimated at 7 percent of direct labor to recognize the cost of construction services and facilities not provided by the individual contractors.

A cost summary for each case will separate values for each account and separated into equipment materials and insulation labor is included in the Appendix A.

\subsubsection{Total Plant Cost}

The TPC level of the estimate consists of the bare erected cost plus engineering and contingencies. The engineering costs represent the cost of architect/engineer (A/E) services for design, drafting, and project construction management services. The cost was determined at 6.5 percent applied to the bare erected cost on an individual account basis. The cost for engineering services provided by the equipment manufacturers and vendors is considered to be included with the equipment costs.

Allowances for process and project contingencies are also considered as part of the TPC. Some of the process technology used in the various systems is still in the development stage. Continuing process development tends to increase the cost of plant components as problems are discovered and resolved. In an attempt to account for the uncertainty in equipment design, performance, and cost, a process contingency was added to the estimated cost of pertinent components and systems.

Consistent with conventional power plant practices, a general project contingency was added to the total plant cost to cover project uncertainty and the cost of any additional equipment that could result from a detailed design. Based on EPRI criteria, the cost estimate contains elements of Classes I, II, and III level estimates. As a result, on the basis of the EPRI guidelines, a nominal value of 15 percent was used to arrive at the plant nominal cost value. This project contingency is intended to cover the uncertainty in the cost estimate itself, Whereas the process contingency covers the uncertainty in the technical development level of specific equipment. In both cases the contingencies represent costs that are expected to occur.

Engineering and contingency values are included in the tables of capital cost in Appendix A. This process was repeated for each case evaluated.

In addition to the TPC cost level, the Total Plant Investment (TPI) and Total Capital Requirement (TCR) were determined for each case. Since the evaluation process is both mechanical and consistent with EPRI TAG, discussion of the basis has been relegated to Appendix A.

The TPC level of capital costs results for each case are included on a separate table in Appendix A and summary results are reported in the Table 6-2. The TPI and TCR values are reported on separate Appendix A tables referenced at the end of Section 6.3.3. 


\subsubsection{Capital Cost Estimate Exclusions}

Although the estimate is intended to represent complete PFBC plants, there remain several qualifications/exclusions as follows:

- Sales tax is not included (considered to be exempt).

- On-site fuel transportation equipment (such as barge tug, barges, yard locomotive, bulldozers) is not included.

- Allowances for unusual site conditions (such as piling, extensive site access, excessive dewatering, extensive inclement weather) are not included.

- Switchyard (transmission plant) is not included. The cost estimated scope terminates at the high side of the main power transformer.

- Ash disposal facility is excluded, other than the 3-day storage in the ash-storage silos. (The ash disposal cost is accounted for in the ash disposal charge as part of consumables costs)

- Royalties are not included. 


\subsection{OPERATING COSTS AND EXPENSES}

The operating costs and related maintenance expenses (O\&M) described in this section pertain to those charges associated with operating and maintaining the 1.5-Generation PFBC power plant over its expected life

The costs and expenses associated with operating and maintaining the plant include:

- Operating labor

- Maintenance (material \& labor)

- Administrative and support labor
- Consumables

- By-Product credit (if applicable)

- Fuel cost

The values for these items were determined consistent with EPRI TAG methods. These - costs and expenses are estimated on a first-year basis, in January 1993 dollars. The first-year costs assume normal operation and do not include the initial start-up costs which are included as part of the TCR determination. .

The operating labor, maintenance material and labor, and other labor-related costs are combined and then divided into two components; fixed O\&M, which is independent of power generation, and variable O\&M, which is proportional to power generation. The first-year operating and maintenance cost estimate allocation is based on the plant capacity factor.

The other operating costs, consumables and fuel, are determined on a daily 100-percent operating capacity basis and adjusted to an annual plant operation basis.

The-development of the actual values was performed on a $G / G$ model that is consistent with TAG. The inputs for each category of operating costs and expenses are identified in the succeeding subsections along with more specific discussion of the evaluation processes.

This section describes the approach, basis, and methods that were used to perform operating cost evaluations of the PFBC power plants. Included in this section are descriptions of:

- Operating Labor (Section 6.3.1)

- Maintenance (Section 6.3.2)

- Consumables, including fuel costs (Section 6.3.3)

Each of these expenses and costs is determined on a first-year basis and subsequently levelized over the life of the plant through application of a levelizing factor to determine the value that forms a part of the economic evaluation. This amount, when combined with fuel cost and capital charges, results in the figure of merit, or Cost of Electricity (COE). 


\subsubsection{Operating Labor}

The cost of operating labor was estimated on the basis of the number of Operating Jobs (OJ) required to operate the plant (on an average-per-shift basis). The Operating Labor Charge (OLC) expressed in first year $\$ / \mathrm{kW}$ was then computed using the average labor rates:

$$
\mathrm{OLC}=\frac{(\mathrm{OJ}) \times(\text { labor rate } \times \text { labor burden }) \times(8760 \mathrm{~h} / \mathrm{yr})}{\text { (net capacity of plant at full load in } \mathrm{kW})}
$$

The operating labor requirements were determined on the basis of in-house representative data for the major plant sections (such as coal handling and steam turbine plant). The number of operating jobs for each case were adjusted in accordance with the capacity and number of trains in each section of the plant.

\subsubsection{Maintenance}

Annual maintenance costs, according to EPRl's methods, are estimated as a percentage of the installed capital cost. The percentage varies widely, depending on the nature of the processing conditions and the type of design.

On the basis of $G / C$ in-house data and EPRI guidelines for determining maintenance costs supplementing previous PFBC maintenance evaluations, representative values expressed as a percentage of system cost were specified for each major system. The rates were applied against individual estimate values. Using the corresponding TPC values, a total annual (first-year) maintenance cost was calculated, including both material and labor components.

Since the maintenance costs are expressed as maintenance labor and maintenance materials, a maintenance labor/materials ratio of 40/60 was used for this breakdown. The operating costs, excluding consumable operating costs, are further divided into fixed and variable components. Fixed costs are essentially independent of capacity factor and are expressed in $\$ / \mathrm{kW}$-yr. Variable costs are incremental, directly proportional to the amount of power produced, and expressed in mills $/ \mathrm{kWh}(\$ / \mathrm{MWh})$. The equations for these calculations are:

$$
\begin{aligned}
\text { Fixed O\&M } & =\text { Capacity Factor (CF) } \times \text { Total O\&M }(\$ / \mathrm{kW}-\mathrm{yr}) \\
\text { Variable O\&M } & =\frac{(1-\mathrm{CF}) \times \text { Total O\&M }(\$ / \mathrm{kW}-\mathrm{yr}) \times 1000 \mathrm{mills} / \mathrm{S}}{(\mathrm{CF} \times 8760 \mathrm{~h} / \mathrm{yr})}
\end{aligned}
$$

\subsubsection{Consumables}

The feedstock and disposal costs are those consumable expenses associated with power plant operation. Consumable operating costs are developed on a first-year basis and subsequently levelized over the 30-year life of the plant. The consumables category consists of water, chemicals, other consumables, and waste disposal. 
The "water" component pertains to the water acquisition charge for water required for the plant steam cycle, and for miscellaneous services.

The "chemicals" component consists of:

- A composite water makeup and treating chemicals requirement in which unit cost and the ratio of chemicals to water were based on data from comparable plants

- The liquid effluent chemical category, representing the composite chemical requirement for wastewater treating, in which unit cost and quality were developed similar to the water makeup and treating chemicals

- The limestone or dolomite required for injection into the boiler or FGD unit, in which the unit cost is the EPRI standard limestone cost.

The "other consumables" component consists of gases. Since these plants do not use significant amounts of the gases in this account, gases were not included.

The results of the evaluation of the individual categories of O\&M expenses for each case are shown on separate summary tables included in Appendix A (Capital Investment and Revenue Requirement Summary) along with summary TPC, TPI and TCR values.

These summary tables also include the annual fuel cost and levelized COE and constituent values of COE. A discussion of the basis for determining these values is included in the appendix along with the discussion of TPI and TCR.

The "waste disposal" component pertains to the cost allowance for off-site disposal of plant solid wastes. The unit cost for disposal is based on an adjusted EPRI value.

The results of individual categories of O\&M expense evaluations for each case are shown on separate summary tables included in Appendix A (Capital Investment and Revenue Requirement Summary) along with summary TPC, TPI and TCR values. These summary tables also include annual fuel cost, levelized COE, and values of COE constituents. A discussion of the basis for determining these values is included in Appendix A, along with the discussion of TPI and TCR. 


\subsection{ECONOMIC SENSITIVITIES}

Three sensitivity studies are discussed in this section:

6.4.1 Sensitivity to Fuel Flow Rates

6.4.2 Sensitivity to PFBC Excess Air, and

6.4.3 Sensitivity to Fuel Prices

All sensitivity cases are based on the intermediate (111-MW) 1.5-Generation PFBC Plant.

\subsubsection{Sensitivity to Fuel Flow Rates}

Operational sensitivity studies were performed to determine the effects of load change on power output and cost of electricity. The studies were based on natural gas topping fuel flow rates from full-load design point down to zero, and on coal feed rates from full-load design point to 40 percent of design. Topping combustor temperature, cycle pressure ratio, net power and fuel consumption are all functions of gas fuel flow.

In these sensitivity analyses, there are no equipment differences from the base case so the TPC and TPI dollar values in the Capital Investment and Revenue Requirement Summary (Appendix A) remain the same as the base intermediate plant. Due to the reduced generating capability, all of the cost $/ \mathrm{kW}$ have increased.

The operating and maintenance costs and land costs dollar values also remain the same as the base cost (see Appendix A). The consumable operating costs and fuel costs per megawatt-hour are slightly higher in the sensitivity cases than in the base case because of reduced plant efficiency at off-design conditions.

The overall effects of fuel flow rates on levelized cost of electricity are shown in Table 6.41 and Figure 6.4-1. Even though natural gas is more expensive than coal, both fuels have the same affect on COE when the plant is operated at below-design conditions.

Figure 6.4-2 shows the COE effect of reduced fuel flow, expressed as percent load. The performance penalty for operating at below-design conditions makes it uneconomical to run with reduced fuel flow rates. 
Table 6.4-1

COE Sensitivity to Fuel Flow Rates

GAS SENSITIVITY

Coal Feed Rate

Gas Feed Rate

Topping Combustor

Temperature

Plant Net Power

Plant HHV Efficiency

Capital Charges

Fixed O\&M

Variable O\&M

Consumables

Fuel

Levelized COE

COAL SENSITIVITY

Coal Feed Rate

Gas Feed Rate

Topping Combustor

Temperature

Plant Net Power

Plant HHV Efficiency

Capital Charges

Fixed O\&M

Variable O\&M

Consumables

Fuel

Levelized COE
No

Natural Gas

$61,581 \mathrm{lb} / \mathrm{h}$

$0 \mathrm{lb} / \mathrm{h}$

1586 of

$84,158 \mathrm{~kW}$

$37.30 \%$

$\$ 65.3 / \mathrm{MWh}$

$21.6 / \mathrm{MWh}$

11.6/MWh

$7.1 / \mathrm{MWh}$

28.1/MWh

$\$ 133.7 / \mathrm{MWh}$

$$
\begin{array}{r}
40 \% \text { of Base } \\
\text { Coal Feed } \\
24,632 \mathrm{lb} / \mathrm{h} \\
7,781 \mathrm{lb} / \mathrm{h} \\
1965 \text { of }
\end{array}
$$

$42,497 \mathrm{~kW}$

$29.74 \%$

$\$ 129.8 / M W h$

42.7/MWh

22.9/MWh

$5.7 / \mathrm{MWh}$

39.1/MWh

$\$ 240.2 / \mathrm{MWh}$
Medium

Natural Gas

$61,581 \mathrm{lb} / \mathrm{h}$

$3,891 \mathrm{lb} / \mathrm{h}$

$1779^{\circ} \mathrm{F}$

$97,444 \mathrm{~kW}$

$38.90 \%$

$\$ 56.5 / \mathrm{MWh}$

18.6/MWh

10.0/MWh

6.2/MWh

27.9/MWh

$\$ 1$ 19.3/MWh

$70 \%$ of Base

Coal Feed

$43,107 \mathrm{lb} / \mathrm{h}$

$7,781 \mathrm{lb} / \mathrm{h}$

1965 oF

$77,102 \mathrm{~kW}$

$36.11 \%$

$\$ 71.5 / \mathrm{MWh}$

23.6/MWh

12.6/MWh

$5.5 / \mathrm{MWh}$

$30.7 / \mathrm{MWh}$

$\$ 1$ 43.9/MWh
Base

Natural Gas

$61,581 \mathrm{lb} / \mathrm{h}$

$7,781 \mathrm{lb} / \mathrm{h}$ 1965 of

$110,741 \mathrm{~kW}$ $40.22 \%$

$\$ 49.8 / M W h$ 16.4/MWh

8.8/MWh

5.5/MWh

27.8/MWh

$\$ 108.4 / \mathrm{MWh}$

Base

Coal Feed

$61,581 \mathrm{lb} / \mathrm{h}$

$7,781 \mathrm{lb} / \mathrm{h}$ 1965 oF

$110,741 \mathrm{~kW}$ $40.22 \%$

$\$ 49.8 / \mathrm{MWh}$

16.4/MWh

8.8/MWh

$5.5 / \mathrm{MWh}$

27.8/MWh

$\$ 108.4 / \mathrm{MWh}$ 


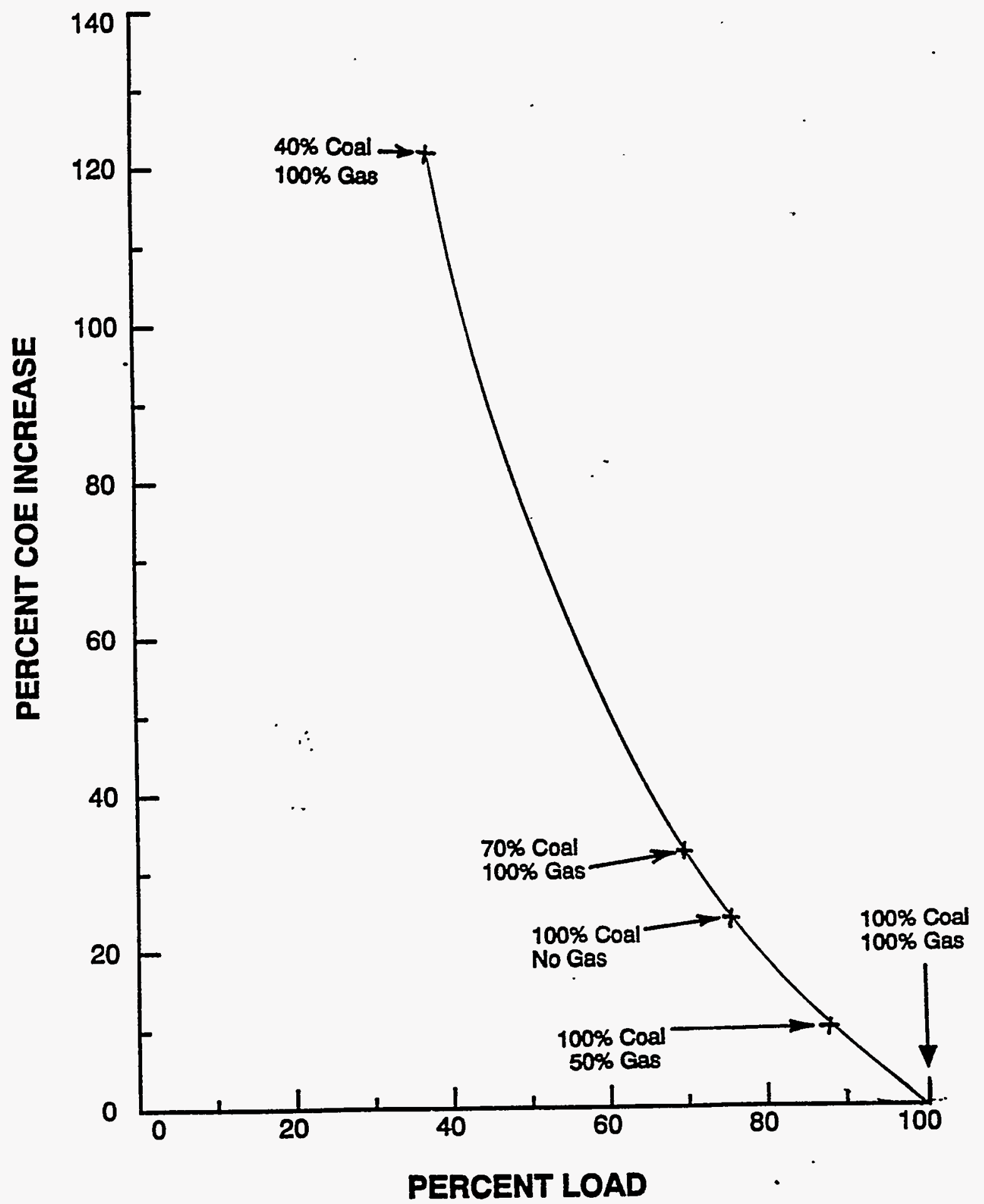

Figure 6.4-1 - Effect of Load Reduction on COE 


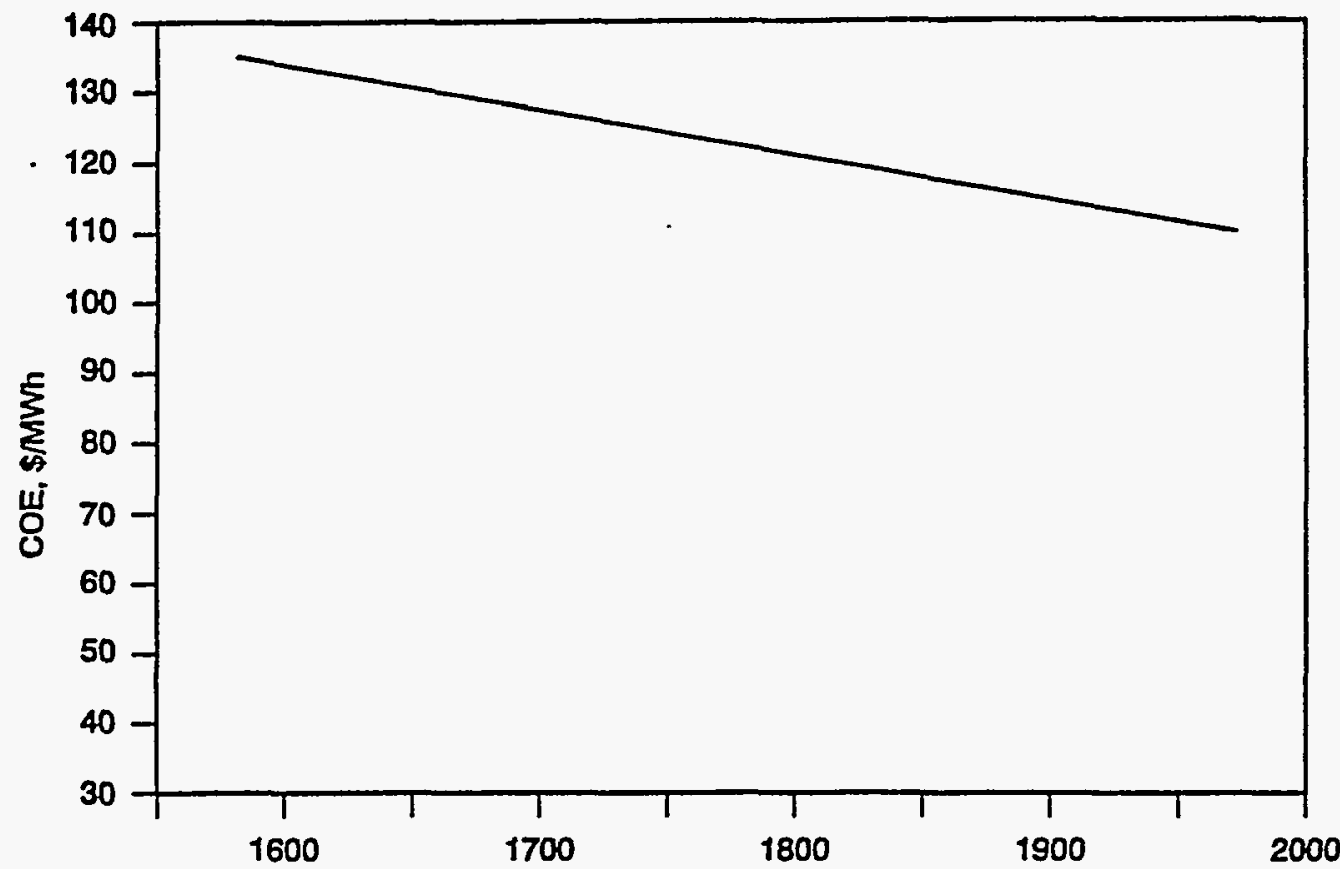

Topping Combustor Temp, $F$

Figure 6.4-2 - Effect of Topping Combustor Temperature on COE

\subsubsection{Sensitivity to PFBC Excess Air}

A design sensitivity study was performed to determine the effects of PFBC excess air on the design, capital cost, and COE of the 1.5-Generation PFBC plant. The range is between about 60 percent and about 414 percent excess air.

In this sensitivity analysis, equipment changes have been made to the base case to meet the performance parameters of the different operating basis. Most notable of the equipment changes is in the Maximum Excess Air case in which all cost associated with the fluid bed heat exchanger have been deleted from the cost estimate to accommodate the system configuration. Other notable changes are, for both cases, the steam turbine generators are modified in capacity as well as the feedwater systems associated with - them. In all items on the Capital Investment and Revenue Requirement Summary (Appendix A) the 60\% Excess Air Case has higher dollar values than the base case, however, due to the greater generating capacity all COE costs/kWh are lower than the base case. The opposite is true of the Maximum Excess Air Case. 
The effect of PFBC excess air on total plant capital cost is shown in Table 6.4-2 and Figure 6.4-3. Plants with lower PFBC excess air use more coal, which increases equipment capital costs (in dollars), but the increased generating capacity results in lower costs per kilowatt.

Table 6.4-2

COE Sensitivity to PFBC Excess Air

Case

PFBC Excess Air

Plant Net Power

Plant HHV Efficiency

Capital Cost, \$k

$\$ / \mathrm{kW}$

LEVELIZED COE

Capital Charges

Fixed O\&M

Variable O\&M

Consumables

Fuel

Levelized COE
Low Excess Air Base Excess Air $63 \%$

$130,287 \mathrm{~kW}$

$39.39 \%$

$\$ 188,640$

$\$ 1447.9 / \mathrm{kW}$

\$46.5/MWh

14.4/MWh

7.8/MWh

5.9/MWh

28.1/MWh

$\$ 102.6 / M W h$ $107 \%$

$110,741 \mathrm{~kW}$

$40.22 \%$

$\$ 171,988$

$\$ 1553 / \mathrm{kW}$

$\$ 49.8 / M W h$

16.4/MWh

8.8/MWh

5.5/MWh

27.8/MWh

$\$ 108.4 / \mathrm{MWh}$
Hiah Excess Air $414 \%$

$55,182 \mathrm{~kW}$

$38.47 \%$

$\$ 103,752$

$\$ 1880.2 / \mathrm{kW}$

\$60.6/MWh

28.0/MWh

15.1/MWh

4.1/MWh

31.1/MWh

$\$ 138.9 / \mathrm{MWh}$ 


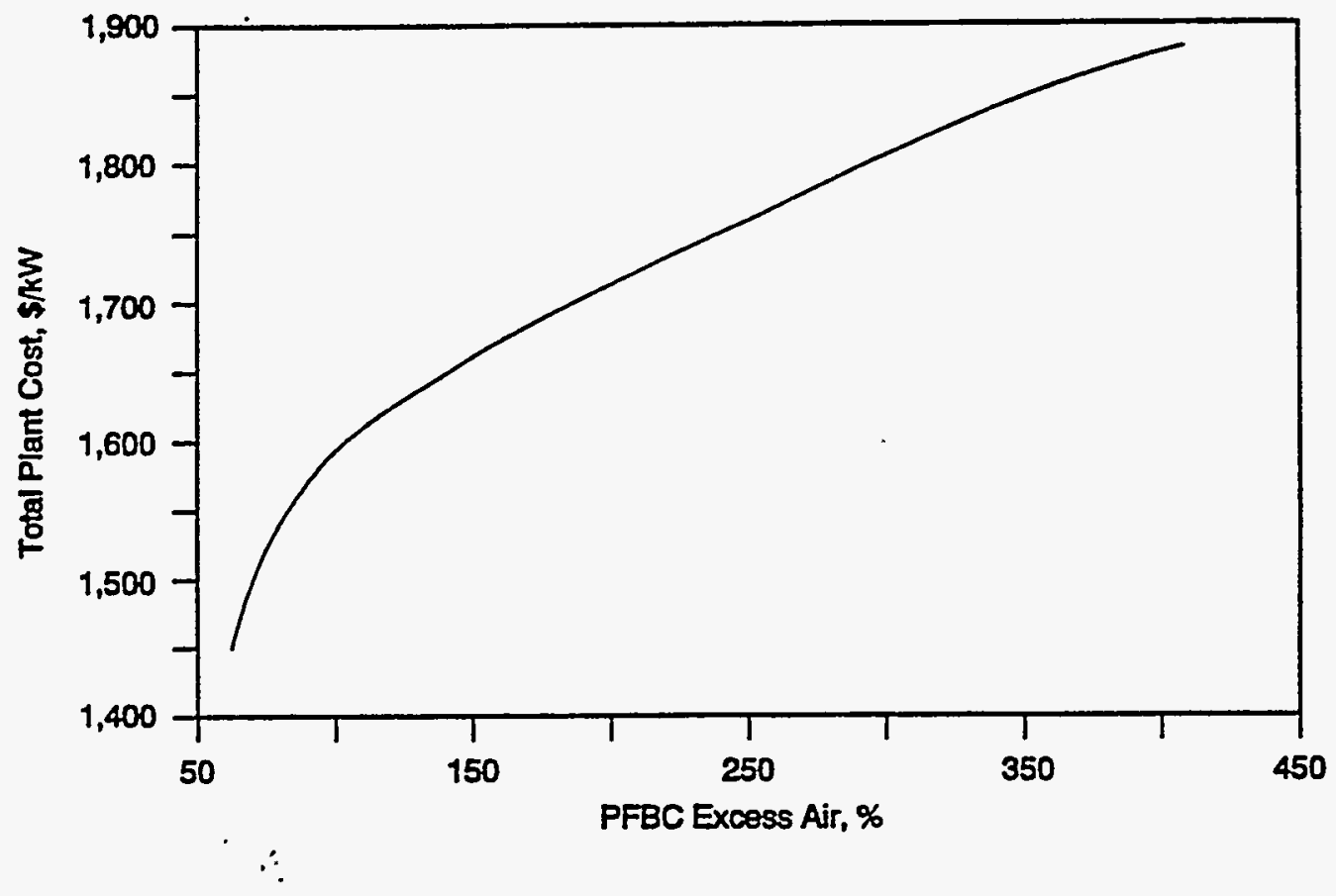

Figure 6.4-3 - Effect of Excess Air on Capital Cost

Plants with higher PFBC excess air have higher levelized costs of electricity, as shown in Figure 6.4-4, because of their reduced power generating capacity. 


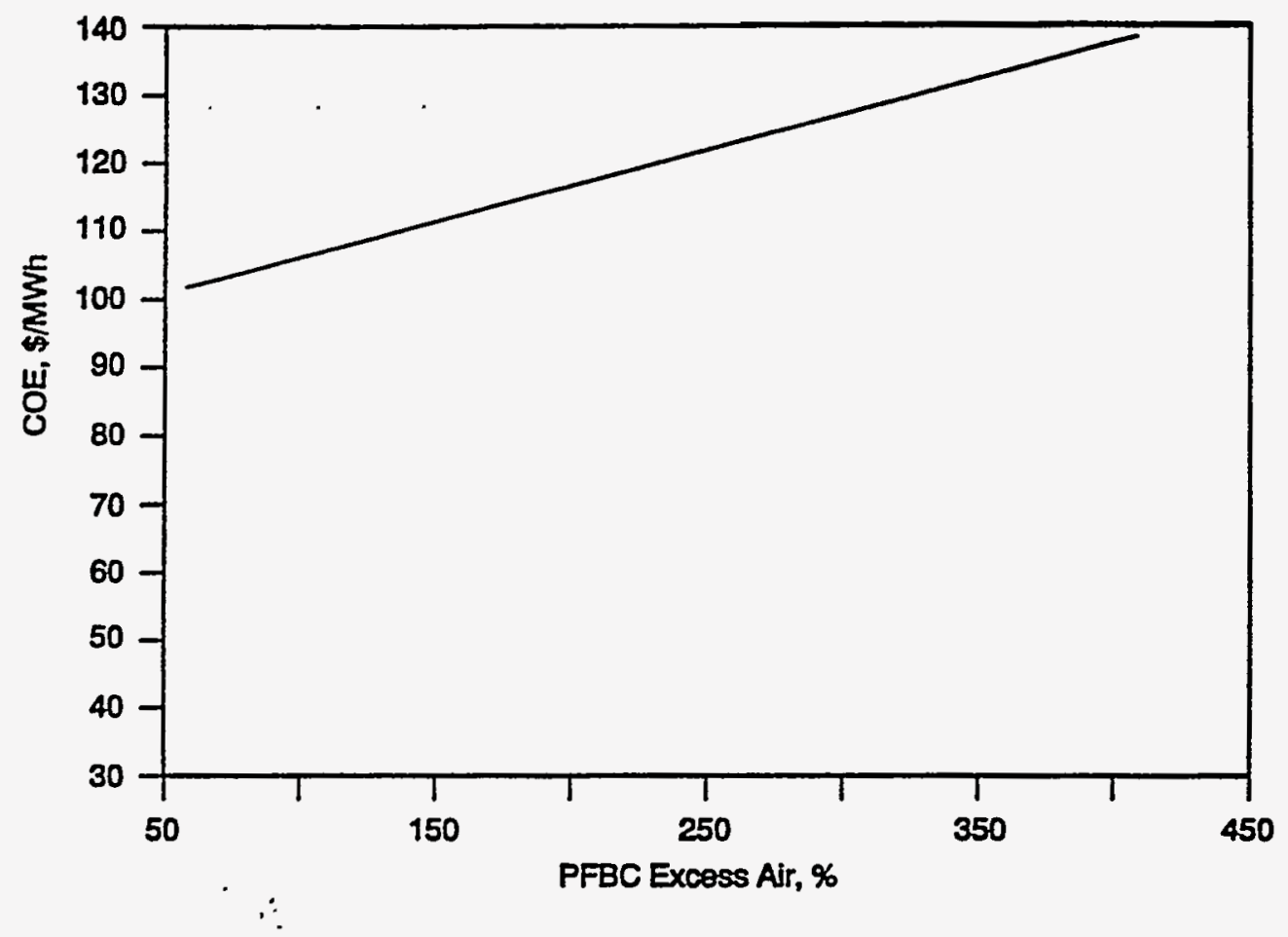

Figure 6.4-4 - Effect of Excess Air on COE

\subsubsection{Sensitivity to Fuel Prices}

An operational sensitivity study was performed to determine the effects of changes in oil, natural gas, and coal prices on the operating costs and COE of the intermediate (111-MW) 1.5-Generation PFBC plant.

In all the cases no equipment changes are made and no operating parameters are different. The only change in the estimates are the cost of the fuels. The range of fuel costs is based on the 1973 to 1991 annual average performance of fuel cost as delivered to electric utilities as reported in the "Energy Information Administration/Monthly Energy Review" [EIA, 1991]. To determine each fuel cost range and percentage increase, the maximum cost during the period was compared to the 1973 cost. The peak fuel costs occurred between 1980 and 1984. The percentage increase was then applied to the current fuel prices to determine the maximum cost of fuels that is likely to occur in the future. The ranges for the fuels are as follows: 


$\begin{array}{lcccc}\text { Coal . } & \$ 1.8 & \text { to } & \$ 7.5 & 415 \% \text { range } \\ \text { Natural Gas } & \$ 2.5 & \text { to } & \$ 26.90 & 1076 \% \text { range } \\ \text { Oil } & \$ 4.4 & \text { to } & \$ 29.45 & 669 \% \text { range }\end{array}$

The results of the fuel cost sensitivity analysis are summarized in Table 6.4-3, and presented in graphic form following the table. The greatest COE sensitivity was the sensitivity to coal price (0.201-percent increase in COE for each 1-percent increase in coal price), followed by the sensitivity to oil price ( 0.106 percent per percent increase) and natural gas price ( 0.063 percent per percent increase).

Table 6.4-3

COE Sensitivity to Fuel Prices

(All cases are $110.7 \mathrm{MW}, 8,484 \mathrm{Btu} / \mathrm{kWh}$ )

\begin{tabular}{|c|c|c|c|c|}
\hline \multirow{4}{*}{$\begin{array}{l}\text { SENSITIVITY } \\
\text { Coal Price } \\
\text { oal Price } \\
\text { Coal Price } \\
\text { Increase } \\
\text { alized Increase }\end{array}$} & $\begin{array}{l}\text { Coal } \\
\text { (\$/MBtu) }\end{array}$ & $\begin{array}{l}\text { Nat. Gas } \\
(\$ / \mathrm{MBtu})\end{array}$ & $\begin{array}{l}\text { Oil } \\
\text { (\$/MBtu) }\end{array}$ & $\begin{array}{l}\mathrm{COE} \\
(\$ / M W h)\end{array}$ \\
\hline & $\begin{array}{l}1.80 \\
4.70 \\
7.50 \\
317 \% \\
1.000\end{array}$ & $\begin{array}{l}2.50 \\
2.50 \\
2.50 \\
- \\
-\end{array}$ & $\begin{array}{l}n / a \\
n / a \\
n / a \\
- \\
-\end{array}$ & $\begin{array}{l}108.4 \\
143.5 \\
177.4 \\
64 \% \\
0.201\end{array}$ \\
\hline & $\begin{array}{l}1.80 \\
1.80 \\
1.80 \\
-\end{array}$ & $\begin{array}{l}2.50 \\
14.7 \\
26.9 \\
976 \% \\
1.000\end{array}$ & $\begin{array}{l}n / a \\
n / a \\
n / a \\
-\end{array}$ & $\begin{array}{l}108.4 \\
141.7 \\
174.9 \\
61 \% \\
0.063\end{array}$ \\
\hline & $\begin{array}{l}1.80 \\
1.80 \\
1.80 \\
- \\
-\end{array}$ & $\begin{array}{l}n / a \\
n / a \\
n / a \\
- \\
-\end{array}$ & $\begin{array}{l}4.40 \\
16.93 \\
29.45 \\
569 \% \\
1.000\end{array}$ & $\begin{array}{l}113.6 \\
147.8 \\
181.9 \\
60 \% \\
0.106\end{array}$ \\
\hline
\end{tabular}


For the Coal Sensitivity Analysis, the cost of coal is varied while the cost of the secondary fuel (Natural Gas) cost is held at the base case value. As expected, the change in COE is due solely to the fuel cost, pre-production costs, and inventory capital items on the Capital Investment and Revenue Requirement Summary (Appendix A). The COE ranges from 108.4 mills/kWh (Base) to 177.4 mills $/ \mathrm{kWh}$, as shown in Figure 6.4-5.

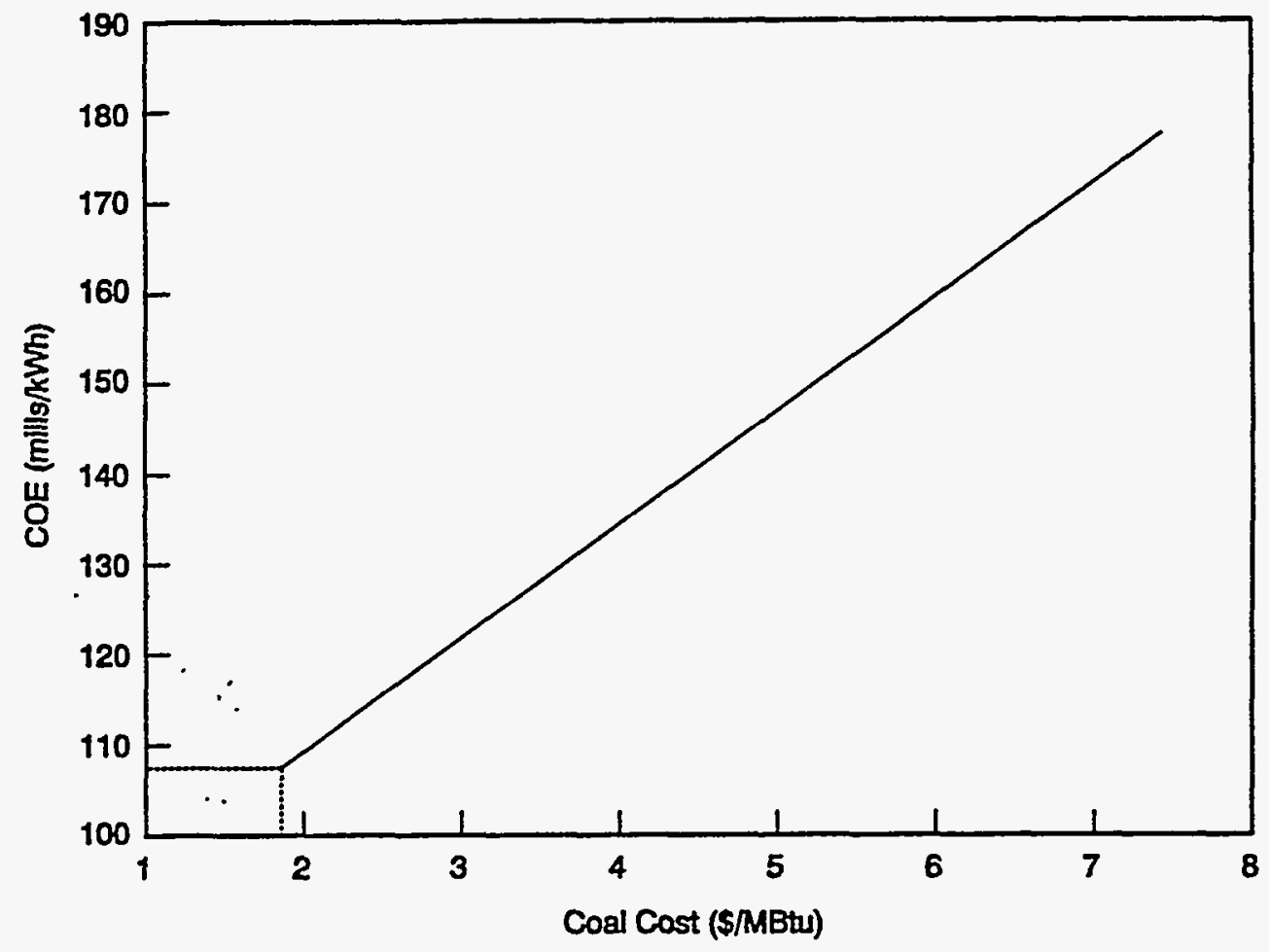

Figure 6.4-5 - COE Sensitivity to Coal Prices 
For the Natural Gas Sensitivity Analysis, the cost of the secondary fuel (natural gas) is varied while the primary fuel (coal) is held at the base case value. The same types of changes occur on the Capital Investment and Revenue Requirement Summary (Appendix A) as in the Coal Sensitivity Study with a resultant change in COE of 108.4 mills/kWh (Base) to 174.9 mills/kWh, as shown in Figure 6.4-6.

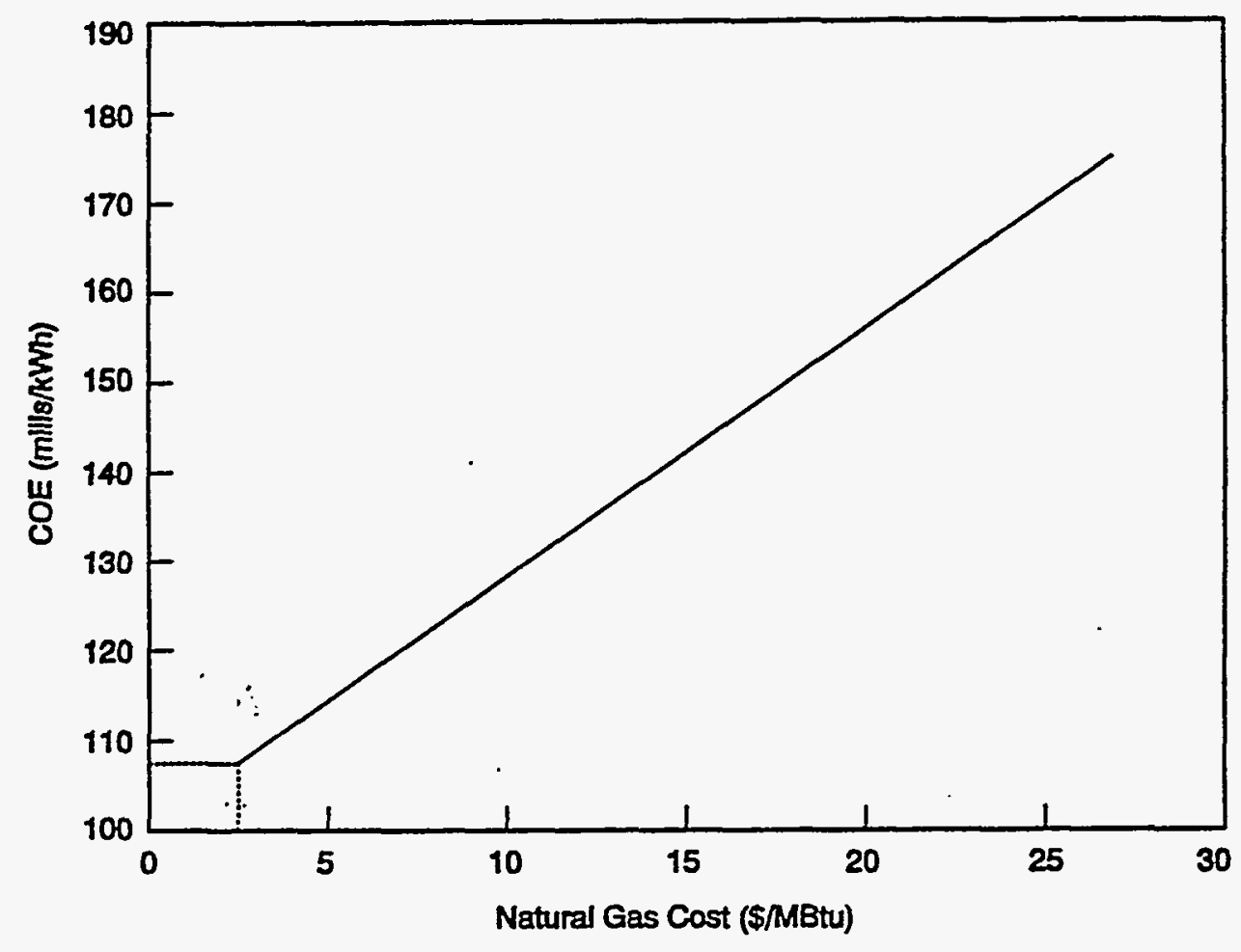

Figure 6.4-6 - COE Sensitivity to Natural Gas Prices 
For the Oil Sensitivity Analysis the cost of oil takes the place on natural gas in the secondary fuel location and is varied while the cost of the primary fuel (coal) is held at the base case value. The same types of changes occur in the Capital investment and Revenue Requirement Summary (Appendix A) as the previous analyses, except that the base COE changes due to the replacement of natural gas with oil as the secondary fuel. The COE values are 113.6 mills $/ \mathrm{kWh}$ (Base) and $181.9 \mathrm{mills} / \mathrm{kWh}$, as shown in Figure 6.4-7.

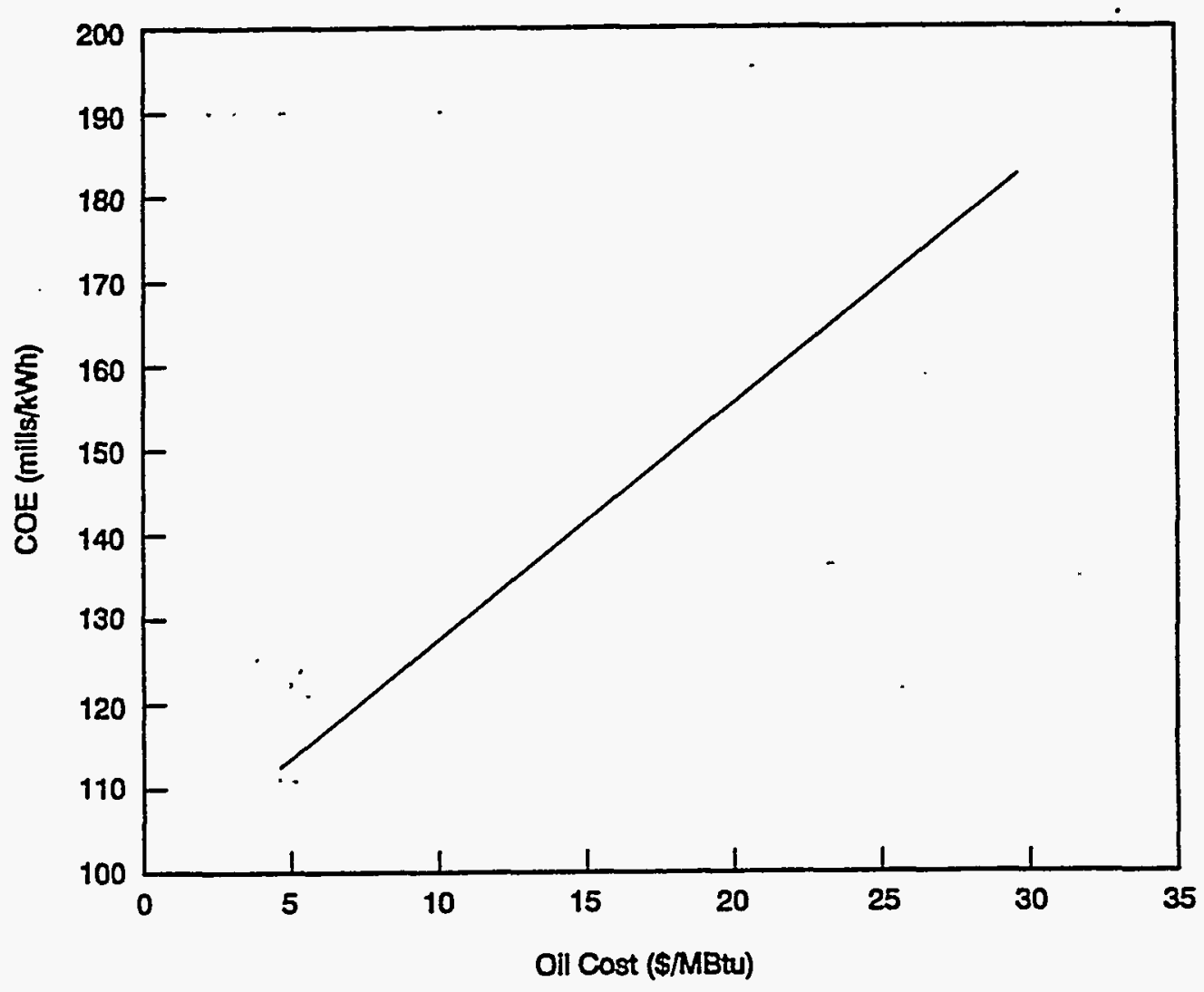

Figure 6.4-7 - COE Sensitivity to Oil Prices 


\subsection{CONCLUSIONS AND RECOMMENDATIONS}

The conceptual design and analysis of the 1.5-Generation PFBC plant leads to the following conclusions.

1. The 1.5-Generation PFBC plant is the logical alternative to 1st-Generation PFBC commercialization, as PFBC technology gains commercial experience and acceptance. The 1.5-Generation PFBC plant is more efficient than the 1stGeneration PFBC plant, and provides a reasonable bridge to 2nd-Generation PFBC technology. The potential for phased installation should be explored: starting with a 1.5-Generation PFBC plant, then later adding a carbonizer and modifying the topping combustor, resulting in a 2nd-Generation PFBC plant.

2. By eliminating the carbonizer and its associated hot-gas cleanup system, the 1.5-Generation PFBC plant combines many of the advantages of a 2nd-Generation PFBC plant with the reduced technological risk of a 1stGeneration PFBC plant.

3. The 1.5-Generation PFBC plant has excellent load-following potential, and is probably more responsive than a 2nd-Generation PFBC plant. The combination of coal and natural gas allows rapid adjustments between 76 and 100 percent of load by adjusting the natural gas flow to the gas turbine, and stable operation down to 38 percent of rated load by adjusting the coal feed rate. Reducing natural gas flow to zero reduces power output by 24 percent with only a 3-point loss of efficiency (from 40 percent to 37 percent). Plant operation is well within commercial equipment and controls design capability.

4. The typical 1.5-Generation PFBC plant is expected to have a greater range of turndown than either a 1st-Generation or 2nd-Generation PFBC plant. In a 1.5-Generation PFBC plant, about $1 / 3$ of the fuel thermal requirements (MBtu/h) are provided by natural gas, with the remaining $2 / 3$ provided by coal. This means that the plant can be turned down by about $1 / 3$ by simply reducing the natural gas flow. Assuming a 50-percent turndown capability for the coal-fired CPFBC and $F B H E$, the remaining $2 / 3$ capacity can be reduced by half -- to 33 -percent load.

5. The operating conditions (particularly the turbine inlet temperature) of the gas turbine in a 1.5-Generation PFBC cycle are relatively close to gas turbine design conditions, allowing fairly "standard" turbines to be considered as candidates.

6. The gas turbine/steam turbine power split is about $34 / 66 \%$ in a $1.5-$ Generation PFBC plant, which places it between the 1st-Generation plant $(23 \% / 77 \%)$ and the 2nd-Generation plant (45\%/55\%).

7. There is a strong correlation between gas turbine contribution and plant thermal efficiency for combined cycle plants, except for IGCCs with their special auxiliary requirements. The HHV efficiency of a large 1.5-Generation PFBC plant is about $41 \%$, which places it between the 1st-Generation plant (40\%) and the 2nd-Generation plant (45\%). 
8. The 1.5-Generation PFBC plant shows a clear economy of scale over the range of sizes studied -4 to $250 \mathrm{MW}$. The COEs for the 246-MW, 111-MW, and 4-MW plants are projected to be about $\$ 83 / \mathrm{MWh}, \$ 108 / \mathrm{MWh}, 349 / \mathrm{MWh}$, respectively.

9. Fuel cost accounts for about 25 percent of the COE, so price increases for coal, natural gas, or oil (as a substitute for natural gas) increase the COE. The greatest COE sensitivity is the sensitivity to coal price (0.201-percent increase in COE for each 1-percent increase in coal price), followed by the sensitivity to oil price ( 0.106 percent per percent increase) and to natural gas price ( 0.063 percent per percent increase).

10. Plants designed with less PFBC excess air have lower capital costs (per kW) and lower COES than plants designed with more PFBC excess air. The lower-excessair plants generate much more power, even though they cost more in absolute dollars.

11. The fuel flexibility and load-following capability of the small plant show promise for remote locations, but its design should be reviewed to include consideration of less complex configurations, such as the steam-injected Cheng cycle. 


\subsection{REFERENCES}

Ahn, Y. K., H. T. Chen, and J. S. White, Korea IGCC Project Annual Report, Gilbert Commonwealth International, Inc., November 20, 1992.

Anders, D., "Operation Experience of the PFBC Plant in Vartan, Stockholm," Proceedings of the 1993 International Conference on Fluidized Bed Combustion, ASME, San Diego, California, May 9-13, 1993.

Anderson, J., and K-J Nilsson, "Principles and Design Philosophy for a 350 MWe PFBC Module," Proceedings of the 1993 International Conference on Fluidized Bed Combustion, ASME, San Diego, California, May 9-13, 1993.

Carpenter, L., W. Langan, R. Dellefield, G. Nelken, and T. Hand, "Pressurized Fluidized Bed Combustion: A Commercially Available Clean Coal Technology," Proceedings of the 1991 International Conference on Fluidized Bed Combustion, ASME, April 21-24, 1991.

EIA, 1991 Monthly Energy Review, Energy Information Administration, August 1991

EPRI, 1993 TAGTM Technical Assessment Guide - Electricity Supply - 1993, EPRI TR102276-V1R7, Vol. 1, Rev. 7, June 1993.

EPRI,1989 Electric Power Research Institute (EPRI), Fossil Plant Cycling Guidelines (Draft), EPRI RP1184-19, Palo Alto, California, December 31, 1989.

Farmer, R., "227-MW Frame 9FA Will Power EPON's 1.7-GW Combined Cycle," Gas Turbine World, May-June 1992.

FWDC,10/92"Second-Generation PFBC Plant - Conceptual Design and Optimization Technical Progress for Phase 2 (10/1/91 through 9/30/92), FWDC October 1992.

FWDC,1989 Second-Generation Pressurized Fluidized Bed Combustion Plant Conceptual Design and Optimization of a Second-Generation PFB Combustion Plant, DOE contract DE-AC21-86MC21023, Phase I Task 1 Report, September 1989.

FWDC,7/92 Second-Generation Pressurized Fluidized Bed Combustion -- Small Gas Turbine Industrial Plant Study, Topical Report, DOE contract DE-AC21-86MC21023, July 1992.

G/C,1992 Gilbert/Commonwealth, PFBC Concepts Analysis for Improved Cycle Efficiency and Cost, DOE Contract DE-AC01-88FE61657, Task 2 Report, June 1992.

G/C,1993 Gilbert/Commonwealth, Very Low Sulfur Emission (VLSE) PFBC System, DOE Contract DE-AC01-88FE61657, Task 6 Report, August 1993.

McKinsey, R. R., G. S. Booras, and J. D. McClung, "Engineering and Economic Evaluation of PFBC Power Plants," Proceedings of the 1991 International Conference on Fluidized Bed Combustion, ASME, April 21-24, 1991. 
Provol, S. J., and S. Ambrose, "The Midwest Power DMEC-2 Advanced PCFB Demonstration Project Ahlstrom Pyroflow Advanced PCFB Technology," Proceedings of the 1993 International Conference on Fluidized Bed Combustion, ASME, San Diego, California, May 9-13, 1993.

Sugiura, T., T. Tanaka, T. Yamamoto, K. Yano, M. Olde, and F. Kitayama, "Conceptual Design for a 350 MWe PCFBC Boiler Combined Cycle System," Proceedings of the 1993 International Conference on Fluidized Bed Combustion, ASME, San Diego, California, May 9-13, 1993.

TAG,1989 Electric Power Research Institute (EPRI), TAGTM Technical Assessment Guide, Vol. 1: Electricity Supply - 1989 (Revision 6), EPRI P-6587-L, Volume 1, Revision 6, Palo Alto, California, November 1989.

von Wedel, G., J. Krein, H. Mollenhoff, H. Rehwinkel, and K. Winkler, "Pressurized Fluidized Bed Combustion in a $15 \mathrm{MWth}$ Test Facility Bubbling And Circulating Experience and Future Development," Proceedings of the 1993 International Conference on Fluidized Bed Combustion, ASME, San Diego, California, May 9-13, 1993.

Wheeldon, J. J., S. G. Drenker, G. S. Booras, and R. R. McKinsey, "Cost and Performance Improvements in Utility-Scale Bubbling PFBC Power Plants," Proceedings of the 1993 International Conference on Fluidized Bed Combustion, ASME, San Diego, California, May 9-13, 1993. 


\section{A COST METHODS AND CASE RESULTS}

\section{CONTENTS}

Cost Methods:

Code of Direct Accounts Summary ..........................................................2

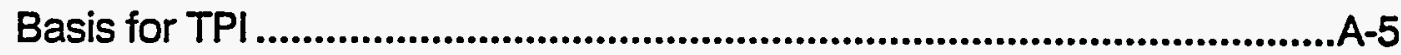

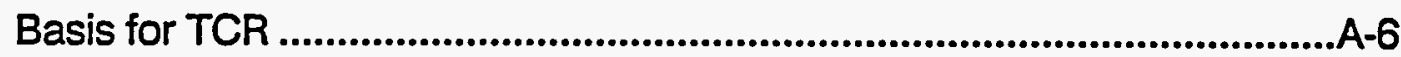

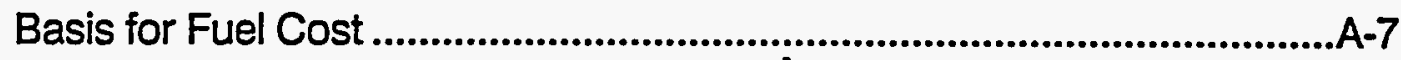

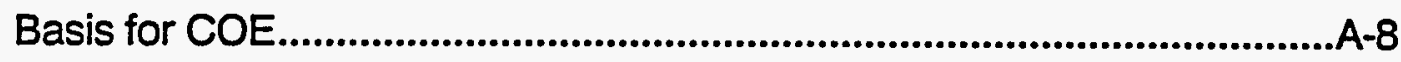

Case Results:

Total Plant Cost Estimate Summaries

Large Commercial Plant ..............................................................9

Intermediate Commercial Plant..................................................A-10

Small Commercial Plant.............................................................A-11

Capital Investment \& Revenue Requirement Summaries

Large Commercial Plant .................................................................12

Intermediate Commercial Plant..................................................1-13

Small Commercial Plant..................................................................-14 
Appendix A

Code of Direct Accounts Summary

Account Number
Account Title

COAL and SORBENT HANDLING (including the following)

Coal Receiving and Unloading Equipment

Coal Stockout and Reclaim Equipment

Coal Storage Bin and Yard Crushers

Other Coal-Handling Equipment

Sorbent Receiving and Unloading Equipment

Sorbent Stockout and Reclaim Equipment

Sorbent Storage Bin and Yard Crusher

Other Sorbent Handling Equipment

Coal and Sorbent Handling Foundations and Structures

COAL and SORBENT PREPARATION and FEEDING (including the following)

Coal Crushing and Drying Equipment

Prepared Coal Storage and Feed Equipment

Coal Injection System

Miscellaneous Coal Preparation and Feed

Sorbent Preparation

Prepared Sorbent Storage and Feed Equipment

Sorbent Injection System

Booster Air Supply System

Foundations and Structures

FEEDWATER and MISCELLANEOUS SYSTEMS and EQUIPMENT (including the following)

Feedwater System

$\therefore \quad$ Makeup Treatment, Pretreating, and Storage

$\because \quad$ Other Feedwater and Condensate Subsystems

Service Water Systems

.. Other Boiler Plant Systems

Fuel Oil Supply System

Waste Treatment Equipment

Miscellaneous Power Plant Equipment

CARBONIZER, PFBC BOILER, and ACCESSORIES or PC BOILER and ACCESSORIES (including the following)

Carbonizer

Pressurized Fluidized Bed Combustor

PFBC Heat Exchanger

Interconnecting Pipe

Miscellaneous PFBC Equipment

Other PFBC Equipment

Major Component Rigging

Foundations and Supports 
HOT GAS CLEAN-UP and HOT GAS PIPING

Carbonizer Gas/Tar CXF Module

CPFBC Gas CXF Module

Hot Gas Piping

Blowback Air Supply System

Foundations and Supports

6

COMBUSTION TURBINE and ACCESSORIES

Combustion Turbine Generator

Combustion Turbine Accessories

Compressed Air Piping

Foundations and Supports

WASTE HEAT BOILER, DUCTING and STACK

Heat Recovery Steam generator

HRSG Accessories

Ductwork

Stack

Foundations

STEAM TURBINE GENERATOR, and AUXILIARIES

Steam Turbine Generator and Accessories

Turbine Plant Auxiliaries

Condenser and Auxiliaries

Steam Piping

Foundations

9

COOLING WATER SYSTEM

Cooling Towers

Circulating Water Pumps

Circulating Water System Auxiliaries

Circulating Water Piping

Make-Up Water System

Component Cooling Water System

Circulating Water Foundations and Structures

ASH/SPENT SORBENT RECOVERY and HANDLING

Ash Coolers

PFBC Ash Depressurizing Equipment

HGCU Ash Depressurizing Equipment

High Temperature Ash Piping

Other Ash Recovery Equipment

Ash Storage Silos

Ash Transport and Feed Equipment

Miscellaneous Ash Handling Equipment

Foundations and Structures 
ACCESSORY ELECTRIC PLANT

Generator Equipment

Station Service Equipment

Switchgear and Control Equipment

Conduit and Gable Tray

Wire and Cable

Protective Equipment

Standby Equipment

Main Power Transformer

Foundations

INSTRUMENTATION and CONTROL

PFBC Control Equipment

Combustion Turbine Control Equipment

Steam Turbine Control Equipment

Other Major Component Control Equipment

Signal Processing Equipment

Control Boards, Panels, and Racks

Computer and Auxiliaries

Instrument Wiring and Tubing

Other Instrumentation and Controls Equipment

IMPROVEMENTS TO SITE

Site Preparation

Site Improvements

Site Facilities

BUILDINGS and STRUCTURES

PFBC Structure or Boiler Building

Gas Turbine Building

Steam Turbine Building

Administration Building

Circulating Water Pumphouse

Water Treatment Buildings

Machine Shop

Warehouse

Other Buildings and Structures

Waste Treatment Buildings and Structures 


\section{Total Plant Investment (TPI)}

TPI at date of start-up includes escalation of construction costs and allowance for funds used during construction (AFDC), formerly called interest during construction, over the construction period. TPI is computed from the TPC, which is expressed on an "overnight" or instantaneous construction basis. For the construction cash flow, a uniform expenditure rate was assumed, with all expenditures taking place at the end of the year. The construction period is estimated to be three years for the large commercial plant, 2-1/2 years for the intermediate commercial plant, and 18 months for the small commercial plant. Given TPC, cash flow assumptions, nominal interest, and escalation rates, TPI was calculated using:

$$
\text { TPI }=\operatorname{TPC} \times A\left[\left(R^{3}-1\right) /(R-1)+\left(R^{3}\right) / 2\right]
$$

where:

$$
\begin{aligned}
& A=\% \text { cost expended per year } \\
& R=\text { Compound adjustment factor }=(1+i) /\left(1+e_{a}\right) \\
& i=\text { Weighted cost of capital, } 11.5 \% \\
& \text { ea }=\text { Inflation rate, } 5 \%
\end{aligned}
$$

The apparent escalation rate and the weighted cost of capital (discount rate) are the standard values currently proposed by EPRI. 


\section{Total Capital Requirement (TCR)}

The TCR includes all capital necessary to complete the entire project. TCR consists of TPI, prepaid royalties, pre-production (or start-up) costs, inventory capital, initial chemical and catalyst charge, and land cost:

- $\quad$ Royalties costs are assumed inapplicable to the mature PFBC plant and thus are not included.

- $\quad$ Pre-production U.S. costs are intended to cover operator training, equipment checkout, major changes in plant equipment, extra maintenance, and inefficient use of fuel and other materials during plant start-up. They are estimated as follows:

- 1 month of fixed operating costs -- operating and maintenance labor, administrative and support labor, and maintenance materials.

- 1 month of variable operating costs as full capacity (excluding fuel) includes chemicals, water, and other consumables and waste disposal charges.

- $\quad 25 \%$ of full capacity fuel cost for 1 month - covers inefficient operation that occurs during the start-up period.

- $\quad 2 \%$ of TPI - covers expected changes and modifications to equipment that will be needed to bring the plant up to full capacity.

- Inventory capital is the value of inventories of fuel, other consumables, and by-products, which are capitalized and included in the inventory capital account. The inventory capital is estimated as follows: Fuel inventory is based on full-capacity operation for 60 days. Inventory of other consumables (excluding water) is normally based on full-capacity operation at the same number of days as specified for the.fuel. In addition, an allowance of $1 / 2 \%$ of the TPC equipment cost is included for spare parts.

- Initial catalyst and chemical charge covers the initial cost of any catalyst or chemicals that are contained in the process equipment (but not in storage, which is covered in inventory capital). No value is shown because costs are minimal and included directly in the component equipment capital cost.

- Land cost is based on 200 acres of land for the large commercial plant, 175 for the intermediate plant, and no additional land for the small plant, at $\$ 8,000$ per acre.

\section{Fuel Cost}

The Fuel (coal) cost was developed on the basis of delivered coal of $\$ 1.80 / 10^{6} \mathrm{Btu}$ (FC), the plant net heat rate Btu/KWh (HR) and the coal higher heating value (HHV) of $12,450 \mathrm{Btu} / \mathrm{lb}$. For the coal as well as for all feedstock and disposal costs, the quantity per day represents the $100 \%$ capacity requirement, while the annual cost values are adjusted for the designated $65 \%$ plant capacity factor. The calculation of first year fuel . cost occurred as follows:

Fuel (ton/day) $=\quad$ HR $\times \mathrm{kW}$ (plant new capacity) $\times 24$ hours

HHV $\times 2000 \mathrm{lb} /$ ton 
Fuel Unit (per ton) Cost $=$

Fuel Cost (1st year) $=$
$\frac{H H V \times 2000 \mathrm{lb} / \mathrm{ton}}{1 \times 10^{6} \mathrm{Btu}} \mathrm{FC}$

Fuel $(t / d) \times$ Fuel Unit Cost $(\$ / t)$

$\times 365$ days $\times 0.65$ (capacity factor)

+ First-year Cost of Secondary Fuel

\section{COST OF ELECTRICITY (COE)}

The revenue requirement method of performing an economic analysis of a prospective power plant is widely used in the electric utility industry. This method permits the incorporation of the various dissimilar components for a potential new plant into a single value that can be compared to various alternatives. The revenue requirement figure-of-merit is COE that is the levelized (over plant life) coal pile-to-busbar cost of power expressed in mills/kWh. The value, based on EPRI definitions and methods, includes the TCR, which is represented in the levelized carrying charge (sometimes referred to as the fixed charges), levelized fixed variable operating and maintenance costs, levelized consumable operating costs, and the levelized fuel cost.

The consolidated basis for calculating capital investment and revenue requirements is given in the succeeding table titled Estimate Basis/Financial Criteria for Revenue Requirement Calculations. The principle cost and economics output for this study, the Capital Investment and Revenue Requirement summary presents key TPC values and other significant capital costs operating costs, maintenance costs, consumables, fuel cost and the levelized busbar COE. A table for each case is included in the appendix.

The levelized carrying charge, applied to TCR, establishes the required revenues to cover return on equity, interest on debt, depreciation, income tax, property tax, and insurance. Levelizing factors are applied to the first year fuel, O\&M costs, and consumable costs to yield levelized costs over the life of the project. A long-term inflation rate of $5 \% / y r$. was assumed in estimating the cost of capital and in estimating the life cycle revenue requirements for other expenses (except that fuel was escalated at $5.5 \% / y r$.$) . To represent these varying revenue requirements for fixed and variable costs,$ a "levelized" value was computed using the "present worth" concept of money based on the assumptions shown in the basis table resulting in a levelized carrying charge of $16.5 \%$ and levelization factor of 1.612 for all other-than-fuel and 1.701 for fuel.

By combining costs, carrying charges, and levelizing factors, a levelized busbar COE for the $65 \%$ design capacity factor was calculated along with the levelized constituent values. The format for this cost calculation is:

Power Cost $($ COE $)=\frac{(L C C+L F O M) \times 1000 \text { mills } / \$+L V O M+L C M-L B+L F C}{C F \times 8760 \mathrm{~h} / \mathrm{yr}}$

where:

LCC = Levelized carrying charge, $\$ / \mathrm{kW}-\mathrm{yr}$

LFOM = Levelized fixed O\&M, $\$ / \mathrm{kW}$-yr

LVOM = Levelized variable O\&M, mills $/ \mathrm{kWh}$

$\mathrm{LCM}=$ Levelized consumable, mills $/ \mathrm{kWh}$ 
LB = Levelized by-products (if any), mills $/ \mathrm{kWh}$

LFC $=$ Levelized fueled costs, mills $/ \mathrm{kWh}$

$\mathrm{CF}=$ Plant capacity factor, $\%$ 


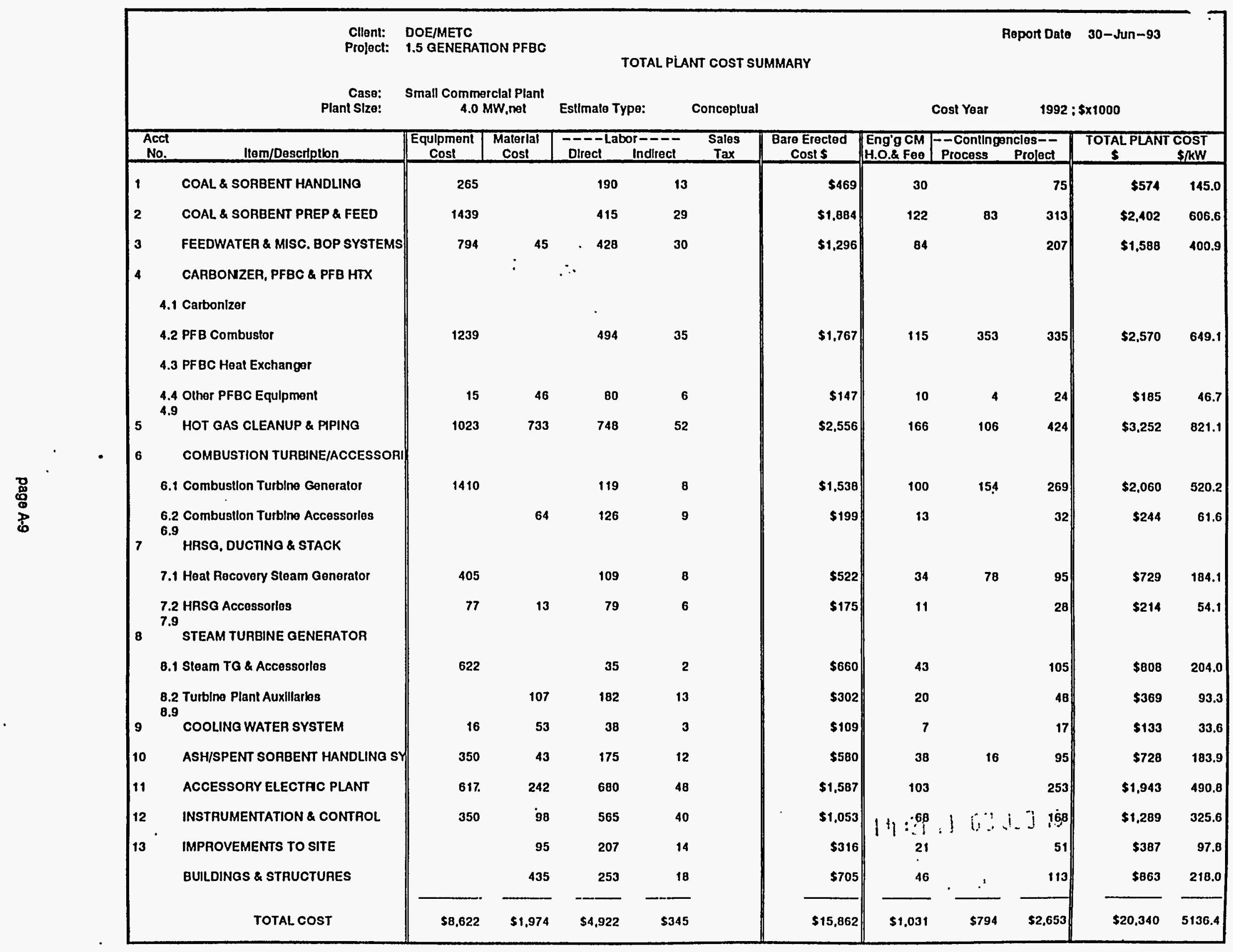




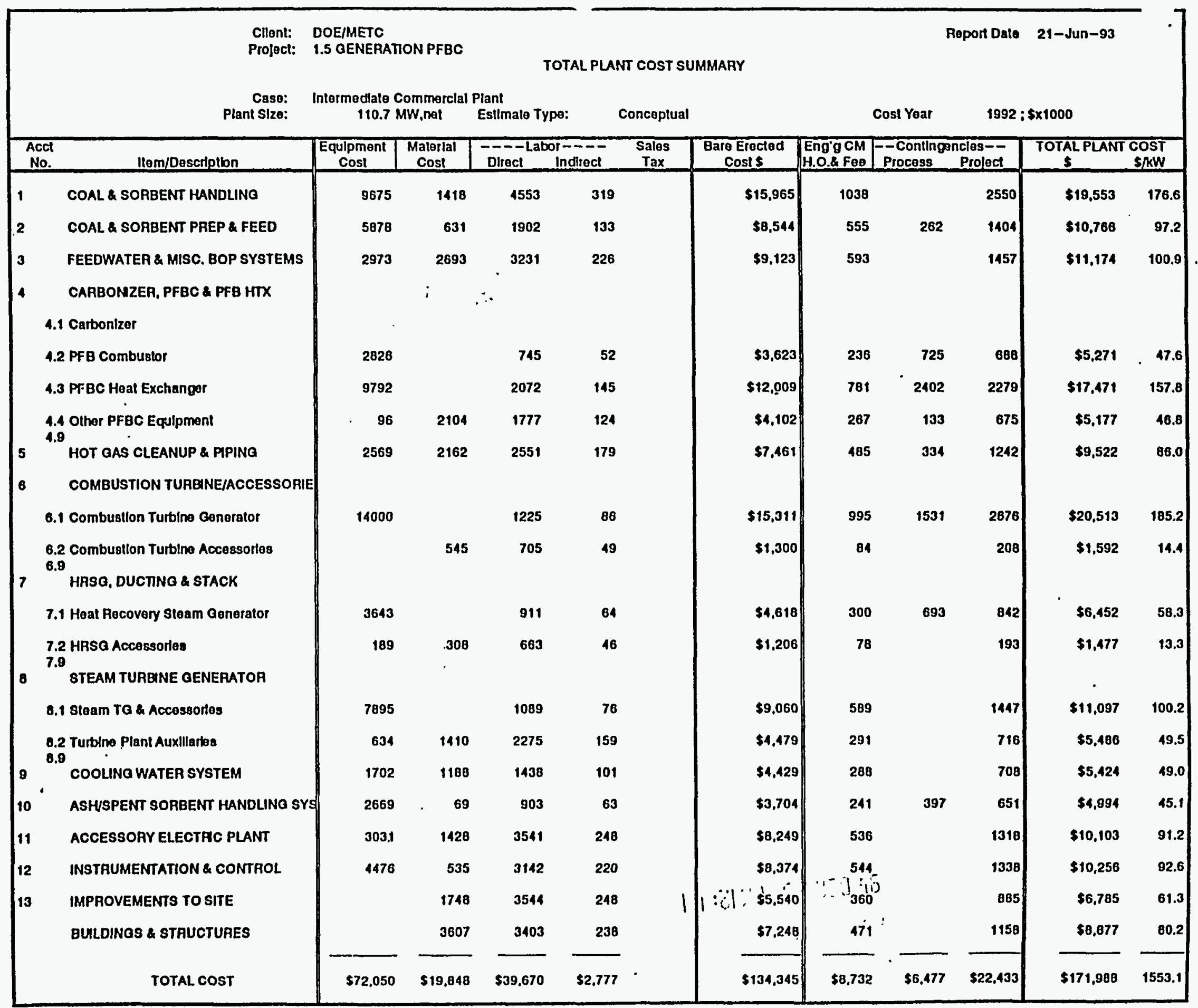




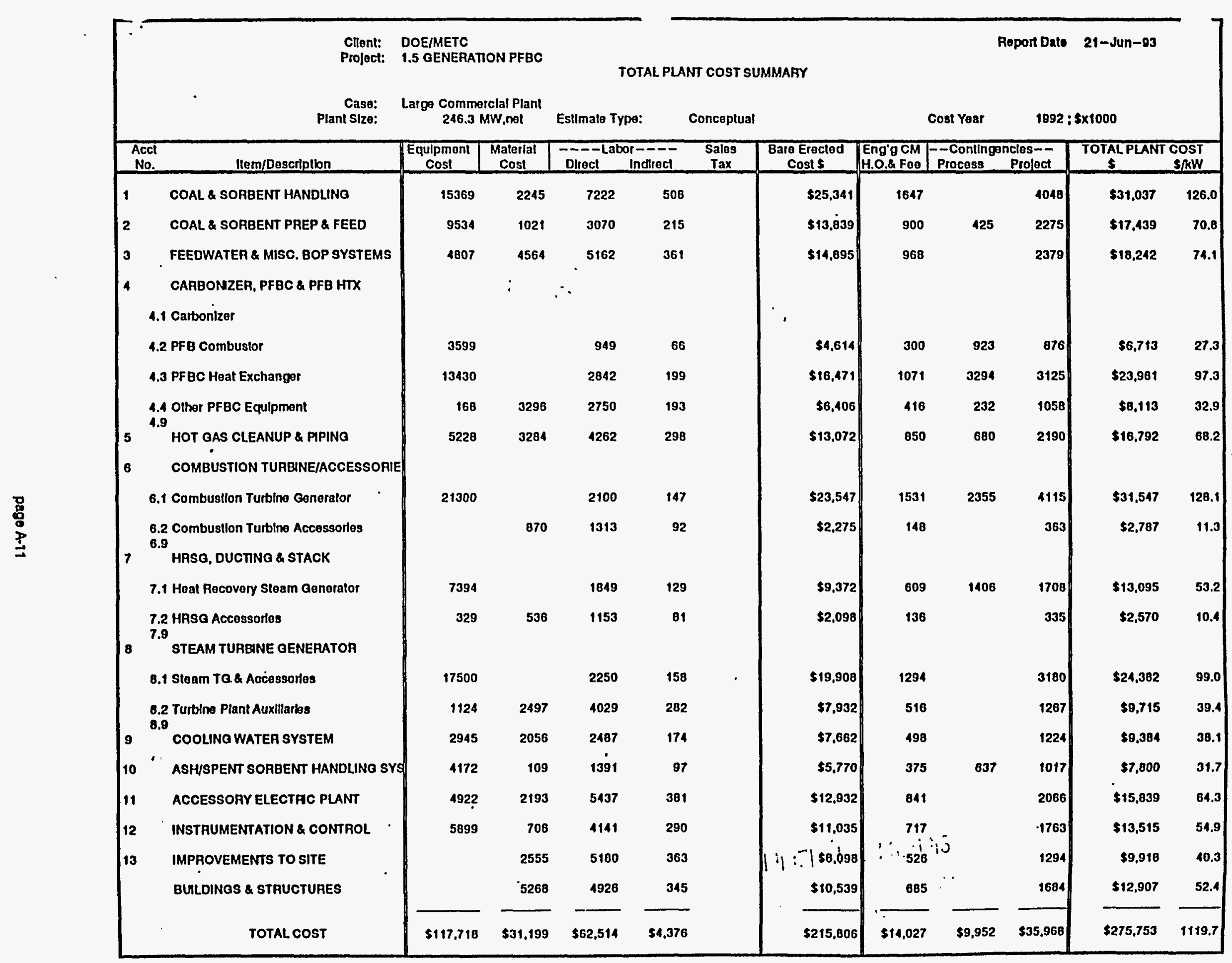


CAPITAL INVESTMENT \& REVENUE REQUIREMENT SUMMARY

TITLE/DEFINITION

Case:

Plant Size:

Primary Fuel(type):

Secondary Fuel(type):

Design/Construction:

TPC(Plant Cost) Year:

Capacity Factor:

CAPITAL INVESTMENT

Process Capital \& Facilities

Engineering(incl.C.M.,H.O.\& Fe日)

Process Contingency

Project Contingency

TOTAL PLANT COST(TPC)

TOTAL CASH EXPENDED

AFDC

TOTAL PLANT INVESTMENT(TPI)
Small Commercial Plant

Pittsburgh \#8

NG

1.5 (years)
1992 (Dec.)
$65(\%)$

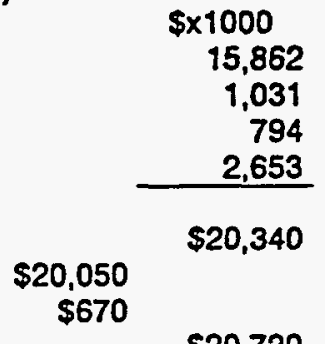

Preproduction Costs

Inventory Capital

Initial Catalyst \& Chemicals(w/equip.)

Land Cost

TOTAL CAPITAL REQUIREMENT(TCR)

OPERATING \& MAINTENANCE COSTS(First Year)

Operating Labor

Maintenance Labor

Maintenance Material

Administrative \& Support Labor

TOTAL OPERATION \& MAINTENANCE(1st yr.)

FIXED $O \& M($ ist yr.)

VARIABLE O \& $M$ (ist yr.)

CONSUMABLE OPERATING COSTS(less Fuel)

Water

Chemicals

Other Consumables

Waste Disposal

TOTAL CONSUMABLES(1st yr.,-fuel)

BY-PRODUCT CREDITS(First Year)

FUEL COST(First Year)

LEVELIZED OPERATION \& MAINTENANCE COSTS

Fixed $O$ \& $M$

Variablo $O$ \& $M$

Consumables

By-product Credit

Fuel

LEVELIZED CARRYING CHARGES(Capital)

LEVELIZED BUSBAR COST OF POWER 30 Year at a Capacity Factor of:
612

202

HeatRate:

Cost:

Cost:

Booklife:

TPI Year:

$\$ \times 1000$

1,031

794

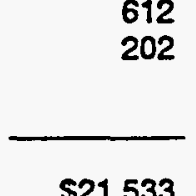

$\$ 21,533$

$$
\begin{array}{r}
\$ \times 1000 \\
1,080 \\
206 \\
309 \\
386 \\
\hline
\end{array}
$$

$\$ 1,981$

$\$ \times 1000$

15

63

33

$\$ 111$

$\$ 556$

$523.9 \mathrm{~S} / \mathrm{kW}-\mathrm{yr}=$

$897.2 \$ / k W-y r=$

$65 \%$

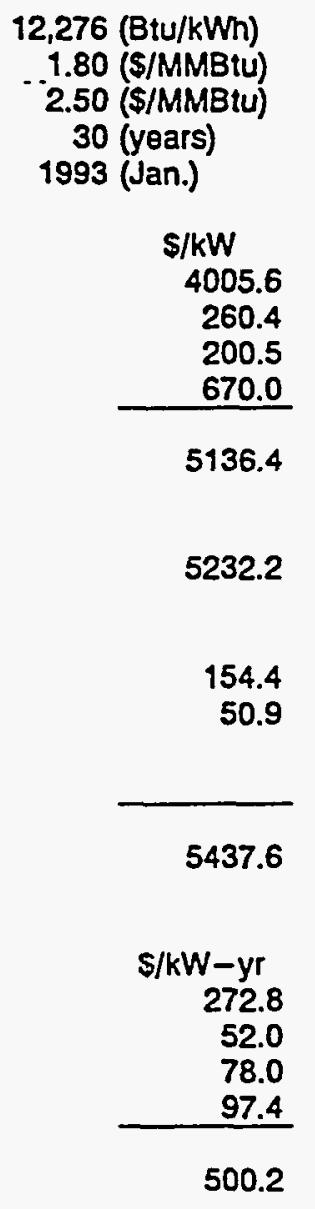

$325.10 \$ / k W-y r$

30.74 mills/kWh

mills/kWh

0.67

2.80

1.46

4.93

24.66

92.0 mills/kWh

49.5 mills/kWh

8.0 mills/kWh mills/kWh .

41.9 mills/kWh

$157.6 \mathrm{mills} / \mathrm{kWh}$

349.0 mills/kWh 
TITLE/DEFINITION

Case:

Plant Size:

Primary Fuel(type):

Secondary Fuel(type):

Design/Construction:

TPC(Plant Cost) Year:

Capacity Factor:

CAPITALINVESTMENT

Process Capital \& Facilities

Engineering(incl.C.M.,H.O.\& Fe日)

Process Contingency

Project Contingency

TOTAL PLANT COST(TPC)

TOTAL CASH EXPENDED

AFDC

TOTAL PLANT INVESTMENT(TPI)

Royalty Allowance

Preproduction Costs.

Inventory Capital

Initial Catalyst \& Chemicals(w/equip.)

Land Cost

TOTAL CAPITAL REQUIREMENT(TCR)

OPERATING \& MAINTENANCE COSTS(First Year)

Operating Labor

Maintenance Labor

Maintenance Material

Administrative \& Support Labor

TOTAL OPERATION \& MAINTENANCE(1st yr.)

FIXED $O \& M$ (1st yr.)

VARIABLE O \& $M$ (ist yr.)

CONSUMABLE OPERATING COSTS(less Fuel)

Water

Chemicals

Other Consumables

Waste Disposal

TOTAL CONSUMABLES(1st yr.,-fuel)

BY-PRODUCT CREDITS(FIrSt Yeas)

FUEL COST(First Year)

LEVELIZED OPERATION \& MAINTENANCE COSTS

Fixed 0 \& $M$

Variable $O$ \& $M$

Consumables

By-product Credit

Fuel

LEVELIZED CARRYING CHARGES(Capital)

LEVELIZED BUSBAR COST OF POWER

30 Year at a Capacity. Factor of:

NG
Intermediate Commercial Plant

Pittsburgh \#8 $\quad$ Cost:

Cost:

2.5 (years) BookLife:

1992 (Dec.) TPJ Year:

$65(\%)$

$\$ \times 1000$

134,345

8,732

6,477

22.433 .

$\$ 171,988$

$\$ 165,514$

$\$ 15,164$

$\$ 180,678$

8,484 (Btu/kWh)

1.80 (\$/MMBtu)

2.50 (\$/MMBtu)

30 (years)

1993 (Jan.)

\section{$\$ / k W$}

1213.2

78.9

58.5

202.6

1553.1

1631.6

5,043

3,321

1.400

$\$ 190,442$

$\$ \times 1000$

4,561

1,407

2,111

1,791

$\$ 9,870$

57.93 \$/kW-yr

5.48 mills/kWh

mills/kWh

239

1,247

669

$\$ 2,154$

0.38

1.98

1.06

3.42

$\$ 10,318$

16.36

$93.4 \$ / k W-y r=$

$283.8 \$ / k W-y r=$

$65 \%$
16.4 mills $/ \mathrm{kWh}$

8.8 mills/kWh

5.5 mills/kWh mills/kWh

27.8 mills/kWh

$49.8 \mathrm{mills} / \mathrm{kWh}$

$108.4 \mathrm{mills} / \mathrm{kWh}$ 
TILE/DEFINITION

Cal ?"

PIefitit slza:

Primary Fuel(typo):

Secondary Fuel(type):

Design/Construction:

TPC(Plant Cost) Year:

Capacity Factor:

CAPITAL INVESTMENT

Process Capital \& Facilities

Engineering(incl.C.M.,H.O.\& Fe日)

Process Contingency

Project Contingency

TOTAL PLANT COST(TPC)

TOTAL CASH EXPENDED

AFDC

TOTAL PLANTINVESTMENT(TPI)

Royalty Allowance

Preproduction Costs

Inventory Capital

Initial Catalyst \& Chemicals(w/equip.)

Land Cost

TOTAL CAPITAL REQUIREMENT(TCR)

OPERATING \& MAINTENANCE COSTS(First Year)

Operating Labor

Maintenance Labor

Maintenance Material

Administrative \& Support Labor

TOTAL OPERATION \& MAINTENANCE(1st yr.)

FIXED $O \&$ \& (1st yr.)

VARIABLE O \& M (1st yr.)

CONSUMABLE OPERATING COSTS(less FUEl)

Water

Chemicals

Other Consumables

Waste Disposal

TOTAL CONSUMABLES(1st yr.,-fuel)

BY-PRODUCT CREDITS(First Year)

FUEL COST(First Year)

\section{LEVELIZED OPERATION \& MAINTENANCE COSTS}

Fixad $O \& M$

Variable $O \& M$

Consumables

By-product Credit

Fuel

LEVELIZED CARRYING CHARGES(CapitaI)

LEVELIZED BUSBAR COST OF POWER 30 Year at a Capactty Factor of:

NG
Large Commercial Plant 246.3 (MW, net)

Pittsburgh \#8

3 (years)
1992 (Dec.)
$65(\%)$

HeatRate:

8,247 (Btu/kWh)

Cost:

Cost:

BookLife:

TPI Year:

$\$ \times 1000$

215,806

14,027

9,952

35,968

$\$ 275,753$

$\$ 262,810$

$\$ 30,413$

$\$ 293,222$

1190.7

8,212

7,022

1,600

$\$ 310,056$

$\$ \times 1000$

4,801

2,257

3,385

2.117

$\$ 12,561$

$33.15 \mathrm{~S} / \mathrm{kW}-\mathrm{yr}$

3.14 mills/kWm

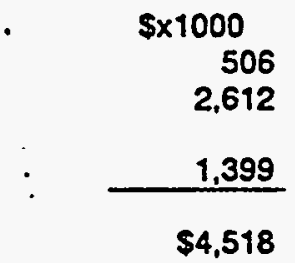

mills/kwn

0.36

1.86

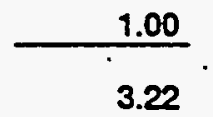

$\$ 22,514$

16.06

$53.4 \$ / k W-y r \doteq$

$207.7 \$ / k W-y r=$

9.4 mills/kWh

$5.1 \mathrm{mills} / \mathrm{kWh}$

$5.2 \mathrm{mills} / \mathrm{kWh}$

mills/kWh

27.3 mills/kWh

36.5 mills/kWh

83.4 mills/kWh 